\title{
Hemorrhagic brain infarction : a clinical, radiological and morphological study with special reference to cardioembolism
}

Citation for published version (APA):

Krijne-Kubat, B. (1993). Hemorrhagic brain infarction : a clinical, radiological and morphological study with special reference to cardioembolism. [Doctoral Thesis, Maastricht University]. Datawyse / Universitaire Pers Maastricht. https://doi.org/10.26481/dis.19930115bk

Document status and date:

Published: 01/01/1993

DOI:

10.26481/dis.19930115bk

Document Version:

Publisher's PDF, also known as Version of record

Please check the document version of this publication:

- A submitted manuscript is the version of the article upon submission and before peer-review. There can be important differences between the submitted version and the official published version of record.

People interested in the research are advised to contact the author for the final version of the publication, or visit the DOI to the publisher's website.

- The final author version and the galley proof are versions of the publication after peer review.

- The final published version features the final layout of the paper including the volume, issue and page numbers.

Link to publication

\footnotetext{
General rights rights.

- You may freely distribute the URL identifying the publication in the public portal. please follow below link for the End User Agreement:

www.umlib.nl/taverne-license

Take down policy

If you believe that this document breaches copyright please contact us at:

repository@maastrichtuniversity.nl

providing details and we will investigate your claim.
}

Copyright and moral rights for the publications made accessible in the public portal are retained by the authors and/or other copyright owners and it is a condition of accessing publications that users recognise and abide by the legal requirements associated with these

- Users may download and print one copy of any publication from the public portal for the purpose of private study or research.

- You may not further distribute the material or use it for any profit-making activity or commercial gain

If the publication is distributed under the terms of Article $25 \mathrm{fa}$ of the Dutch Copyright Act, indicated by the "Taverne" license above, 


\section{HEMORRHAGIC BRAIN INFARCTION}

\section{A clinical, radiological and morphological study}

with special reference to cardioembolism 
Production: DATAWYSE | Universitaire Pers Maastricht

\section{CIP DATA KONINKLIJKE BIBLIOTHEEK, DEN HAAG}

Krijne-Kubat, Bela

Hemorrhagic brain infarction : a clinical radiological and morphological study with special reference to cardioembolism / Bela Krijne-Kubat. - Maastricht :

Universitaire Pers Maastricht. - III.

Proefschrift Maastricht. - Met lit. opg. - Met

samenvatting in het Nederlands.

ISBN 90-5278-053-6

NUGI 742

Trefw.: hemorrhagisch herseninfarct / cardioembolisch. herseninfarct. 


\title{
HEMORRHAGIC BRAIN INFARCTION
}

\author{
A clinical, radiological and morphological study \\ with special reference to cardivembolism
}

\section{PROEFSCHRIFT}

ter verkrijging van de graad van doctor aan de Rijksuniversiteit Limburg te Maastricht, op gezag van de Rector Magnificus, Prof.Mr. M.J. Cohen, volgens het besluit van het College van Dekanen, in het openbaar te verdedigen

op vrijdag, 15 januari 1993 om 14.00 uur

$$
\text { door }
$$

\section{Bela Krijne-Kubat}

geboren te Praag, Tsjechoslowakije in 1957

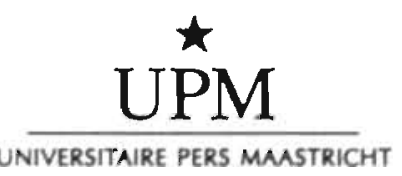




\section{Promotores:}

Prof.dr. J. Troost

Prof.dr. J.W. Arends

\section{Co-promotor: \\ Dr. J. Lodder}

\section{Beoordelingscommissie:}

Prof.dr. J.A. Knottnerus (voorzitter)

Dr. P.J. Koudstaal

Prof.dr. R.S. Reneman

Prof.dr. H.J.J. Wellens

Prof.dr. J.T. Wilmink

Financial support by the Netherlands Heart Foundation for the publication of this thesis is gratefully acknowledged. 
De woorden van je leer mogen niet als een verplichting op je lasten, maar je mag je van hen ook niet bevrijden.

(Menachot)

VOOR RUUD 


\section{CONTENTS}

\section{GENERAL INTRODUCTION}

\section{CHAPTER 1}

Review of the literature

I. The morphology and CT appearance of cerebral infarction, 13

II. The pathophysiology of cerebral hemorrhagic infarction, 21

III. Embolic brain infarcts; the heart-brain relationship, 31

\section{CHAPTER 2}

Cerebral hemorrhagic infarction at autopsy: presumed cardioembolic cause and the relationship to the cause of death, 57

\section{CHAPTER 3}

Hemorrhagic infarction on CT in presumed cardioembolic stroke,

\section{CHAPTER 4}

Clinical and CT features predicting cardioembolic versus atherothrombotic non-lacunar brain infarction, 73

\section{CHAPTER 5}

CT features of autopsy confirmed hemorrhagic infarction, 83

\section{CHAPTER 6}

Timing of autopsy-confirmed hemorrhagic infarction with reference to cardioembolic stroke, $\quad 89$

\section{CHAPTER 7}

Low risk of early anticoagulation in stroke patients with non-rheumatic atrial fibrillation, 95

\section{CHAPTER 8}

Summary and conclusions, $\quad 103$

Samenvatting en conclusies, $\quad 107$

TOT SLOT, $\quad 111$

CURRICULUM VITAE， 112 



\section{General introduction}

Cerebrovascular disease ranks third among the most frequent causes of death and is one of the major causes of permanent disability in western society. Approximately 80 per cent of all stroke patients have cerebral infarctions. 2,10,20 In the Netherlands $20,000-25,000$ people suffer a stroke each year. ${ }^{2,10}$ Fifteen to 20 per cent of these patients have a potential cardioembolic source which, in about two-thirds of these cases directly leads to cerebral infarction because of embolism. 1,9,21 Early recurrence in cardioembolic stroke is frequent: approximately $12 \%$ (range $2-20 \%$ ) suffer a new stroke within the first year, with a maximum risk period during the first two weeks following the first stroke, and five per cent yearly thereafter. 4,17 The recurrence rate is similar in various types of cardioembolic sources, although non-valvular atrial fibrillation has a somewhat lower recurrence rate, and rheumatic atrial fibrillation a higher one. $3,6,7,8,14,15,18,19$ Besides increasing handicap, stroke recurrences probably add to the risk of multi-infarction dementia. ${ }^{5}$ Ideally, the lowering of the risk of stroke recurrences should start as early as possible. For this purpose in cardioembolic stroke, anticoagulation with heparin or coumarine derivates seems to be a rational choice. However, neither shortterm nor long-term anticoagulation have proven beneficial so far. The risk estimates of anticoagulation therapy in cardioembolic stroke diverge $3,7,11$ 13,15-18, but none of these studies were large enough or randomized. Adverse effects of anticoagulation can be as equally devastating as the primary disease itself; so, therefore the risks of anticoagulation should be balanced against possible benefits. One of the most feared adverse effects of early anticoagulation, especially in cardioembolic stroke, is hemorrhagic transformation of an initially pale infarction, with consequent worsening of the neurological deficit.

Differentiation between hemorrhagic infarction and primary cerebral bleeding is sometimes difficult. Therefore, $C T$ features differentiating between these two should be validated, preferably by pathological comparison. To put the risk of early anticoagulation into perspective, the frequency of hemorrhagic infarction should be known. Furthermore, knowledge about the time course of hemorrhagic transformation could guide the temporization of early anticoagulation. The presence of a cardiogenic source of embolism is often interpreted as indicating an increased risk of hemorrhagic transformation. However, the magnitude of this feature in predicting such risk relative to other ischemic stroke subtypes has not been established by clinical studies. 
The prevailing ideas about cardioembolic stroke as a cause of hemorrhagic infarction, stem from autopsy studies. These studies however, are most probably biased towards relating hemorrhagic infarction with a cardioembolic stroke, because cardioembolism more often causes large infarctions that are more likely to come to autopsy. Apart from all presumptions about the relationship between hemorrhagic infarction and cardioembolic stroke cause, the most relevant question is whether early anticoagulation would put stroke patients at a significant risk of cerebral bleeding complications. Studies performed so far, were either rather small or retrospective.

The aim of this thesis is:

1) to review the literature on the pathophysiology of hemorrhagic infarction related to different cardiac illnesses that can potentially cause embolism to the brain (Chapter 1),

2) to study if and why, autopsy studies are biased towards relating a cardiac source of embolism with hemorrhagic infarction (Chapter 2),

3) to measure the frequency of early hemorrhagic infarction in cardioembolic stroke (Chapter 3),

4) to study whether the presence of a potential cardioembolic source and severe neurological deficit are predictors of hemorrhagic infarction (Chapter 4),

5) to compare the computer tomographic appearances of hemorrhagic infarction with the autopsy findings (Chaipter 5),

6) to study the temporal development of hemorrhagic infarction (Chapter 6),

7) to measure the risks of early anticoagulation in cardioembolic stroke patients (Chapter 7). 


\section{REFERENCES}

1. Aberg $\mathrm{H}$. Atrial fibrillation. I. A study of atrial thrombosis and systemic embolism in necropsy material. Acta Med Scand 1969;185:373-379.

2. Bamford J, Sandercock PAG, Dennis M, Burn J, Warlow CA. A prospective study of acute cerebrovascular disease in the community: the Oxfordshire Community Stroke Project 1981-1986. Incidence, case fatality rates and overall outcome at one year of cerebral infarction, primary intracerebral and subarachnoid haemorrhage. J Neurol Neurosurg Psych 1990;53:16-22.

3. Cerebral Embolism Study Group. Immediate anticoagulation of embolic stroke: brain hemorrhage and management options. Stroke 1984;15:779-789.

4. Cerebral Embolism Task Force. Cardiogenic brain embolism. Arch Neurol 1986;43:71-84.

5. Fields WS. Multi-infarct Dementia. In: Neurologic Clinics. Hutton $\int \mathrm{T}$ (ed). W.B.Saunders Co, 1986. Vol 4:2, pp 405-413.

6. Fisher CM. Reducing the risks of cerebral embolism. Geriatrics 1979;34:59-66.

7. Hart RG, Coul BM, Hart D. Early recurrent embolism associated with nonvalvular atrial fibrillation: a retrospective study. Stroke 1983;14:688-693.

8. Hart RG, Sherman DG. Nonvalvular atrial fibrillation and stroke. Current Concepts of Cerebrovascular Disease and Stroke 1986;21:5-8.

9. Hinton RC, Kistler JP, Fallon JT, Friedlich AL, Fisher CM. Influence of etiology of atrial fibrillation on incidence of systemic embolism. Am J Cardiol 1977;40:509-513.

10. Herman B, Leyten ACM, van Luijk JH, Frenken CWGM, Op de Coul AAW, Schulte BPM. Epidemiology of Stroke in Tilburg, The Netherlands. The population-based stroke register: 2. Stroke 1982;13:629-634.

11. Hornig CR, Dorndorf W. Hämorrhagische Hirninfarkte mit Ventrikelblutung. Nervenarzt 1987;58:432-435.

12. Kopecky SL, Gersh BJ, McGoon MD, Whisnant JP, Holmes DR, Ilstrup DM, Frye RL. The natural history of lone atrial fibrillation, N Engl J Med 1987;317:669-674.

13. Lodder J, Dennis M, van Raak L, Jones LN, Warlow CP. Co-operative study on the value of long-term anticoagulation in stroke patients with non-rheumatic atrial fibrillation. Brit Med J 1988;296:1435-1438.

14. Miller VT, Hart RG. Heparin anticoagulation in acute brain ischemia. Current Concepts of Cerebrovascular Disease and Stroke 1987;22:7-11.

15. Sage JI, Van Uitert RL. Risk of recurrent stroke in patients with atrial fibrillation and non-vaivular heart disease. Stroke 1983;14:537-540.

16. Sato Y, Mizoguchi K, Sato Y, Okhita Y, Kaji M. Anticoagulant and thrombolytic therapy for cerebral embolism of cardiac origin. The Kurume Med J 1986;33:89-95.

17. Sherman DG, Hart RG, Easton JD. The secondary prevention of stroke in patients with atrial fibrillation. Arch Neurol 1986;43:68-70.

18. Shields RW, Laureno $\mathrm{R}$, Lachman $\mathrm{T}$, Victor M. Anticoagulant related hemorrhage in acute cerebral embolism. Stroke 1984;15:426-437.

19. Todnem K, Vik-Mo H. Cerebral ischemic attacks as a complication of heart disease: the value of echocardiography. Acta Neurol Scand 1986;74: 323-327.

20. Toole JF (ed). Cerebrovascular disorders. Raven Press. New York, 1988.

21. Wolf PA, Dawber TR, Thomas HE, Kannel WB. Epidemiologic assessment of chronic atrial fibrillation and risk of stroke: the Framingham study. Neurology 1978;28:973-977. 



\title{
Review of the literature:
}

\author{
Part I \\ The morphology and CT \\ appearance of cerebral infarction
}

The term "brain infarction" refers to focal total and partial brain necrosis caused by circulatory impairment, resulting in functional deficit. The pathogenetic mechanism of cerebral infarction resembles the "ischemic" or socalled "pale" infarction in other organs, such as myocardium, kidneys, liver and adrenals. However, the morphological pattern of ischemic cerebral infarction often differs from that of other organs, where in non-cerebral infarctions, the ischemic area is nearly always almost completely necrotic. This is contrary to brain infarction. In all organs the morphology of infarction depends on several factors: calibre of the obstructed artery, dynamics of ischemia development, state of the general circulation such as anatomical variations of the vascular tree, degree of atherosclerosis, presence of hypertension, and the availability of collateral circulation. Differences in morphology between cerebral and non-cerebral infarction are mainly due to two factors: firstly, the cellular elements of nervous tissue vary in their vulnerability to oxygen deprivation, whereas in other tissues this is almost non-existent. Secondly, the collateral circulation of the brain may, under some conditions, determine the extent and the morphology of the infarction.

The different cerebral tissues show decreasing sensitivity to ischemia in the following sequence: neurons, oligodendroglia, astroglia, and finally microglia with blood vessels. If ischemia is moderate oligo- and astroglia may recover. 


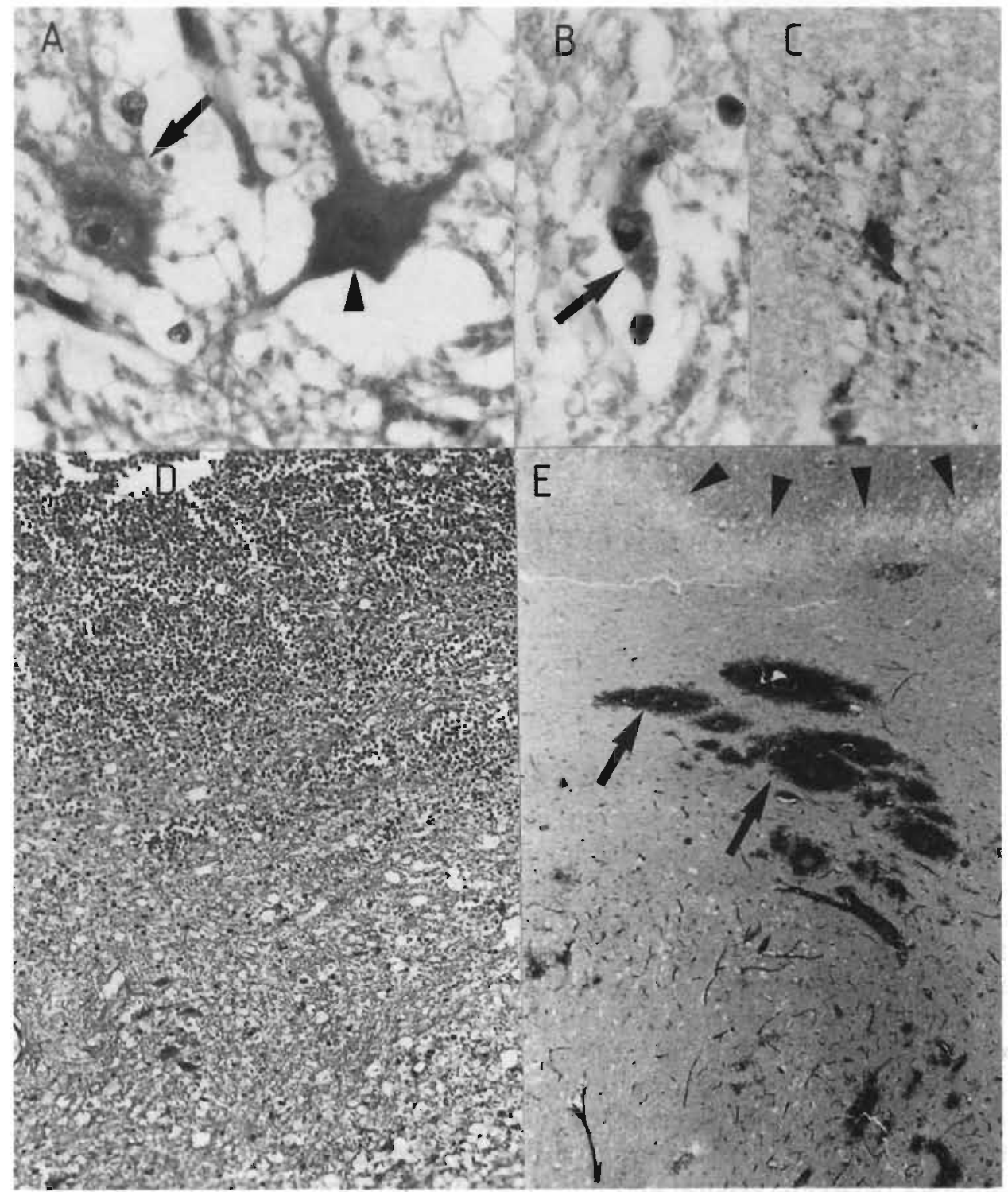

Figure A) Ischemic damage of a neuron $(\rightarrow)$ : swollen cell body and vacuolation of cytoplasm and lateralization of the nucleus. A second ganglion cell shows homogenization of the cytoplasm and dark lateralized nucleus $(>)$, hematoxylin eosin, 830 $\mathrm{x}$; B) Shrunken neuron with pycnotic nucleus $(\rightarrow)$, hematoxylin eosin, $830 \mathrm{x}$; C) Disintegration of astroglial processes marked by crumbs of glial fibrillary acidic protein visualized by immunohistochemistry, anti-GFAP reaction, $830 \mathrm{x} ; \mathrm{D}$ ) Leucocytic infiltration of the infarcted area, hematoxylin eosin, $53 \mathrm{x} ;$ E) Hyperemia and perivascular hemorrhages $(\rightarrow)$ within a hemorrhagic infarction, demarcated by a rim of edema $(>)$, hematoxylin eosin, $33 \mathrm{x}$. 
The mesenchymal components (microglia and blood vessels) often remain vital; they necrotize only in cases of severe, extensive infarction.

Macroscopically the first signs of cerebral infarction can be seen five to six hours after the onset of ischemia: the borderline between grey and white matter becomes less distinct and blurred. Later on, swelling, softening and a slight yellowish discoloration appear. Within 48-72 hours the infarcted area can thus be easily recognized.

The first microscopic features of cerebral infarction appear six to twelve hours after the onset of ischemia. At first the neuron cell bodies become swollen and filled with small vacuoles, accompanied by disarrangement and lysis of the Nissl substance in the cytoplasm. After a short time the neuron cell bodies become eosinophilic, deformed and shrunken. In large ganglion cells, for example the Purkinje cells, the cytoplasm appears glassy. This condition is termed "homogenization". The neuronal nuclei are at first hyperchromatic, shrunken and mostly displaced towards the periphery of the cell body (lateralization of the nucleus). The nuclear pycnosis is rapidly followed by karyorhexis. Necrosis of the glial component is generally marked by similar nuclear changes (Figures $A$ to $C$ ).

The swelling of the infarcted area, which is visible macroscopically, is caused by edema. Often perivascular hemorrhages due to increased permeability of the capillaries occur and contribute to this swelling. Approximately 48 hours after the onset of ischemia leucocytosis of small vessels and capillaries, and leucodiapedesis set in. This is in fact an inflammatory response to the necrosis and it may even simulate a septic infarction. In cerebral infarctions with total central necrosis, the so called "coagulation necrosis", the "inflammatory" reaction takes place at the periphery (Figure D).

About 72-96 hours after the onst of cerebral infarction, a scavenging process begins. Leucocytes are replaced by macrophages that are mainly of microglial and monocytic origin. They phagocytize and accumulate sudanophilic fat droplets and crystalline anisotropic metabolites from disintegrated neurons and myelin, thus dissolving the necrotic debris. This scavenging process lasts for approximately two weeks. After this, the number of phagocytes decreases, but some phagocyting cells remain in the interstitium for months or even years. The scavenging process is macroscopically reflected by increasing accumulation of fluid, and softening of the infarcted area; this appearance prompted the name "encephalomalacia" to be given to cerebral infarction.

Five days following the ischemic insult the surviving astrocytes start to proliferate. When the infarcted area is small, they replace the lost nervous tissue area with an astroglial scar. In extensive infarctions the astrocytes produce a gliofibrillary encapsulation. After colliquation of the central necrotic tissue, a wall of scar tissue and a cavity filled with fluid, in some cases traversed by still surviving blood vessels, remains. This is the "post-necrotic pseudocyst". 
Ischemic (anemic, pale, white) infarction is a common morphological substrate of stroke. Within the ischemic infarction, small, mostly microscopic, hemorrhages are very frequent. However, in some cases these hemorrhages are more pronounced and often become confluent. They even may form small blood pools in the necrotic tissue (Figure E). The ischemic infarction is thus transformed into a hemorrhagic infarction. For about four to five days such a lesion is dark red. Subsequently it turns brown due to breakdown of hemoglobin from the disintegrating erythrocytes.

Hemorrhagic cerebral infarctions are usually found in the cerebral cortex, basal ganglia and thalamus. They can also develop after obstruction of a venous drainage, e.g. vena magna Galeni or a venous sinus. Such venous lesions involve both the grey and the white matter equally. They are always rather extensive and are not confined to an arterial vascular territory. $1,2,6,7,14$ The patho-mechanism of hemorrhagic infarction is discussed in part 2 of this chapter.

Before the advent of CT scanning the clinical diagnosis of cerebral infarction was based on the patient's history, physical examination and sometimes arteriographical demonstration of an arterial obstruction in the appropriate territory. The diagnosis of a hemorrhagic infarction was impossible, unless blood was found in the cerebrospinal fluid, which, could not however differentiate primary intracerebral hematoma or subarachnoid hemorrhage from hemorrhagic infarction. With the introduction of CT scanning, changes in the diagnostic possibilities and patient management of a stroke emerged. The CT scan can show the size and location of the infarction and is able to differentiate between ischemic and hemorrhagic infarctions. Thus, hemorrhagic infarction can also be studied in patients who do not die ${ }_{s}$ and therefore, have not been included in post-mortem studies. Furthermore, serial scanning enables the assessment of the frequency and temporal evolution of hemorrhagic transformation of cerebral infarctions during life.

As in macroscopic morphology, the earliest sign of cerebral infarction on CT is brain swelling due to edema. It may appear in the early hours following the ictus. ${ }^{5,10}$ Depending on the size of the infarction and the extent of edema, more or less severe space-occupying signs, the so-called "mass effect", may be visible on $\mathrm{CT}$. These signs are: straightening or disappearance of cerebral sulci, compression of ventricles, and shift of midline structures to the side opposite to the lesion. Houser et al (1981) ${ }^{10}$ observed mass effect in $33 \%$ of their cases with cerebral infarction. Masdeu et al (1977) ${ }^{12}$ reported that $70 \%$ of the patients revealed mass effect on CT during the first week following stroke. This percentage decreased to $29 \%$ at the end of the third week, whereas by week eight space-occupying signs had disappeared in all cases. If the lesion is small the initial CT scan may remain normal. Houser et al (1981) ${ }^{10}$ imaged only $45 \%$ of cerebral infarctions within the first 48 hours after the ictus. Both they and Masdeu et al (1977) 12 reported that about $20 \%$ of all infarctions 
remained undetected during the first two weeks. In a recent study Horowitz et al $(1991)^{9}$ found evidence of acute infarction on CT in as many as 28 out of 50 patients $(56 \%)$ within four hours after the stroke onset, whereas in 11 patients $(22 \%)$ no CT abnormalities were found even on day seven after stroke.

Recent ischemic infarction is reflected on CT by a more sharply demarcated, hypodense area after about seven days. This is due to the disappearance of edema, which itself has no sharp outline. The hypodense, sharply demarcated infarction within the edematous area, then becomes visible. Between the second and third week the infarction may become isodense. Thereafter the density gradually decreases again. Finally, when a cystic cavity has developed, the density on the CT scan becomes equal to, or only slightly higher than that of the cerebrospinal fluid. 5,15 In small infarctions, which result morphologically in a glial scar without a cavity, CT reveals a loss of cerebral volume on the side of the infarction, represented by an increase of the cerebrospinal fluid space at the cerebral convexity and/or ventricle enlargement. In some cases a midline shift towards the affected side can be found. ${ }^{5}$ Occasionally, small infarctions disappear on the CT because the visualization of the volume decreases or because the residual pseudocyst is beyond the resolution power of the CT scan. ${ }^{3}$

Blood on the CT scan is hyperdense, and therefore, a hemorrhagic infarction can be seen on CT scan provided the hemorrhage is large enough. Tonghi et al (1981) ${ }^{14}$ compared CT scan findings with post-mortem examinations in patients who died following cerebral infarction. At that time they were able to demonstrate hemorrhages larger than $1 \mathrm{~cm}$ in diameter on CT. If smaller petechial hemorrhages accumulate, they can be visualized by $\mathrm{CT}$ as well. ${ }^{5} \mathrm{~T}$ The typical appearance of a hemorrhagic infarction consists of a hypodense area with one or more small, irregular hyperdensities. As the blood component disintegrates and gradually disappears, the hemorrhagic infarction first becomes isodense, and then hypodense after two to four weeks. ${ }^{15}$

\section{In summary}

Cerebral infarction has, compared to infarctions in other organs, a broader spectrum of morphological changes, due to a varying sensitivity of the different brain tissue components to ischemia. Petechial, mostly perivascular hemorrhages, often only visible at microscopic level, appear in most cerebral infarctions. In some infarctions the hemorrhages are more numerous, larger and sometimes confluent. If the infarcted area appears red on macroscopical examination it is called "hemorrhagic".

In contrast to the morphological examination, $\mathrm{CT}$ scanning enables diagnosis of hemorrhagic infarction in patients surviving their stroke. It also provides information on the time spectrum of hemorrhagic transformation of stroke. 
Although some authors believe that the differentiation between hemorrhagic infarction and primary cerebral bleeding on CT is easy ${ }^{8,11}$, others stress that large, confluent secondary hemorrhages within an infarcted area may be indistinguishable from primary cerebral bleeding. 4,5,10 Primary brain hemorrhage on CT often has only a narrow hypodense rim around the homogeneous central hyperdensity, and blood is sometimes found in the ventricles. ${ }^{5}$ Extensive hemorrhagic infarction with confluent blood pools may appear equally homogeneous and may sometimes cause bleeding into the ventricular cavity. $4,5,10$ If the hyperdensity lies within a hypodense area compatible with a vascular territory of a major cerebral artery or one of its branches, then it most probably is a hemorrhagic infarction. Homogeneous hyperdensity, located in the deep parts of the hemispheres even with blood in the ventricular system, may not exclude hemorrhagic infarction. However, validation of CT criteria with post-mortem findings in hemorrhagic infarction has not yet been performed. A comparison of CT features and post-mortem data in hemorrhagic strokes is reported in Chapter 5. 


\section{REFERENCES}

1. Bednár B, Fingerland A, Jedlicka V (eds). Pathologická Anatomie. Státní zdravotnické nakladatelství. Praha, 1963.

2. Blackwoodi W, McMenemey WH, Meyer A, Norman RM, Russel DS (eds). Greenfield's Neuropathology. Edward Arnold Ltd. London. 1967, 2nd ed.

3. Brahme F.J. CT diagnosis of cerebrovascular disorders - a review. Comput Tomogr 1978:2:173-181.

4. Cosgrove GR, Leblanc R, Meagher-Villemure K, Ethier R. Cerebral amyloid angiopathy. Neurology 1985;35:625-631

5. Davis KR, Taveras JM, New PFJ, Schnur JA, Roberson GH. Cerebral infarction diagnosis by computerized tomography. Am J Röntgenol 1975;124:643-660.

6. Eder M, Gedick $P$ (eds). Lehrbuch der algemeinen Pathologie und der pathologischen Anatomie. Springer Verlag, Berlin. 1977, 30ste Ed.

7. Esiri M, Oppenheimer LJ. Diagnostic neuropathology. Blackwell Scientific Publications, Oxford, 1989.

8. Hakim AM, Ryder-Cooke A, Melanson D. Sequential computerized tomographic appearance of strokes. Stroke 1983;14:893-897.

9. Horowitz SH, Zito JL, Donnarumma R, Patel M, Alvir J. Computed tonnographic-angiographic findings within the first five hours of cerebral infarction. Stroke 1991;22:12451253.

10. Houser OW, Campbell IK. Computed tomography in cerebrovascular disease: influences of morphology, topography, clinical factors, and temporal profile. in: Moossy J, Reinmuth OM (eds). Cerebrovascular Diseases. Raven Press, New York. 1981, pp. 181-191.

11. Inoue Y, Takemoto K, Miyamoto T, Yoshikawa N, Taniguchi S, Saiwai S, Nishimura Y Komatsu T. Sequential computed tomography scans in acute cerebral infarction. Neuroradiol 1980;135:655-662.

12. Masdeu JC, Azar-Kia B, Rubino FA. Evaluation of recent cerebral infarction by computerized tomography. Arch Neurol 1977;34:417-421.

13. Peters G. Klinische Neuropathologie. Georg Thieme Verlag, Stuttgart. 1970, zweite Ed.

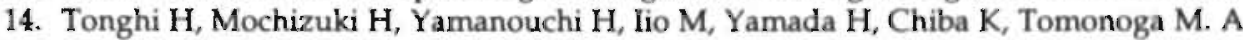
comparison between the computed tomogram and the neuropathologicall findings in cerebrovascular disease. J Newrol 1981;224:211-220.

15. Vonofakos D, Artmann H. CT findings in hennorrhagic cerebral infarct. Comput Radiol 1983;7:75-83;. 


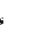




\section{Review of the literature:}

\section{PART II \\ The pathophysiology of cerebral hemorrhagic infarction}

Early knowledge about the morphology and pathogenesis of infarction came from studies performed during the 19 th century on lung, spleen and kidney infarctions whereas studies on brain infarction were rare before 1900. The first descriptions of infarctions referred to observations in post-mortern material, but animal model studies were used shortly afterwards as well. The origin of the word "infarction" is uncertain, but generally two explanations are offered. The first connects INFARCTION with the latin word INFARCIRE, which means "to stuff". It was used as a name for a heart filled with thrombi, and for blood vessels filled with thrombotic material. Later it referred to the result of vascular thrombosis, i.e. circumscribed ischemic tissue necrosis in the vascular territory of the occluded vessel. The other explanation attributes the name INFARCTION to the Latin name of blood sausage which is INFARCIMENTUM, which refers to the macroscopical similarity between hemorrhagic infarction of the small intestine and this nutrient. Laennec $(1835)^{35}$ described hemorrhagic infarction of the lung as "une sorte d'infarctus" and "hemoptoique infarctus". Virchow (1847) 50 translated these terms into German as "hämoptoischer Infarkt" and "hämorrhagischer Infarkt". He studied organ embolization in animals, using rubber, muscle, fat and blood clot emboli. The co-existence of infarction and arterial obstruction in the lung was described by Bouillaud in $1826 .{ }^{7}$ In 1852 Kirkes $^{33}$ finally established that hemorrhagic pulmonary infarction resulted from arterial embolism but the patho-mechanism of hemorrhagic infarction remained unclear, and several explanations were offered. Cohn (1860) ${ }^{11}$ and Cohnheim (1872) ${ }^{12}$ introduced the theory of venous reflux and ischemic endothelium damage as the cause of 
blood extravasation after arterial obstruction in the lung. However, after experimental ligation of the renal artery and vein, Cohn was still able to produce hemorrhagic infarction in the kidney, and therefore abandoned the venous reflux theory. 11

In 1876 Kossuchin ${ }^{34}$ introduced the idea of blood influx from collateral arteries as the cause of hemorrhagic infarction. In 1880 Litten $^{36}$ demonstrated that endothelium was much more resistant to ischemia than it had been thought to be. He concluded that the endothelial damage was not responsible for the blood extravasation. Instead, he postulated that blood flows into the infarcted area by way of collateral circulation, and accumulates there due to lack of vis a tergo. He ascribed the blood extravasation to extreme capillary dilatation and rupture. Welch (1887) 51 experimented with small intestine, and proved that hemorrhagic infarction resulted from arterial collateral influx and not from venous reflux. Forbes (1901) 21 demonstrated that the red colour in the early stage of infarction was due to vessel congestion and not to blood extravasation, whereas earlier pathologists believed that all infarctions were initially red i.e. hemorrhagic. Karsner and Austin (1911) ${ }^{32}$ observed that splenic and renal infarctions were hyperemic after four hours, then after 24 to 48 hours became hemorrhagic, and finally turned pale due to central coagulation necrosis. McCallum (1940) ${ }^{38}$ stated that whether an infarction would remain anemic or become hemorrhagic depended on the architecture of the vascular supply and the density of the tissue involved. In solid tissue bleeding is minimal. The red cells are broken down, and the released hemoglobin pigment diffuses out of the infarcted area. Therefore, in organs with a high tissue density such as the heart and the kidney, infarctions tend to be pale. In contrast, arterial infarctions in loose tissue like the lungs, are so intensively hemorrhagic that they remain red all the time.

Prior to 1800 cerebral infarction, referred to as "encephalomalacia alba" or "rubra" meaning white or red brain softening, was attributed to inflammation. When Rostan 44 suggested, in 1820, that in some cases encephalomalacia might be a form of necrosis he met with strong opposition. Carswell (1838) 8 definitely established the necrotic nature of the pale brain softening as a result of ischemic damage due to obstruction of cerebral arteries. In $1846 \mathrm{Hase}^{23}$ presented a small series of cases with brain softening due to plugged arteries, and so did Virchow ${ }^{50}$ in 1847 . Others followed 11,45 and soon the idea that pale infarction of the brain was due to arterial obstruction was generally accepted. The pathophysiology of hemorrhagic cerebral infarction, however, remained the subject of dispute. In 1930 Schwart $z^{47}$ stated that hemorrhagic infarction and massive hemorrhage in the brain were basically the same, the only difference being quantitative. One year later Böhne ${ }^{5}$ opposed this view, stating that as in other tissues, infarction of the brain was pale first and became hemorrhagic afterwards. Hiller (1935) ${ }^{25}$ supported Böhne's view, suggesting that blood extravasation was caused by collateral arterial influx. Fazio (1949) 18 noticed that cerebral hemorrhagic infarctions are not homogeneously 
hemorrhagic, but are interspersed with pale areas. He attributed this phenomenon to partial vessel occlusions causing non-uniform blood stasis and extravasation, FOLLOWING WHICH necrosis might occur. He also suggested that vasospasm proximal to the occlusion could lead to the development of hemorrhagic infarction. Hain et al (1952) 22 found hemorrhagic infarction after the occlusion of the canine middle cerebral artery in the zone of the perforating branches, whereas when the occlusion lay distally to all the perforating vessels, it resulted in an ischemic infarction, thus illustrating the role collateral flow might play in the development of hemorrhages in an infarcted area, at least in an animal model. Faris et al (1963) ${ }^{17}$ suggested that the degree of collateral flow was influenced by systemic blood pressure: ligation of the middle cerebral artery in hypertensive dogs produced hemorrhagic infarction, whereas in normotensive dogs the infarction remained pale. The authors concluded that collateral blood flow in the brain of the hypertensive animals was better than in the normotensive ones, and this was considered to be the reason why the hypertensive group developed hemorrhagic infarctions.

The mainstay of the present concept on the pathophysiology of hemorrhagic brain infarctions in man stems from the results of Fisher and Adams' meticulously performed pathological study in 1950 on 57 cases that died following an embolic brain infarction. 20 Thirty-eight of these 57 infarctions were partially hemorrhagic. The hemorrhagic part was usually situated proximal to the pale part, corresponded with an arterial vascular territory, and was mostly confined to the grey matter. In only 12 of the 38 cases vessel dissection revealed an embolic plug. In 10 of these 12 cases the embolus was located distally to the hemorrhagic part of the infarction, often at the apex of the pale portion. From these findings the authors concluded: "An embolus upon reaching a brain artery becomes slowed up or arrested in a narrowed part of the vessel, usually at a bifurcation and causes ischemic necrosis of the tissue supplied by that vessel. The embolic material then undergoes a change; it may become more compact, assume a different shape, shatter, or fragment and the pieces are then carried into the distant peripheral branches or arterial twigs where they are difficult to find at post-mortem. Or instead of fragmenting, the entire embolus may move distally for a short distance and then become securely lodged in one or two large branches. Proximal branches, which were previously occluded, are now exposed to the force of the arterial blood pressure, and the capillary bed which they supply becomes congested with blood. Extravasation occurs through the distended capillaries and other small vessels. Parts of the brain supplied by vessels which are still occluded by emboli remain pale except at the extreme margins between normal and ischemic brain where collateral vessels permit some limited influx of blood into the damaged capillary bed." The theory of clot migration and fragmentation, postulated by Fisher and Adams ${ }^{20}$ was later confirmed by arteriographical studies. $2,15,27,43,49,52,53$ In 1965 Zatz et al ${ }^{53}$ published their observations of serial angiography in six patients with acute cerebral vessel occlusion. All 
patients had an embolic stroke, two of them from a mural thrombus in the internal carotid artery, and the other four from the heart. Two of the six patients received a "fibrinolytic mixture", whereas four were treated with a placebo. In three of the four patients who did not receive fibrinolytic therapy, reopening of the occluded vessel was found within 1 to 34 hours, whereas in two of them fragmentation of the clot with occlusions of more distal arteries was documented. The authors concluded that reopening of occluded vessels probably occurs early after stroke onset, which may explain why carotid angiograms frequently show no occlusion when performed at a later date, and also why only few occlusions are found in post-mortem studies of embolic stroke. Irino et al (1977) 28 examined 45 patients with embolic stroke, most probably originating from the heart. They found reopening of the involved vessels within one week in 17 cases. The authors also correlated angiographic findings after vessel reopening with the presence of space-occupying signs such as midline shift on CT. Eight of the 17 cases with reopened arteries showed apparent capillary blush in the territory of the affected artery whereas nearly all cases had an abnormal circulation time. Eleven of thi reperfused cases revealed space-occupying signs, six of whom demonstratec a shift of midline structures on CT. Of all 11 cases with mass effect, eigh showed a capillary blush. The authors concluded that reopening of occludec arteries after embolic stroke is common, but that such reopening is not followed by normal circulation. They also concluded that edema and hemorrhagic transformation often occur, whereas hyperemia and space-occupying effect on angiography might indicate spontaneous reopening of the vessel prior to the angiography. Yamaguchi et al $(1984)^{52}$ examined a large series of embolic (120) and thrombotic (109) stroke patients. In the embolic series they found 45 cases ( $36 \%$ ) with hemorrhagic infarction, 42 of whom showed reopening of the previously occluded artery on angiography. In 10 of the embolic cases a migration of the clot was documented on repeated angiography. Twenty cases in the embolic group were without any occlusion at the time of the first angiogram, even when performed on the day of the stroke onset. In the thrombotic group only two patients $(2 \%)$ developed hemorrhagic infarction, one with reopening of the occluded artery and the other without. The authors concluded that the shorter the interval between stroke onset and angiography, the more likely that angiography will demonstrate an occlusion, and the more apical this occlusion will be within the embolic brain infarction. Angiography studies thus proved that reopening of occluded vessels after cerebral embolism occurs rather frequently, the reported incidence varying from 41 to $75 \%, 19,28,52$ Circulation in the territory of the obstructed artery after the reopening seems to be abnormal. The occurrence of many hemorrhagic infarctions coincides with a reopening of the previously occluded artery, whereas hemorrhagic transformation of the infarcted area develops after reperfusion. 52 Thus, recent angiographical data support the concept of Fisher and Adams ${ }^{20}$ postulated more than 30 years earlier. 
Fragmentation of embolic material followed by reperfusion is not the only possible mechanism leading to hemorrhagic brain infarction. Hemorrhagic transformation has also been observed without reopening of the feeding artery. $4,14,29,30,41,43$ Blackwood $(1967)^{4}$ postulated that at the edge of an infarction the collateral influx is sufficient to protect the tissue from serious damage, whereas the deeper parts become congested due to damage to capillary walls. This would lead to vessel distension and blood stasis, which in turn causes blood extravasation. He illustrated this theory with observations of leucocytic infiltration as a sign of circulating blood in hemorrhagic infarctions caused by a total obstruction of the feeding artery. This theory, however, is difficult to reconcile with the existence of pure ischemic brain infarctions, unless one assumes that in some cases the collateral influx is better than in others. Collateral circulation plays a major role in the induction of small petechial hemorrhages on the border of an extensive ischemic infaretion. Ogata et al (1989) 43 suggested that in stroke cases without reopening of the feeding artery the development of hemorrhagic infarction could be induced by surges of high blood pressure following stroke onset, which, if they take place before the development of brain edema, will facilitate blood extravasation. If the blood pressure rises after the edema has developed, no collateral influx will occur due to compression of collateral vessels, and the infarction will consequently remain pale.

There is, however, still another aspect in the pathogenesis of hemorrhagic brain infarction, which has not as yet, in our opinion, been fully appreciated. This concerns the special quality of the brain tissue related to a singularly high content of water, 774 grs water per $\mathrm{kg}$ fresh brain tissue. The blood, which is sometimes called "liquid tissue", contains about 680 grs water per kg blood.16 The shape of the brain is kept constant by organic substances which bind and integrate the water ions into the tissue, and this, at the same time, also offers a physical support and a protection to the vascular bed. Ischemia leads to disintegration of this delicate construction. The water ions are released and accumulate outside the cells, together with edema due to increased permeability of blood vessels in the ischemic area, thus contributing to the colliquation of the necrotic tissue. In the quickly developing pulp, the supportive function of the brain tissue is lost. Without mechanical tissue support the capillaries and small vessels may not only dilate and increase their permeability, but also burst more easily, allowing erythrocytes to pass from the vessel lumen into the pulpous necrotic tissue without hincler.

More recent animal models of hemorrhagic infarction lend support to the view that both arterial reperfusion, as well as collateral flow determine hemorrhagic transformation, whereas early development of edema leading to decreased tissue supportive function could also contribute. Seki et al (1983) ${ }^{48}$ demonstrated that blood extravasation occurred early after reperfusion of the infarction. In their dog model of thalamic infarction blood extravasation appeared after 6-12 hours of reperfusion, suggesting that hemorrhagic trans- 
formation is linked to reperfusion. Mellergard and co-workers (1989)40 investigated the temporal development of brain edema after focal ischemia and reperfusion in rats. The development of edema appears to be bi-phasic. Early edema reaches its maximum at 30 minutes of reperfusion and disappears after six hours. After 24 hours edema reoccurs. From this and other studies it appeared that early edema development depends on the intensity of reperfusion and on the duration i.e. severity of the ischemia. In gerbils, who have an incomplete circle of Willis and therefore impaired collateral circulation, early edema does not appear at all. 3,39,40 Because prolonged ischemia is often followed by "hypo-hyper-perfusion" the hyper-perfusion most probably stimulates the development of early edema.6,31 The nature of this early edema, whether it is cytotoxic, vasogenic, or both, is not yet known. However, it was demonstrated in animal models that cerebral ischemia is accompanied by an early significant increase in tissue osmolarity 24,26 , which leads to intracellular accumulation of water (cytotoxic edema). This phenomenon resembles what in man is called "early post-ischemic edema". 40

Nishigaya and co-workers (1991) ${ }^{42}$ investigated vascular changes after ischemia and reperfusion in rats. Two-hours of ischemia was sufficient to produce endothelial denudation in small arteries. Medial smooth muscle cells were even more vulnerable; after two hours of ischemia, a complete medial necrosis appeared allowing edema and erythrocyte extravasation to develop. The arterial lesions healed within 10 days. Hypertension could further contribute to hemorrhagic transformation. 6 This was further studied by Saku et al $(1990)^{46}$ in hypertensive rats. They concluded that hemorrhagic transformation can be induced by a rapid increase of perfusion pressure in the ischemic brain tissue by forced hypertension. Furthermore, they suggest that the restoration of blood flow through leptomeningeal collaterals plays an important role when hemorrhagic transformation occurs without being preceded by reopening of the occluded arteries. Cole et al (1990)13 investigated the influence of hemodilution and hypertension on hemorrhagic transformation of reperfused ischemic infarctions in rats. They concluded that although hypertension may decrease the extent of ischemic brain injury, it significantly increases the risk of intraparenchymal hemorrhage in the injured area following reperfusion.

\section{In conclusion}

There are three possible mechanisms to explain hemorrhagic transformation of an ischemic brain infarction:

1. reperfusion through collateral vessels

2. deterioration of the vascular tree integrity caused by loss of the brain tissue's supportive function due to tissue necrosis

3. fragmentation of emboli with distal lodgernent, reperfusion and extravasation of blood through damaged vessel walls. 
Which of the three factors prevails in an individual patient is difficult to assess. Collateral blood influx seems to be less important in man than it is in animal models. The degree of ischemic damage to vessel walls in man still remains unknown.

Although hypertensive stroke patients are known to have a larger risk of hemorrhagic transformation, the question of the mechanism causing it, i.e. increased collateral blood influx, overfilling of the feeding vessels in the infarcted area or both, is still unanswered.

Based on the theory of Fisher and Adams (1950) ${ }^{20}$ and other post-mortem studies 1,30 hemorrhagic infarction was thought mainly to result from embolism, most of which was assumed to be cardioembolic at that time. However, later CT scan studies showed that hemorrhagic infarction is associated with large infarctions regardless of their etiology.9,10 Cardioembolic strokes are often large and fatal. Therefore, studying only autopsy series might bias towards finding hemorrhagic infarction to be related to a cardioembolic stroke cause. This problem will be addressed in Chapter 2.

The role of the loss of the supportive function of the brain tissue and consequent disintegration of the vascular tree within the infarcted area has not been fully appreciated until now. However, hemorrhagic infarction often appears in large infarctions, in which this factor plays a more important role than in the smaller lesions. Considering the morphological changes in cerebral infarction and their temporal development, the loss of the supportive function is probably most pronounced after the disintegration of cellular elements and before the appearance of substantial scar development. Consequently hemorrhagic infarction would be expected to be rare immediately after the onset of ischemia, and to develop within the first week of the disease in most cases. The timing of the hemorrhagic transformation in ischemic stroke plays an important role if anticoagulation is to be considered. The frequency of hemorrhagic infarctions at stroke onset and the temporal profile of hemorrhagic transformation are dealt with in Chapters 3 and 6. 


\section{REFERENCES}

1. Adams RD, van der Eecken HM. Vascular diseases of the brain. Ann Rev Med 1953;4:213252.

2. Allcock JM. Occlusion of the middle cerebral artery: serial angiography as a guide to conservative therapy. J Neurosurg 1967;27:353-363.

3. Avery S, Crockard A, Russel RR. Evolution and resolution of edema following severe temporary cerebral ischemia in the gerbil. J Neurol Neurosurg Psych 1984;47:604-610.

4. Blackwood W. Vascular disease of the central nervous system. In: Greenfield's Neuropathology. Edward Arnold Ltd, London, 1967, 2n ed., chapter 2.

5. Böhne $\mathrm{C}$. Kompakte Hirnblutung and hämorrhagische Hirnerweichung. Z Klin Med 1931:117:30-54.

6. Bolander HG, Persson L, Hillered L, d'Argy R, Ponten U, Olsson Y. Regional cerebral blood flow and histopathologic changes after middle cerebral artery occlusion in rats. Stroke 1989;20:930-937.

7. Bouillaud J. Observations pour servir a l'histoire de l'apoplexie pulmonaire. Arch Gen Med 1826;12:392-406.

8. Carswell R. Pathological Anatomy. London, 1883.

9. Cerebral Embolism Study Group. Immediate anticoagulation of embolic stroke: brain hemorrhage and management options. Stroke 1984;15:779-789.

10. Cerebral Embolism Study Group. Cardioembolic stroke: early anticoagulation and brain hemorrhage. Arch Intern Med 1987;147:636-640.

11. Cohn B. Klinik der embolischer Gefässkrankheiten. Hirschwald, Berlin, 1860.

12. Cohnheim J. Untersuchungen über die embolischen Prozesse. Hirschwald, Berlin, 1872.

13. Cole DJ, Drummond IC, Ruta TS, Peckham NH. Hernodilution and hyportension offocts on cerebral hemorrhage in cerebral ischemia in rats. Stroke 1990;21:1333-1339.

14. Dalal PM, Shah PM, Sheth SC, Deshapande CK. Cerebral embolism, angiographic observations on spontaneous clot lysis. Lancet 1965;1:61-64.

15. Dalal PM, Shah PM, Aiyar RR. Arteriographic study of cerebral embolism. Lancet 1965:2:358-361.

16. Diem K, Lentner C (eds). Documenta Geigy, Wisschenschaftliche Tabellen. JR Geigy AG, Pharma, Basel. 1969, 7. Auflage, pp 515 and 557.

17. Faris AA, Hardin CA, Poser CM. Pathogenesis of hemorrhagic infarction of the brain. I. Experimental investigation of role of hypertension and of collateral circulation. Arch Neurol 1963;9:468-472.

18. Fazio C. Red softening of the brain. J Neuropathol Exp Neurol 1949;8:43-60.

19. Fieschi C, Bozzano L. Transient embolic occlusion of the middle cerebral and the internal carotid arteries in cerebral apoplexy. J Neurol Neurosurg Psych 1969;32:236-245.

20. Fisher $M$, Adams RD. Observations on brain embolism with special reference to infarction. (1950) Furlan AJ (ed). The heart and stroke. Springer Verlag, London, 1987, chapter 2.

21. Forbes cited in: Beattie JM, Dickson WWC. General Pathology, Heinemann, Springer, Berlin, 1925, 3rd ed.

22. Hain RF, Westhaysen PW, Swank RL. Hemorrhagic cerebral infarction by arterial occlusion; experimental study. J Neuropath Exp 1952;11:34-43.

23. Hase KE. Ueber die Verschliessung der Hirnarterien als nächste Ursache einer Form der Hirnerweichung. Z Rad Med 1846;4:91-111.

24. Hatashita $S$, Hoff $\pi$, Slamat SM. Ischemic brain edema and the osmotic gradient between blood and brain. J Cerebr Blood Flow Metab 1988;8:552-559.

25. Hiller F, in: Bumke O, Foerster O (eds). Handbuch der Neurologie. Springer, Berlin, 1935, vol. 11, p. 311. 
26. Hossman KA, TagakiS. Osmolality of brain in cerebral ischemia. Exp Neurol 1976;51:124131.

27. Irino T, Minami T, Taneda M, Hara K. Brain edema and angiographical hyperaemia in postrecanalized cerebral infarction. Acta Neurol Scand 1977;56,suppl 64:134-135.

28. Irino T, Taneda M, Minami T. Angiographic manifestations of postrecanalized cerebral infarction. Neurol 1977;27:471-475.

29. Irino $T$, Taneda M, Minami $T$. Sanguineous cerebrospinal fluid in recanalized cerebral infarction. Stroke 1977;8:22-24.

30. Jörgensen L, Torvik A. Ischemic cerebrovascular diseases in an autopsy series. Part 2. Prevalence, location, pathogenesis, and clinical course of cerebral infarcts. J Neurol Sci 1969;9:285-320.

31. Kaplan B, Brint S, Tanabe J, Jacewicz M, Wang X-J, Pulsinelli W. Temporal thresholds for neocortical infarction in rats subjected to reversible focal cerebral ischemia. Stroke 1991;22:1032-1039.

32. Karsner HT, Austin JH. Studies in infarction. JAMA 1911:57:951-958.

33. Kirkes WS. On some of the principal effects resulting from the detachment of fibrinous deposits. Med Chir Tr 1852;35:281-324.

34. Kossuchin A. Zur Lehre von dem embolischen Infarkte. Virchows Arch Path Anat $1876 ; 67: 449-491$.

35. Laennec RTH. A treatise on the disease of the chest and on mediate auscultation. London. 1835,4 th ed.

36. Litten $\mathbf{M}$. Untersuchungen über den haemorrhagischen Infarkt und über die Einwirkung arterieller Anämie auf das lebende Gewebe. Z Klin Med 1880;1:131-227.

37. Lodder J. CT-detected hemorrhagic infarction; relation with the size of the infarct and the presence of midline shift. Acta Neurol Scan 1984;70:329-335.

38. MacCallum WG. A Textbook of pathology. Saunders, Philadelphia. 1940, 7th ed.

39. Matsumoto M, Hatakeyama T, Morimoto K, Yanagihara T. Cerebral blood flow and neuronal damage during progressive cerebral ischemia in gerbils. Stroke 1990;21:14701477 .

40. Mellergard P, Bengtsson F, Smith ML, Riesenfeld V, Siesjö BK. Time course of early brain edema following reversible forebrain ischemia in rats. Stroke 1989;20:1565-1570.

41. Mohr JP, Barnett HJM. Classification of ischemic stroke. In: Barnett HIM, Stein BM, Mohr JP, Yatsu FM (eds). Stroke, pathophysiology: Diagnosis and Management. Churchill Livingstone Inc, New York. 1986, pp 128-291.

42. Nishigaya $\mathrm{K}$, Yoshida $\underline{Y}$, Sasuga $\mathrm{M}$, Nukui $\mathrm{H}$, Doneda $\mathrm{G}$. Effect of recirculation on exacerbation of ischemic vascular lesions in rat brain. Stroke 1991;22:635-642.

43. Ogata J, Yutani C, Imakita M, Ishibashi-Ueda H, Sakui Y, Minematsu K, Sawada T, Yamaguchi. $\Upsilon$. Hemorrhagic infarct of the brain without a reopening of the occluded arteries in cardioembolic stroke. Stroke 1989;20:876-883.

44. Rostan L.. Recherches sur une maladie encore peu connue qui a reçu le nom de Ramollissement du Cerveau. Paris, 1882.

45. Rühle A. Drei Fälle halbseitiger Lähmung verursacht durch Verstopfung einer Gehirnarterie. Virchows A.rch Path Anat 1853;5:187-198.

46. Saku Y, Choli J, Waki R, Masuda J, Tamaki K, Fujishima M, Ogata J. Hemorrhagic infarct induced by arterial hypertension in cat brain following middle cerebral artery occlusion. Stroke 1990;21:589-595.

47. Schwartz P. Die Arten der Schlaganfälle des Gehirns und ihre Entstehung. Monographien aus dem Gesamtgebiete der Neurologie und Psychiatrie. 1930, vol. 57.

48. Seki H, Ogawa A, Yoshimoto FT, Sato H, Suzuki J. Hemodynamics in hemorrhagic infarction - an experimental study: No To Shinkei 1983:35:460-464. 
49. Sinderman F, Dichgans J, Bergleiter R. Occlusion of the middle cerebral artery and its branches: angiographic and clinical correlates. Brain 1969;92:607-620.

50. Virchow R. Ueber die akute Entzündung der Arterien. Virchows Arch Path Anat 1847;1:272-378.

51. Welch WH. Hemorrhagic infarction. Trans Assoc Amer Phys 1887;2:121-132.

52. Yamaguchi T, Minematsu K, Choki J, Ikeda M. Clinical and neuroradiological analysis of thrombotic and embolic cerebral infarction. Jap Circul 1984;48:50-58.

53. Zatz LM, lannone AM, Eckman PB, Hecker SP. Observations concerning intracerebral vascular occlusions. Neurol 1965;15:389-401. 


\section{Review of the literature:}

\section{PART III \\ Embolic brain infarctions; the heart-brain relationship}

The diagnosis of cardiogenic brain embolism is difficult and complex considering the numerous publications on this issue, as well as the frequent "bed-side" discussions between cardiologists and neurologists. Most of the patients with suspected cardioembolic stroke are elderly, often with concomitant hypertension, diabetes mellitus or other sequela predisposing to stroke. The presence of a potential cardioembolic source does not fully ascertain the stroke cause, nor does it contradict large vessel ernbolism. Therefore, often the diagnosis of cardiogenic embolic stroke depends on the attending clinician's judgement, the scrutiny with which he performs ancillary testing, and the criteria for cardiogenic embolic source he uses. These are important notes to consider when comparing different studies on cardiogenic brain embolism. The clinical diagnosis of cardioembolic stroke is based on neurological, CT scan, and cardiological "predictors", features that are neither specific nor sensitive indicators of a cardioembolic stroke mechanism. 37,164

As neurological "predictors" of cardioembolic stroke mechanisms have been considered:

1. abrupt onset of maximal neurologic deficit $30,36,133,134$

2. isolated focal deficit (e.g. isolated aphasia) 16,37

3. loss of consciousness at onset ${ }^{164}$

4. seizures at onset 132,202

5. headache at onset ${ }^{202}$

6. onset during activity ${ }^{30}$

7. nausea and vomiting at onset 202 
8. clinical evidence of two separate sites of embolization (different cerebral vascular territories or embolization in the brain and other organs) $30,133,134$

9. specific location and size of the stroke (large, cortical infarctions, not in the vertebro-basilary territory) $16,37,200$

Abrupt onset of maximal neurological deficit has been reported in $25-82 \%$ of ischemic strokes with a potential cardioembolic source, but also in $14-66 \%$ of patients with other ischemic stroke causes.18,30,164 Ramirez-Lassepas et al (1987) ${ }^{164}$ demonstrated that the rapidity of stroke onset is significantly associated with the presence of a cardioembolic source. Although this symptom is highly specific, it is not sensitive, and therefore it is not a reliable predictor of cardioembolic stroke. ${ }^{164}$ A non-sudden, stuttering or progressive onset occurs in about $10 \%$ of ischemic strokes with a cardioembolic source. In these cases disintegration and distal migration of embolic fragments $38,61,134$, or moulding and superimposed thrombosis of the lodged emboli61,202 may explain the stroke progression. Whether re-embolization of the same vascular territory can occur, is unknown. Statistically it seems unlikely, although, sometimes recurrent emboli prefer specific vascular territories. 195,202 Isolated focal deficit, especially isolated Wernicke's aphasia, global aphasia without hemiparesis and isolated posterior cerebral artery syndromes have been reported to be most likely cardioembolic in origin. $29,59,115,152$

Ramirez-Lassepas et al (1987) ${ }^{164}$ found loss of consciousness at stroke onset to be significantly associated with a cardioembolic source. However, as with "sudden onset", this sign was not sensitive.

Seizures or headache at onset do not distinguish cardioembolic stroke from other causes 18,30,66,164 and the same is true for stroke onset during activity. $30,134,164$ Nausea and vomiting could indicate raised intracranial pressure rather than cardioembolic stroke, and can therefore occur in both cardioembolic and thrombotic stroke as well as in other abnormalities associated with increased intracranial pressure, such as cerebral hemorrhage. 158 Diagnosis of multiple infarctions in the brain or in other organs has also been used as a sign of cardiogenic embolism in post-mortem as well as in radiological studies. ${ }^{164}$ Only post-mortem studies might indicate that multifocal infarctions favour an embolic cause, because concomitant vascular lesions can be excluded in such studies. So far no clinical study has established the predictive value of multiple brain infarctions in a prospective, well-defined series of different brain infarction subtypes in relation to a cardioembolic stroke cause.

Most cardicembolic strokes are located in the cerebral cortex, and are large $30,57,96,97,171$ Subcortical infarctions occur in $16-22 \%$ of presumed cardioembolic strokes, whereas almost half of these infarctions have a potential cardioembolic source, 20,177 However, lacunar strokes as well as amaurosis fugax can occur in heart disease, and might result from small embo-

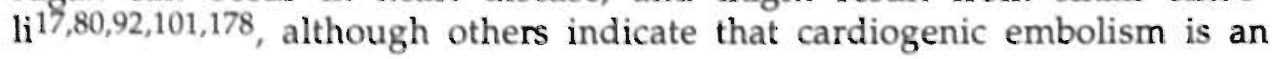


unlikely cause of lacunar infarctions. 19,20,119,131 Cardioembolic infarctions in the vertebro-basilary and anterior cerebral artery territory are uncommon. 30,34

The presence of hemorrhagic infarction on CT scan is often considered to indicate cardiogenic brain embolism. 97,134 This inference originates from post-mortem studies, that revealed a high number of hemorrhagic infarctions in these patients. ${ }^{60,96}$ The theory of fragmentation, distal migration, dissolvement of emboli, subsequent reperfusion and hemorrhagic transformation supported the claim of this criterium. ${ }^{60}$ However, so far, clinical studies challenging the specificity of this sign are lacking. Embolic strokes more often show hemorrhagic transformation merely because they tend to be large (Chapter 2).89,147 As far as post-mortem studies are concerned, large infarctions more often lead to death, and therefore such studies are probably biased towards finding a high number of hernorrhagic infarctions related to cardioembolic stroke cause.

A cardiac source of embolism is mandatory for the diagnosis of cardioembolic stroke, but the presence of this source does not fully define the stroke cause. 36,37 Concomitant precerebral vessel disease on angiography was reported in $13-48 \%$ of minor stroke or TIA patients with a cardioembolic source. $14,17,18,65,164$ Particularly elderly patients are found to be at higher risk for atherothrombotic stroke, and this also is true for those with a potential cardiac source of embolism. 187

Although it is uncertain to what extent cardioembolism caused the stroke rather than thromboembolism from large vessel disease, in the presence of both, the heart is usually considered to be the most likely cause. ${ }^{16}$ Moreover, the degree of certainty may vary between different types of cardioembolic sources. This could be related to differences in the nature of the embolic material. In marantic endocarditis, e.g. the thrombi are mostly composed of platelets. Laminated fibrin rich thrombi occur on the ventricular wall, whereas tumour thrombi may arise from myxomas. ${ }^{37}$

The following cardiac conditions are generally recognized as obvious cardioembolic sources:

1. bacterial endocarditis

2. rheumatic heart disease

3. prosthetic valves

4. acute myocardial infarction

5. dilated cardiomyopathy

6. non-rheumatic atrial fibrillation

7. marantic endocarditis

8. atrial myxomas

9. hypo-or akinetic ventricular wall segment. 
There are other causes of presumed cardiogenic embolism which are either very rare, making it difficult to establish their emboligenic potency with certainty, or doubtful:

1. congenital heart disease and paradoxical embolism

2. atrial septal aneurysm

3. ventricular aneurysm and thrombi remote from acute myocardial infarction

4. mitral valve prolapse

5. calcified aortic stenosis

6. mitral annulus calcification

\section{Bacterial endocarditis (BE)}

$\mathrm{BE}$ is an exceptional condition among the cardioembolic sources. The underlying bacterial or fungal infection prompts a specific approach. Embolic stroke occurs in $15-20 \%$ patients with BE. $31,47,71,77,80,82,150,161,172-174,186,213$ It can be the presenting symptom of $\mathrm{BE} .773,214$

The majority of strokes occur on presentation or during the first 48 hours after diagnosis. 80,174 Emboli occur in both mitral and aortic valvular involvement and are especially frequent in staphylococcus aureus and fungal infections. $33,82,135,161,174$ Some authors demonstrated that patients with echocardiographically diagnosed valvular vegetations experience systemic embolism in $34 \%$, versus $7 \%$ of patients without vegetations. However, due to methodological differences in these retrospective studies, the predictive value of valvular vegetations for embolism remains controversial. $24,26,80,81,125,174$ Transoesophageal echocardiography may increase the sensitivity of diagnosing BE. ${ }^{37}$ Abdominal CT scans in BE reveal a substantial prevalence of silent (mostly splenic) infarctions. ${ }^{75}$ This may prompt prophylactic anticoagulation. On the other hand, these patients have an increased bleeding risk due to para-infectious coagulopathies, especially in streptococcus aureus infections. Spontaneous cerebral hemorrhage occurs in $20 \% .80$ Development of cerebral mycotic aneurysms occurs in some $2 \%$ of mycotic endocarditis 80 , and these aneurysms tend to bleed at unpredictable times. ${ }^{37}$ Therefore the use of anticoagulants in these patients remains controversial.36,40,98 Initiation of antimicrobial therapy appears to be a major factor that reduces embolism. ${ }^{47}$ The risk of recurrent stroke in controlled infection is extremely low. 80,174

\section{Rheumatic heart disease (RHD)}

RHD with proven cardioembolic source inciudes rheumatic mitral valve abnormalities and rheumatic atrial fibrillation. Embolism usually complicates rheumatic mitral stenosis or mixed stenosis-regurgitation, whereas pure regurgitation less frequently results in embolism. $68,91,138$ The incidence of embolization in rheumatic mitral stenosis is about $4 \%$ yearly and occurs within all degrees of the stenosis. $83,91,209$ Coexistent atrial fibrillation (AF) increases 
the risk of embolism three to seven times as compared to rheumatic mitral stenosis alone. $64,91,191,207$ The identification of thrombi within the left atrium in patients with rheumatic mitral stenosis has been variably correlated with the embolic potential. ${ }^{36}$ Efforts to correlate embolic risk in these patients with other factors, e.g. enlarged left atrium, severity of stenosis or associated cardiac failure were inconclusive. ${ }^{91,191}$ Embolic recurrences were reported in $30-75 \%$ of patients with rheumatic mitral valve stenosis and are particularly common during the first year. $32,46,53,64,191$ It is generally agreed, though not scientifically proven, that prophylactic anticoagulation is indicated to reduce the risk of recurrent embolism. $32,116,148,191,200,209$

\section{Prosthetic valves}

Despite oral anticoagulation mechanical prosthetic cardiac valves are associated with embolism in $4 \%$ yearly of patients with such a valve in the mitral position, and $2 \%$ yearly of patients with artificial aortic valves. 54,163 Additional anti-platelet therapy may' further reduce the risk. ${ }^{36}$ Some authors reported that patients with prosthetic valves who were on anticoagulation, have a high risk of hemorrhagic transformation should a stroke occur ${ }^{35}$ However, these observations are merely case reports, whereas large consecutive series are not available. In retrospective analysis of patients with infected prosthetic valves, the risk of embolism remains substantial even if anticoagulation is continued. $47,106,174$ As in bacterial endocarditis, antimicrobial therapy appears to be the most important factor in reducing embolism. 47 Continuation of anticoagulation therapy with frequent cerebral CT to monitor the brain infarction in small and medium sized infarctions without substantial spaceoccupying signs, may be the most prudent strategy ${ }^{36}$ in patients with prosthetic valves with, or without superimposed infection. Bioprosthetic valves have an embolic potential of $1-2 \%$ per year despite anticoagulation in patients with the prosthesis in the mitral position, and in non-anticoagulated patients with aortic bioprosthesis. $15,36,39,55,70$ In the absence of AF or dilated atria, bioprosthetic valves most probably do not require long-term anticoagulation. ${ }^{70}$ In recent studies platelet anti-aggregation drugs were reported to reduce the risk of embolism to below $1 \%$ yearly in bioprosthetic valves. 36,37 Other reports, however, contradict these results, leaving the management of patients with bioprosthetic valves still controversial. 36,37

\section{Acute myocardial infarction (AMI)}

In AMI about 2.5\% (11.1-7.3\%) of the patients will experience ischemic stroke within the first 2-4 weeks. $85,93,95,107,162,203$ About $90 \%$ of the strokes occur in patients with a transmural anterior AMI and $4-12 \%$ of patients with transmural anterior AMI experience a stroke during the acute phase, compared to $1 \%$ in inferior AMI 4,50,74,93,95,142 Large AMI's were reported to bear a higher 
risk than small and medium size infarctions ${ }^{113,194}$, possibly because in large infarctions the wall motility is impaired the most. Both extreme CPK elevation 93,194 and low cardiac output ${ }^{107}$ have been reported to correlate with a higher embolic risk, supporting the significance of the size of the AMI. Left ventricular mural thrombi are present in about $40 \%$ of all patients with anterior transmural AMI and are always confined to areas of mural dyskinesia and aneurysm. However, it is important to consider that small apical thrombi $(<5 \mathrm{~mm})$, still large enough to cause a devastating stroke, will often remain undetected by echocardiography. The development of these small thrombi may e.g. be induced by reactive inflammation of the infarcted area which causes endothelial damage. Thrombi lodged between the ventricular trabecules may be missed with transthoracic $2 \mathrm{D}$ echo. A comparison of transthoracic $2 \mathrm{D}$ echo and heart $\mathrm{CT}$ scan capacity to diagnose intraventricular thrombi in stroke patients with AMI showed a definite superiority of the CT scanning, especially in the apical region. 87 The frequency of thrombi in anterior AMI and stroke might be even larger than routine echocardiography suggests and the absence of thrombi on 2D echo, therefore, does not necessarily rule out the possibility of embolization from the heart. ${ }^{37}$ Ventricular thrombi are infrequent in inferior and posterior AMI.5,67,85,93,199 About 20\% of patients with left ventricular thrombi and AMI will experience stroke within four weeks. 4,50,85,93,95,198,203 Left ventricular thrombi are usually absent on echocardiography performed within the first 24 hours after AMI onset. Most of these thrombi develop during the first two weeks with a peak between the first and seventh day and may persist for months. Occasionally ventricular thrombus develops even months after the AMI. $5,8,67,74,95,142,198$ About one-third of the thrombi protrude into the left ventricle. This was reported by some authors to represent an increased embolic risk. 4,50,74,95,142 Anticoagulation reduces the incidence of the left ventricular thrombi in AMI, especially if administered in the early stages of the disease. $4,5,49,74,142,198$ B-Adrenergic blocking medication, which limits ischemic myocardial injury, appears to increase the incidence of left ventricular thrombi, and may perhaps slightly increase the risk of early stroke. ${ }^{94}$ Concomitant AF increases the embolic risk in AMI. ${ }^{113}$ Anticoagulation therapy significantly reduces eariy stroke risk in unselected patients with AMI from 2.9 to $2.1 \% .93,98,203$ However, the absolute stroke reduction is snnall, therefore its clinical significance is questionable. Further trials should identify subgroups of patients who are at a higher stroke risk, and who might therefore benefit most from anticoagulation. ${ }^{37}$ Because the risk of embolic stroke in non-transmural anterior and in inferior wall AMI is low, unless AF is present, anticoagulation is not indicated in these patients. ${ }^{107}$ Other therapeutical measures, such as low dose anticoagulation, fibrinolytic or platelet anti-aggregating agents still have to be tested in prospective trials before their efficacy in AMI and left ventricular thrombi can be measured. 37 


\section{Dilated cardiomyopathy (DCMP)}

DCMP is associated with frequent brain embolism although the exact prevalence remains uncertain (estimations go as high as $12 \%$ per year) $69,72,196$ Echocardiographic and post-mortem examinations revealed a high number of intraventricular thrombi $36,69,72,179$, which develop within the dilated, hypokinetic ventricle. In some DCMP's endocardial lesions may predispose to thrombi prior to overt clinical heart failure, and brain embolism may be the presenting sign of the DCMP. ${ }^{36}$ It is generally agreed that long-term anticoagulation therapy is indicated in all patients with DCMP, because the heterogeneity of causes and severity have hampered identification of highand low-risk groups. 37

\section{Non-rheumatic atrial fibrillation (NRAF)}

NRAF is the most common cardiac condition associated with a presumed cardioembolic stroke. Six to $24 \%$ of all ischemic strokes have been associated with NRA.F in recent studies. $78,103,112,139,143,206$ It affects $2-5 \%$ of the elderly population. ${ }^{137}$ Because NRAF encompasses a wide spectrum of heart diseases, the risk of embolism probably depends on the type and the degree of associated heart disease, which itself may, however, serve as an independent embolic source ${ }^{36}$ Stasis within the left atrium, particularly the appendage, may lead to the development of thrombi ${ }^{36,181}$ Population-based studies show at least a five-fold increase of stroke risk compared with age-matched controls 63 , this being less than $3 \%$ per year for patients younger than 60 years of age, but it exceeds 5\% for patients older than 70 years of age.63,146,206 Inpatient populations have a higher stroke risk (5-9\% yearly), compared to out-patient populations (1.7-4.8\% yearly), 48,154 Post-mortem data support an embolic cause for the majority of strokes in NRAF, because ipsilateral carotid stenosis has been found in less than $10 \%$ of AF related strokes. ${ }^{25,112,193,201}$ Clinical and pathological studies have suggested that about two-thirds of strokes in patients with $\mathrm{AF}$ are of cardioembolic origin. $1,88,183$ Van Merwijk et al ${ }^{131}$ compared the frequency of NRAF in primary intracerebral hemorrhage, cortical infarctions and lacunar stroke. They found that the frequency of NRAF in primary intracerebral hemorrhage and lacunar stroke did not differ. In cortical infarctions, however, it was significantly higher than in the other two groups. They concluded that about $70 \%$ of all cortical infarctions are caused by NRAF when present. NRAF associated with sick sinus syndrome constitutes a higher risk for emboli. 62

A low stroke incidence has been reported in patients with lone AF (i.e. NRAF without other evidence of heart disease). 42 Three recent studies established the stroke risk in lone AF in patients younger than 60 years of age to be less than $0.5 \%$ yearly. $42,108,146$ Others, however, found that lone AF does predispose to embolism more frequently. ${ }^{11,23,37}$ Differences in diagnostic criteria 
in lone AF and the age of the patients explain some of these discrepancies. 37,124

The embolism rate in uncontrolled thyrotoxicosis during the first two to four months of treatment ranges from five to ten per cent. $11,156,160$ It may be higher in concomitant cardiomegaly or congestive heart failure. In these groups the rate has been reported to be as high as 30 per cent. $11,90,210$

The role of some additional findings in NRAF as e.g. increased left atrial size, intermittent dysrythmia or left atrial thrombi, still remains undetermined, due to small study size, or the absence of reliable non-invasive diagnostic tools. ${ }^{3,169,192,205}$

It is difficult to visualize the left atrial appendage with transthoracic 2D echocardiography. 87 Transoesophageal echocardiography appears a more sensitive technique for the evaluation of the left atrium including its appendage. 45,114

However, it is more of a burden for the patient than the transthoracal 2D echo and therefore cannot be used in all patients. CT scanning of the heart may provide a good diagnostic alternative. 87

It has generally been accepted that the presence of a thrombus in the left atrial appendage in a stroke patient with AF supports a cardioembolic mechanism. The significance of the presence of such thrombi has not been systematically evaluated so far. Aschenberg et $\mathrm{al}^{6}$ demonstrated that anticoagulant therapy does not result in the disappearance of left auricular thrombi. Lodder et al ${ }^{120}$ found no difference in the long term outcome between two groups of stroke patients with NRAF in which one group was treated with anticoagulation and the other was not.

From clinical studies it seems that NRAF of recent onset $(<1$ year) carries an increased stroke risk. ${ }^{79,153,208}$ Therefore the question arises whether the mere presence of left auricular thrombus should be viewed as an additional risk. It is possible that additional factors leading to the formation of a new thrombus in fact cause the stroke. Such factors could be left atrial enlargement or abnormal turbulences in the left atrium, some of which can cause spontaneous contrast appearance on echocardiography. Although these factors have been frequently discussed in the literature, the conclusions are controversial.

In NRAF, as in AMI, the most important strategy should be the prevention of thrombus formation, because these thrombi seldom resolve after the initial period. ${ }^{74,86}$ In the presence of thrombi, prevention of superimposed thrombus formation might be crucial. Once thrombi become well-organized the risk of embolization could diminish. In fact a reduction of the embolic potential of chronic left ventricular thrombi has been reported.27,85,141 
Congestive heart failure also appears to increase the risk of embolism. $90,205,207,210$

In $13-35 \%$ of patients with NRAF without clinical symptoms of stroke silent cerebral infarctions have been diagnosed on CT scans. This indicates that a substantial number of cerebral embolism in NRAF may go undiagnosed. However, whether the frequency of asymptomatic infarctions differs between cardioembolic and thromboembolic stroke, remains unclear. Whether silent embolic cerebral infarctions predict future stroke is also unknown.56,57,105,157 In a recent study187, most of the asymptomatic infarctions were lacunar, which may merely indicate the presence of a concomitant cerebral small-vessel disease rather than silent cardiogenic cerebral emboli.

Stroke recurrence in NRAF may vary between $10-20 \%$ yearly with the risk being especially high within the first two weeks according to some 104,176, but not to others. 58,170 Recent results of four randomized trials addressing the problem of primary stroke prevention have been published. These studies were the "Copenhagen Atrial Fibrillation, Aspirin, Anticoagulation Study" (AFASAK) 155, the "Stroke Prevention in Atrial Fibrillation Study" (SPAF)189, "Boston Area Anticoagulation Trial for Atrial Fibrillation" (BAATAF)22, and the "Canadian Atrial Fibrillation Anticoagulation Study" (CAFA). ${ }^{44}$ In all four trials patients with general contraindications to anticoagulation or aspirin, those with rheumatic heart disease, recent previous stroke or TIA, and recent antithrombotic or aspirin therapy were excluded. Other exclusion criteria employed in the individual studies are listed in Table 1. Table 2 summarizes the results of these studies. Patients in the AFASAK study had the highest median age and received the most intensive anticoagulation. AFASAK and SPAF studies also evaluated the efficacy of aspirin. Summarizing the results the embolic rate in the anticoagulated patients ranged from $0.4 \%$ to $3.0 \%$ yearly, in the control groups from $3.7 \%$ to $7.5 \%$ yearly. The relative stroke reduction ranged from $35 \%$ to $86 \%$. The lowest reduction was in CAFA, which was terminated early. The studies that continued for the longest period showed significant stroke reductions of $58 \%$ to $86 \%$. The highest reduction was in BAATAF, the study with the lowest anticoagulation level. Contrary to the AFASAK study, the SPAF study showed a significant relative risk reduction in the aspirin-treated group, compared to the placebo group. The lesser effect of aspirin in the AFASAK trial as compared to the SPAF study could be related to the lower daily dose of aspirin (in AFASAK 75 $\mathrm{mg}$ daily versus $335 \mathrm{mg}$ daily in SPAF); the higher mean age of the patients (in AFASAK 74 versus 67 years in SPAF); and the higher percentage of patients with congestive heart failure (in AFASAK 50\% versus $15 \%$ in SPAF). The studies mentioned above confirm the risk of stroke in patients with NRAF, even when there was no effort made to identify low and high risk groups. They proved that anticoagulation prevents thromboembolic events in about two-thirds of these patients and that the reduction is the same in severe strokes as in all strokes. The major rate of bleeding under warfarin therapy 
TABLE 1. Additional exclusion criteria in four "primary stroke prevention in AF" trials

\begin{tabular}{lcccc}
\hline & AFASAK & SPAF & BAATAF & CAFA \\
\hline $\begin{array}{l}\text { hyperthyioidism } \\
\text { AMI /LV thrombus }\end{array}$ & & + & + & + \\
$\begin{array}{l}\text { treated coronary artery disease } \\
\text { severe CHF }\end{array}$ & & + & + & + \\
$\begin{array}{l}\text { severe uncontrolled hypertension } \\
\text { intracardiac thrombus }\end{array}$ & + & + & & \\
PAF & + & + & & \\
lone AF & & +
\end{tabular}

AMI acute myocardial infarction; LV left ventricle; CHF congestive heart failure; PAF paroxysmal atrial fibrillation; AF atrial fibrillation

TABLE 2. Results of the four "primary stroke prevention in atrial fibrillation" trials

\begin{tabular}{lllll}
\hline & AFASAK & SPAF & BAATAF & CAFA \\
\hline No. patients & 1.007 & 1.330 & 420 & 378 \\
age (years) & 74 & 67 & 68 & 68 \\
mean LAD & - & 46 & 41 & 41 \\
hypertension (\%) & 33 & 52 & 39 & 51 \\
MI (\%) & 8 & 8 & 12 & 13 \\
CHF (\%) & 51 & 19 & 26 & 22 \\
AC intensity (INR) & $2.8-4.2$ & $2.0-3.5$ & $1.5-2.7$ & $2.0-3.0$ \\
relat. stroke red. (\%) & 58 & 67 & 86 & 35 \\
aspirin dose (mg/day) & 75 & 325 & - & - \\
relat. stroke red. (\%) & 15 & 42 & - & - \\
\hline
\end{tabular}

LAD left atrial diameter; MI myocardial infarction; CHF congestive heart failure; INR international normalized ratio

ranged from $0.8 \%$ to $2.5 \%$ yearly which is an acceptable incidence considering the high percentage reduction achieved. The role of aspirin is under further investigation at present. 189 Until these results are known anticoagulation for primary stroke prevention is the therapy of choice. The population most likely to benefit appears to be patients with chronic NRAF, who are over the age of 50 years and do not have specific contraindications to this therapy. Young patients with lone $\mathrm{AF}^{108}$ and patients with paroxysmal $\mathrm{AF}^{99}$ may have a lower risk of emboli and the benefits of anticoagulation in these groups remain uncertain. Aspirin therapy as primary stroke prevention could for the present be reserved for these patients and for those with contraindications to warfarin. 28,190

Neither the efficacy nor the risks of anticoagulation in secondary stroke prevention in NRAF are known so far. There is presently one ongoing trial, 
the European Atrial Fibrillation Trial, which is examining the value of anticoagulation in secondary stroke prevention. A prospective evaluation of the risks of early anticoagulation is reported in Chapter 7.

\section{Marantic endocarditis (ME)}

Marantic (non-bacterial, thrombotic) endocarditis occurs in chronic malignant and non-malignant wasting diseases including AIDS. 43,122 It is associated with approximately $27 \%$ of ischemic strokes in patients with cancer. ${ }^{73,122}$ Clinical emboli complicate ME in some $30 \%$ of patients and are usually multiple. In cancer they occur particularly during chemotherapy. ${ }^{145,168}$ The prothrombotic state is probably the most important cause of ME, whereas it is usually associated with underlying valvular disease. ${ }^{122}$ Therapeutic measures are mostly modified to match the individual needs of the patient. $\mathrm{He}-$ parin is often recommended, based on empirical grounds. ${ }^{122,168}$ However, the value of anticoagulation has not been systematically studied. ${ }^{36}$

\section{Atrial myxoma (AM)}

$\mathrm{AM}$ is the most common heart tumour. It occurs predominantly between the ages of $30-60$ years. 36,129 AM is associated with a $27-55 \%$ rate of embolic complications, primarily to the brain. 128,175 The prevalence of AM in stroke/TIA patients has been reported 1/359 to 1/891.18,30,175 Emboli are mostly composed of tumour fragments and the therapy of choice is tumour surgery. ${ }^{36}$ It is unclear whether patients awaiting surgery should be anticoagulated. ${ }^{37}$ (Metastases have only rarely been reported. ${ }^{167}$ )

\section{Mitral valve prolapse (MVP)}

Depending on the choice of criteria (auscultatory and echocardiographic) $2-6 \%$ of the general population have been reported to have MVP, most of whom are young women. ${ }^{37}$ The most common cerebral ischemic events associated with MVP are TIA's or small strokes, whereas large infarctions are uncommon, unless NRAF is also present. ${ }^{92,180}$ It is difficult to establish a causal relationship between the stroke and MVP in an individual patient. Some have suggested that, whereas the majority of asymptomatic MVP has no increased risk of embolic stroke, subpopulations in this group might have. Whilst MVP is most common in young women, ischemic complications are more frequent in older patients and in men. ${ }^{7}$ Clinical and echocardiographic findings, that may distinguish these subpopulations, are: age, male sex, redundant and thickened mitral valve leaflets with associated mitral regurgitation, tricuspid valve prolapse, and mitral annulus abnormalities. 117,140,151,211 Recurrent cerebral embolization, usually TIA's, has been observed. ${ }^{92}$ Based 
on the observation of platelet-fibrin emboli and fibrin activation, treatment with platelet anti-aggregating drugs seems rational. 10,36

\section{Aneurysms and mural thrombi in healed myocardial infarction (MI)}

Surgical and post-mortem studies showed that mural thrombi occur in about $50 \%$ of left ventricular aneurysms in healed MI. ${ }^{27,141}$ Recent echocardiographic investigations confirmed these observations and related the embolic potential to the shape of the thrombus; protruding or mobile thrombi being more emboligenic. $27,85,93,118,198$ Whereas previous, retrospective studies revealed a low embolic rate in patients with left ventricular aneurysm or thrombus in healed $\mathrm{Ml}^{27,85,141}$, recent studies showed conflicting results. ${ }^{37}$ Most emboli in these patients seem to occur between one and four months after the MI. Aggregate data suggest that anticoagulation may lower the rate of embolism. Subsequent organization of the thrombus could explain the temporal reduction of embolic risk. ${ }^{2}$ There are no data on the effect of platelet anti-aggregating agents on stroke recurrence in these patients. ${ }^{36}$

\section{Atrial septal aneurysm (ASA)}

ASA is an area of localized bulging of the fossa ovalis in the left or the right atrium. The frequent association with MVP suggests a possible laxity of connective tissue ${ }^{37,166}$ Concomitant small defects in the foramen ovale are frequent. 12,182 Individual case reports suggest that ASA can serve as an embolic source and in one study it was diagnosed echocardiographically in $2 \%$ of patients with an embolism. $12,149,184$

\section{Congenital heart disease and paradoxical embolism}

These are rare possible sources of cerebral embolic stroke, occurring in right to left shunting in the heart or lungs. Patent foramen ovale, present in about $6 \%$ of all persons, could lead to intermittent right-left blood shunting during Valsalva manoeuvre. In the presence of a peripheral venous thrombosis, which, however, is often not clinically apparent cerebral emboli may occur. $13,84,123$ Intermittent right to left shunting has been demonstrated echocardiographically in $10-18 \%$ of these patients. $37,76,127$ In young adults with unexplained stroke, patent foramen ovale has been found in $54-56 \% .37$ Therapy and prevention of recurrent embolism focuses on the treatment and prophylaxis of the venous thrombosis. Anecdotal follow-up of these patients has shown a low recurrence risk. ${ }^{13,84}$ 


\section{Calcified aortic stenosis (CAS)}

Small, often retinal, calcified emboli have been reported in association with CAS. In the absence of infective endocarditis or mitral valve disease brain embolism only infrequently complicates CAS. $51,91,111,121$ Other, more likely sources of cerebral ischemia should be excluded before attributing the stroke or TIA to CAS. ${ }^{36}$ Adequate therapy is unknown. Platelet anti-aggregating agents have been suggested because of the observations of platelet-fibrin deposits in surgical aortic valve specimens. ${ }^{188}$

\section{Mitral annulus calcification (MAC)}

MAC has been linked to cerebral ischemic events, particularly retinal emboli and TIA's. ${ }^{21}$ Calcified emboli have been documented in some case reports. $109,159,165$ However, it is more likely that MAC is rather a sign of generalized atherosclerosis, which caused the stroke. Unless calcified emboli are found, the diagnosis of MAC as an embolic source should be regarded with suspicion even if other stroke causes are not identified. ${ }^{36}$

\section{In conclusion}

The ulagnusls or caralogenic brain embolism remains dirncuit. Neurological symptoms, although by some suggested to predict cardiogenic brain embolization, are inaccurate. The same is true for cerebral CT criteria, with the exception of lacunar infarctions, which even in the presence of a cardioembolic source most probably result from small-vessel disease. The value of some clinical and CT features as predictors of cardioembolic rather than thrombotic stroke mechanism is evaluated in Chapters 2 and 3. Therefore, the diagnosis of cardiogenic stroke is based on the presence of a cardiogenic and embolic source and the absence of other stroke causes, including the fact that the brain infarction should not be lacunar. ${ }^{20}$ This implies that the diagrosis cardioembolic stroke should be based on the results of three tests (Table 3):

1. cerebral CT scanning: exclusion of lacunar stroke, and stroke in the basilary artery territory

2. non-invasive pre- and cerebral vessel investigation; possibly additional carotid angiography

3. cardiac evaluation

Cerebral CT scanning is almost always routinely performed in stroke patients.

Angiography of the involved carotid artery territory is a burdening procedure for the patient with a certain, although small, risk. Non-invasive evaluation of the common carotid artery and carotid bifurcation could be a useful alternative. Good diagnostic yield is only achieved in luminal stenosis of approximately $50 \%$ or more. More sophisticated non-invasive equipment might 
TABLE 3. Diagnostic management of patients with ischemic stroke/TIA

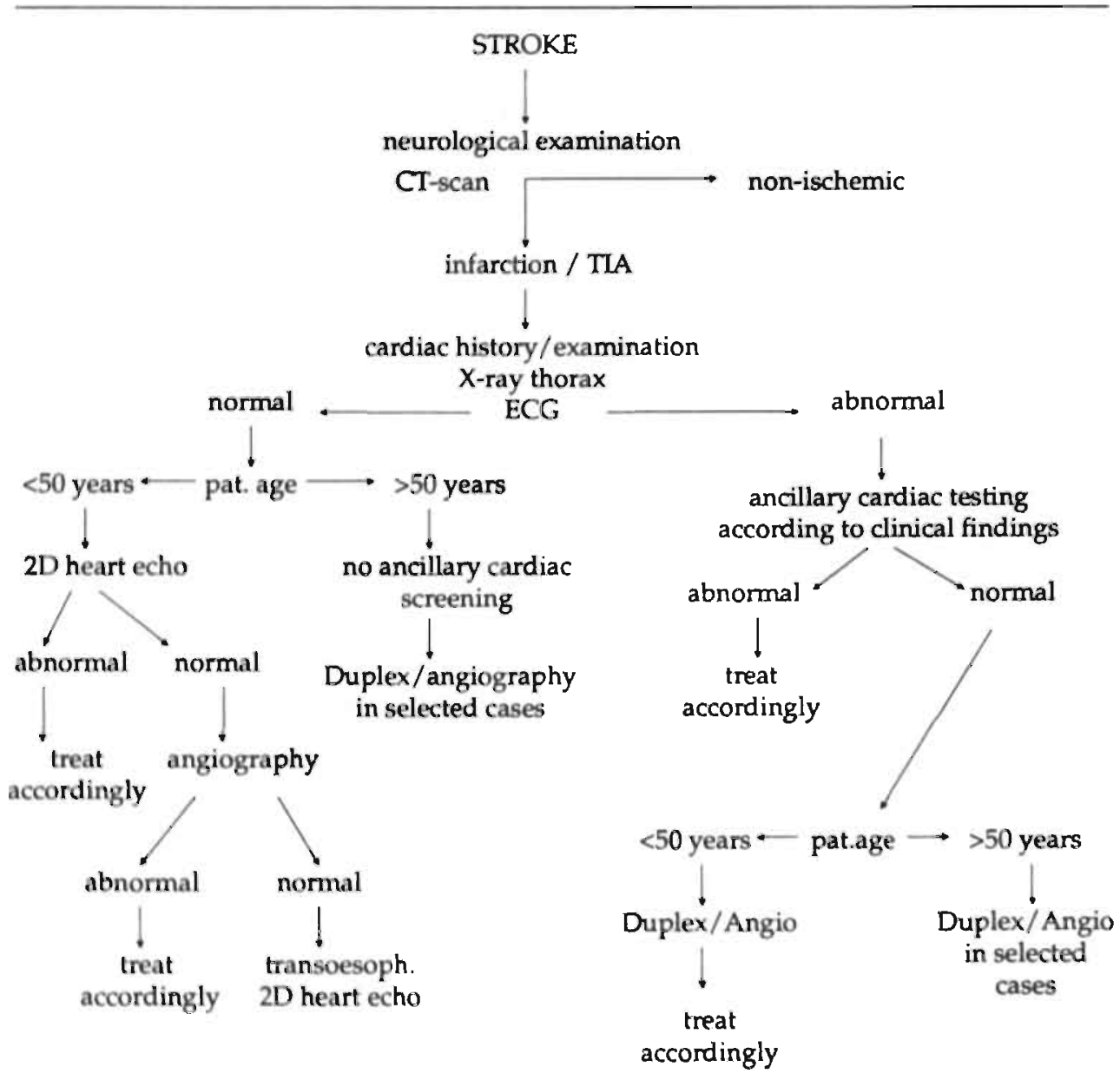

diagnose small carotid lesions 130 , but is not widely available. For clinical purposes, diagnosis of a high grade stenosis, reliably done by non-invasive testing, is of the most relevance, because the risk of stroke correlates with the degree of internal carotid stenosis. One recent study showed that patients who suffer a TIA or a minor stroke and who have a carotid obstructive lesion of $70 \%$ diameter reduction benefit from carotid artery endarterectomy. 52 Therefore non-invasive tests are most valuable and valid in screening TIA and minor stroke patients. 
Ancillary cardiological tests are indicated when there are signs or symptoms of cardiac disease. In the absence of these, the yield of further testing is low. ${ }^{113}$ The main risks of anticoagulation in early stroke are the induction of hemorrhagic transformation and brain hemorrhage, leading to clinical deterioration. The risks and the value of anticoagulation in stroke recurrence prevention in NRAF patients is currently being studied in the European Atrial Fibrillation Trial. However, this trial will not answer the question of the optimal timing of the start of anticoagulation treatment. Chapter 7 deals with the safety of early anticoagulation in stroke patients with NRAF.

Fibrinolytic therapy in acute stroke remains controversial, even though animal studies did not show an increase of intracerebral hemorrhages. $41,126,214,215$ These studies would imply that very early reperfusion by thrombolysis is not associated with an increased risk of hemorrhagic transformation of the infarction. Reports on clinical application of thrombolytics in the very early stage of stroke seem to support this. $136,144,212,216$ Late treatment with thrombolytic agents, however, does increase the frequency of infarctionrelated hemorrhage. 185 Occasional reports of "late" thrombolysis in man usually involve severe infarctions with a very bad prognosis, whereas the patients often receive the treatment rather late. ${ }^{197}$ However, some patients died from massive brain edema following early thrombolysis after non-massive initial stroke. ${ }^{110}$ These observations underline that caution should be taken in extrapolating results from animal models to man. A large multicentered European Trial is currently being planned.

The tables 3,4 and 5 show schematically the approach in patients with presumed cardioembolic stroke sources. 
TABLE 4. Primary stroke prevention.

\section{Frequent embolic sources}

non-rheumatic atrial fibrillation

anterior and apical AMI

with - aneurysm

- atrial fibrillation

- congestive heart failure

interior AMI

Less frequent sources

rheumatic heart disease

mechanic prosthetic valves

dilated cardiomyopathy

bacterial endocarditis

(anticoagulation possible,

however, the bleeding risk is high)

Other cardiac conditions

congenital septal defect/

paradoxic emboli

marantic endocarditis

MVP, MAC

calcified aortic stenosis

heart aneurysm in remote $\mathrm{MI}$

(atrial) myxoma anticoagulation (alternative: aspirin)

anticoagulation

anticoagulation

(alternative: aspirin)

no anticoagulation

anticoagulation

anticoagulation

anticoagulation

antibiotics

anticoagulation for

venous thrombosis

anticoagulation

aspirin $80-300 \mathrm{mg} / \mathrm{d}$

no anticoagulation

surgery

TABLE 5. Secondary stroke prevention (after TIA or stroke)

In general: all patients can receive aspirin $80-300 \mathrm{mg} / \mathrm{d}$

Presumed cardioembolic stroke

anterior and apical AMI

rheumatic heart disease

prosthetic valves

dilated cardiomyopathy

non-rheumatic atrial fibrillation

Stroke due to carotid stenosis:

Lacunar stroke: anticoagulation

anticoagulation

anticoagulation

anticoagulation

? (AC often given on empirical grounds)

aspirin, endarterectomy

aspirin 


\section{REFERENCES}

1. Aberg H. Atrial fibrillation. I. A study of atrial thrombosis and systemic embolism in necropsy material. Acta Med Scand 1969;185:373-379.

2. Adams HP, Butler MJ, Biller J, Toffal GJ. Nonhemorrhagic cerebral infarction in young adults. Arch Neurol 1986;43:793-796.

3. Aronow WS, Gutstein H, Hsieh FY. Risk factors for thromboembolic stroke in elderly patients with chronic atrial fibrillation. Am J Cardiol 1989;63:366-367.

4. Arvan S, Boscha K. Prophylactic anticoagulation for left ventricular thrombi after acute myocardial infarction: a prospective randomized trial. Am Heart J 1987;113:688-693.

5. Asinger RW, Mikell FL, Elspelger J, Hodges M. Incidence of left ventricular thrombosis after acute transmural myocardial infarction. N Engl J Med 1981;305:297-302.

6. Assenberg W, Siglow V, Kremer P, Schlüter M, Bleifeld W. Thromben im linken Herzohr bei Mitralvitien trotz adequater Antikoagulation. Dtsch Med Wochenschrift 1989;12:663668

7. Baddour LM, Bisno AL. Infective endocarditis complicating mitral valve prolapse: epidemiologic, clinical and microbiologic aspects. Rev Infect Dis 1986;117-136.

8. Bahatnager SK, Hudak A, Al-Yusuf AR. Left ventricular thrombosis, wall motion abnormalities, and blood viscosity changes after first transmural anterior myocardial infarction. Chest 1985;88:40-44.

9. Barletta GA, Gagiiardi R, Benvenuti L, Fantini F. Cerebral ischemic attacks as a complication of aortic and mitral valve prolapse. Stroke 1985;16:219-223.

10. Barnett HJM. Embolism in mitral valve prolapse. Ann Rev Med 1982;33:489-507.

11. Bar-Sela S, Ehrenfield M, Eliakim M. Arterial embolism in thyrotoxicosis with atrial fibrillation. Arch Intern Med 1981;141:1191-1192.

12. Belkin RN, Hurwitz BJ, Kisslo KB. Atrial septal aneurysm: association with cerebrovascular and peripheral embolic events. Stroke 1987;18:856-862.

13. Biller J, Adams HP, Johnson MR, Kerber RE, Toffol GJ. Paradoxical cerebral embolism: eight cases. Neurology 1986;36:1356-1360.

14. Blackwood W, Hallpike JF, Kocen RS, Mair WGP. Atheromatous disease of the carotid arterial system and embolism from the heart in cerebral infarction: a morbid anatomical study. Brain 1969;92:897-910.

15. Bloomfield P, Kitchin AH, Wheatly DJ, Waldbaum PR, Lutz W, Miller HC. A prospective evaluation of the Bjork-Shiley, Hancock, and Carpentier-Edwards heart valve prosthesis. Circulation 1986;73:1213-1222.

16. Bogousslavsky J, Cachin C, Regli F, Despland PA, van Melle G, Kappenberger L. Cardiac sources of embolism and cerebral infarction - clinical consequences and vascular concomitants: The Lausanne Stroke Registry, Neurology 1991;41:855-859.

17. Bogousslavsky J, Hachinski VC, Boughner DR, Fox AJ, Vinuela F, Barnett HJM. Clinical predictors of cardiac and arterial lesions in carotid transient ischemic attacks. Arch Neurol 1986;43:229-233.

18. Bogousslavsky J, Melle GV, Regli F. The Lausanne Stroke Registry: analysis of 1000 consecutive patients with first stroke. Stroke 1988;19:1083-1092.

19. Boiten J, Lodder J. Cardiac and carotid embolism are unlikely causes of lacunar infarction. J Neurol 1990;237:150 (abstract).

20. Boiten J, Lodder J, Lacunar infarcts. Pathogenesis and validity of the clinical symptoms. Stroke 1991;22:1374-1378.

21. DeBono DP, Warlow CP. Mitral-annulus calcification and cerebral or retinal ischemia. Lancet 1979;2:383-385.

22. The Boston Area Anticoagulation Trial for Atrial Fibrillation Investigators. The effect of low-dose warfarin on the risk of stroke in patients with nonrheumatic atrial fibrillation. N Eng J Med 1990;323:1505-1511. 
23. Brand FN, Abbott RD, Kannel WB, Wolf PA. Characteristics and prognosis of lone atrial fibrillation. JAMA 1985;254:3449-3453.

24. O'Brien JT, Geiser EA. Infective endocarditis and echocardiography. Am Heart J 1984;108:386-394.

25. Britton $\mathrm{M}$, Gustafson $\mathrm{C}$. Nonrheumatic atrial fibrillation as a risk factor for stroke. Stroke 1985;16:182-188.

26. Buda AJ, Zotz RJ, Le Mire MS, Buch DS. Prognostic significance of vegetatious detected by two-dimensional echocardiography in infective endocarditis. Am Heart J 1986;112:1291-1296.

27. Cabin HS, Roberts WC. Left ventricular aneurysm, intra-aneurysmal thrombus and systemic embolus in coronary heart disease. Chest 1980;77:586-590.

28. Cairns JA. Stroke prevention in atrial fibrillation Trial. Circulation 1991;84:933-935.

29. Caplan LR. Top of the basilar syndrome. Neurology 1980;30:72-79.

30. Caplan LR, Hier DB, D'Cruz I. Cerebral embolism in the Michael Rees Stroke Registry. Stroke 1983; 14:530-536.

31. Carpenter JL, McAllister CK. Anticoagulation in prosthetic valve endocarditis. South Med J 1983;76:1372-1375.

32. Carter AB. Prognosis of cerebral embolism. Lancet 1965;2:514-519.

33. Case 27-2979. Case records of the Massachusetts General Hospital: Weekly clinicopathological excercises. N Engl J Med 1979;301:34-42.

34. Cerebral Embolism Study Group. Immediate anticoagulation of embolic stroke: A randomized trial. Stroke 1983;14:668-676.

35. Cerebral Embolism Study Group. Immediate anticoagulation of embolic stroke: Brain hemorrhage and management Options. Stroke 1984;15:779-789.

36. Cerebral Embolism Task Force. Cardiogenic brain embolism. Arch Neurol 1986;43:71-84.

37. Cerebral Embolism Task Force. Cardiogenic brain embolism; The second report. Arch Neurol 1989;46:727-743.

38. Chambers BR, Donnan GA, Bladen PF. An analysis of the first 700 consecutive admissions to the Austin Hospital Stroke Unit. Aust NZ J Med 1983;13:57-64.

39. Chesebro JH, Adams PC, Fuster V. Antithrombotic therapy in patients with valvular heart disease and prosthetic heart valves. J Am Coll Cardiol 1986;8:41B-56B.

40. Christie RU. Penicillin in bacterial endocarditis. Lancet 1945;2:123-127.

41. Clark WM, Madden KP, Lyden PD, Zivin JA. Cerebral hemorrhagic risk of aspirin or heparin therapy with thrombolytic treatment in rabbits. Stroke 1991;22:872-876.

42. Close JB, Evans DW, Bailey SM. Persistent lone atrial fibrillation: its prognosis after clinical diagnosis. J Roy Coll Gen Prac 1979;29:547-549.

43. Commarosano $\mathrm{C}$, Lewis $\mathrm{W}$. Cardiac lesions in acquired immune deficiency syndrome (AIDS). J Am Coll Cardiol 1985;5:703-706.

44. Connoly SJ, Laupacis A, Gent M, Roberts RS, Cairns JA, Joyner C. Canadian Atrial Fibrillation Anticoagulation (CAFA) study. Circulation 1991;18:349-355.

45. Cujec B, Polasek P, Voll C, Shuaib A. Transoesophageal echocardiography in the detection of potential cardiac source of embolism in stroke patients. Stroke 1991;22:727-733.

46. Darling RC, Austin WC, Linton RR. Arterial embolism. Surg Gynecol Obstet 1967; $124: 106-114$.

47. Davenport JG, Foster JW, Hart RG. Prosthetic valve endocarditis: antibiotics, anticoagulation and stroke. Stroke 1988;19:145 (Abstract).

48. Davis PH, Dambrosia JM, Schoenberg BS, Schoenberg DG, Pritchard DA, Lilienfeld AM, Whisnant JP. Risk factors for ischemic stroke: a prospective study in Rochester, Minnesota. Ann Neurol 1987;22:319-327.

49. Davis MJE, Ireland MA. Effect of early anticoagulation on the frequency of left ventricular thrombi after anterior wall acute myocardial infarction. Am J Cardiol 1986;57:1244-1247. 
50. Domenicucci $S_{\text {, Bellotti }} \mathrm{P}_{\mathrm{s}}$ Chiarella F, Lupi G, Vecchio C. Spontaneous morphologic changes in left ventricular thrombi: prospective two-dimensional echocardiographic study. Circulation 1987;75:737-743.

51. Dry T], Willius FA. Calcareous disease of the aortic valve: a study of 228 cases. Am Heart J 1939;17:138-157.

52. ECSTCG. MRC European carotid surgery trial: interim results for symptomatic patients with severe $(70-99 \%)$ or with mild $(0-29 \%)$ carotid stenosis. Lancet 1991;may 25:12351243.

53. Easton JD, Sherman DG. Management of cerebral embolism of cardiac origin. Stroke 1980;11:433-444.

54. Edmunds LH. Thromboembolic complications of current cardiac valvular prosthesis. Ann Thor Surg 1982;34:96-106.

55. Edmunds LH. Thrombotic and bleeding complications of prosthetic heart valves. Ann Thorac Surg 1987;44:430-445.

56. Feinberg WM, Seeger JF, Carmody RF, Hart RG, Anderson DC, Miller VT. Asymptomatic cerebral infarction in patients with atrial fibrillation. Circulation 1988;78:600 (abstract).

57. Fisher CM. Reducing risks of cerebral embolism. Geriatrics 1979;34:59-66.

58. Fisher CM. Embolism in atrial fibrillation. In: Kulbertus HE, Olsson SB, Schlepper M (eds.). Atrial Fibrillation. AB Hässle, Mölndal, Sweden 1982:192-210.

59. Fisher CM. The posterior cerebral artery syndrome. Can J Neurol Sci 1986;13:232-239.

60. Fisher $C M$, Adams RD. Observations on brain embolism with special reference to hemorrhagic infarction (1950). In: Furlan J, (ed), The heart and stroke, Springer Verlag, London, 1987.

61. Fisher CM, Peariman A. The non-sudden onset of cerebral embolism. Neurology 1967;17:1025-1032.

62. Fisher CM, Kase CS, Stelle B, Mills RM. Ischemic stroke after cardiac pacemaker implantation in sick sinus syndrome. Stroke 1988;19:712-715.

63. Flegel KM, Shipley MJ, Rose G. Risk of stroke in nonrheumatic atrial fibrillation. Lancet 1987;1:526-529.

64. Fleming HA, Bailey SM. Mitrai valve disease, systemic embolism and anticoagulants. Postgrad Med J 1971;47:599-604.

65. Fogelholm R, Melin J. Echocardiography in ischemic cerebrovascular disease. Br Med J Clin Res 1987;295:305-306.

66. Foulkes MA, Wolf PA, Price TR, Mohr JP, Hier DB. The Stroke Data Bank: design, methods, and baseline characteristics. Stroke 1988;19:547-554.

67. Friedman Ml, Carlson K, Marcus Fl, Woulfender JM. Clinical correlations in patients with acute myocardial infarction and left ventricular thrombus detected by two-dimensional echocardiography. Am J Med 1982;72:894-898.

68. Fukuda $Y$, Nakamura $K$. The incidence of thromboembolism and hemocoagulative background in patients with rheumatic heart disease. Jpn Circ J 1984;48:59-66.

69. Fuster V, Gersh BJ, Giuliani ER, Tajik Aj, Brandenber RO, Fryo RL. The natural history of idiopathic dilated cardiomyopathy. Am J Cardiol 1981;47:525-531.

70. Gallo I, Ruiz B, Duran CG. Isolated mitral valve replacement with the Hancock Porcine Bioprosthesis in rheumatic heart disease: Analysis of 213 operative survivors followed up 4,5-8,5 years. Am J Cardiol 1984;53:178-181.

71. Garvey GJ, Neu HC. Infective endocarditis: An evolving disease. Medicine 1978;57:105126.

72. Gottdiener JS, Gay JA, van Voorhees L, DiBianco R, Fletcher RD. Frequency and embolic potential of left ventricular thrombus in dilated cardiomyopathy: assessment by two-dimensional echocardiography. Am J Cardiol 983:52:1281-1285. 
73. Graus F, Rogers LR, Posner JB. Cerebrovascular complications in patients with cancer. Medicine 1985;64:16-35.

74. Gueret P, Dubourg O, Ferrier A, Farcot JC, Rigaud M, Bourdarias JP. Effects of full-dose heparin on the development of left ventricular thrombosis in acute transmural myocardial infarction. J Am Coll Cardiol 1986;8:419-426.

75. Haft JI, Altieri J, Smith LG, Heskowitz M. Computed tomography of the abdomen in the diagnosis of splenic emboli. Arch Intern Med 1988;148:193-197.

76. Hagen PT, Scholz DG, Edwards WD. Incidence and size of patent foramen ovale during the first 10 decades of life: an autopsy study of 965 normal hearts. Mayo Clin Proc 1984;59:17-20.

77. Harrison MJG, Hampton JR. Neurological presentation of bacterial endocarditis. Br Med J 1967;2:148-151.

78. Harrison MIG, Marshall J, Atrial fibrillation. TIA's and completed strokes. Stroke $1984 ; 15: 441-442$.

79. Hart RG, Easton JD, Sherman DG. Duration of nonvalvular atrial fibrillation and stroke. Stroke 1983;14:827.

80. Hart RG, Foster JW, Luther MF, Kanter MC. Stroke in infective endocarditis. Stroke 1990;21:695-700.

81. Hart RG, Foster JW, Luther MF. Bacterial endocarditis, stroke, and brain hemorrhage. Stroke 1987;18:298 (Abstract).

82. Hart RG, Kagen-Hallet $\mathrm{K}$, Joerns SE. Mechanisms of intracranial hemorrhage in infective endocarditis. Stroke 1987;18:1048-1056.

83. Hart RG, Miller VT. Cerebral infarction in young adults: A practical approach. Stroke 1983; 14:110-114.

84. Harvey JR, Teague SM, Anderson JL, Voyles, WF, Thadani U. Clinically silent atrial septal defects with evidence of cerebral embolisation. Ann Intern Med 1986;805:695-697.

85. Haugland JM, Asinger RW, Mikell FL, et al. Embolic potential of left: ventricular thrombi detected by two-dimensional echocardiography. Circulation 198:4;70:588-598.

86. Held AC, Gore JM, Paraskos J, Pape L, Ball SP, Corao JM, Alpert JS. Inpact of thrombolytic therapy on left ventricular mural thrombi in acute myocardial infarction. Am J Cardiol 1988;62:310-311.

87. Helgason CM, Chmoka E, Louie E, Rich S, Zajac E, Roig E, Wilbur A, Brundage BH. The potential role for ultrafast cardiac computed tomography in patients with stroke. Stroke 1989;20:465-472.

88. Hinton RC, Kistler JP, Fallon JT, Friedlich AL, Fisher CM. Influence of etiology of atrial fibrillation on incidence of systemuc embolism. Am J Cardiol 1977:40:509-5i13.

89. Homing CR, Dorndorf W, Agnoli AL. Hemorrhagic cerebral infarction: a prospective study, Stroke 1986;17:179-185.

90. Hurley DM, Hunter AN, Hewett MJ, Stockig1 JR. Atrial fibrillation and arterial embolism in hyperthyroidism. Aust NZ J Med 1981;11:391-393.

91. Jabbari B, Lawrence PJ, Houtt AD. Aortic stenosis and calcific cerebral embolisation. Md State Med ) 1980;29:33-35.

92. Jackson AC, Boughner DR, Barnett HJM. Mitral valve prolapse and cerebral ischemic events in young patients. Neurology 1984;34:784-787.

93. Johanessen KA, Nordrehaug JE, Von der Lippe G. Left ventricular thrombosis and cerebrovascular accident in acute myocardial infarction. Br Heart J 1984;51:553-556.

94. Johanessen KA, Nordrehaug JE, von der Lippe G. Increased occurrence of left ventricular thrombi during early treatment with thimolol in patients with acute myocardial infarction. Circulation 1987;75:151-155. 
95. Johanessen KA, Nordrehaug JE, von der Lippe G, Vollset SE. Risk factors for embolization in patients with left ventricular thrombi and acute myocardial infarction. Br Heart J 1988;60:104-110.

96. Jörgensen L, Torvik A. Ischemic cerebrovascular disease in an autopsy series. Part I. J Neurol Sci 1966;3:490-509.

97. Jörgensen L, Torvik A. Ischemic cerebrovascular disease in an autopsy series. Part Il. J Neurol Sci 1969;9:285-320.

98. Kanis JA. The use of anticoagulants in bacterial endocarditis. Postgrad Med J 1974;50:312313.

99. Kannel WB, Abbott RD, Savage DD, McNamara PM. Coronary heart disease and atrial fibrillation: the Framingham study. Am Heart J 1983;106:389-396.

100. Kannel WB, Drawber TR, Cohen MS et al. Vascular diseases of the brain: Epidemiologic aspects: The Framingham study. Am J Public Health 1965;55:1355-1366.

101. Kapila A, Hart RG. Calcific cerebral emboli and aortic stenosis: detection by computed tomography. Stroke 1986;17:619-621.

102. Kaplan K. Prophylactic anticoagulation following acute myocardial infarction. Arch Intern Med 1986;146:593-597.

103. Kelly RE, Berger JR, Alter M, Kovacs AG. Cerebral ischemia and atrial fibrillation: prospective study. Neurology 1984;34:1285-1291.

104. Kelley RE, Berger JR, Alter $\mathrm{M}_{*}$ Kovacs AG. Cerebral ischemia and atrial fibrillation. Neurology 1985;35:938-939.

105. Kempster PA, Gerraty RP, Gates PC. Asymptomatic cerebral infarction in patients with chronic atrial fibrillation. Stroke 1988;19:955-958.

106. Keyser DL, Biller J, Coffman T], Adams HP. Neurological complications of prosthetic valve endocarditis. Ann Neurol 1988;24:130 (abstract).

107. Komrad MS, Coffey E, Coffey KS, McKinnis R, Massey EW, Califf RM. Myocardial infarction and stroke. Neurology 1984;34:1403-1409.

108. Kopecky SL, Gersh BJ, McGoon MD, Whisnant JP, Holmes DR, Ilstrup DM, Frye RL. The natural history of lone atrial fibrillation. N Engl J Med 1987;317:669-674.

109. Korn D, DeSanctis RW, Sell S. Massive calcification of the mitral annulus: a clinical pathological study of 14 cases. N Engl J Med 1962;267:900-909.

110. Koudstaal PJ, Stibbe J, Vermeulen M. Fatal ischemic brain edema after early thrombolysis with tissue plasmogen activator in acute stroke. Brit Med J 1988;297:1571-1574.

111. Kumpe CW, Bean WB. Aortic stenosis: a study of the clinical and pathologic aspects of 107 proved cases. Medicine 1948;27:139-185.

112. Kuramoto $\mathrm{K}$, Matsushita $\mathrm{S}$, Yamanouchi $\mathrm{H}$. Atrial fibrillation as a cause of myocardial and cerebral infarctions. Jpn Circ J 1984; $488: 67-74$.

113. Lambert $C D$. Neurological manifestations of acquired cardiac disease and dysthythmias. In: Neurology and general medicine. Aminoff MJ (ed), Churchill Livingstone, New York, 1989, pp 69-83.

114. Lee RJ, Bartzokis T, Yeoh TK, Grogin HR, Choi D, Schnittger I. Enhanced detection of intracardiac sources of cerebral emboli by transoesophageal echocardiography. Stroke 1991;22:734-739.

115. Legatt AD, Rubin MJ, Kaplan LR, Healton EB, Brust JCM. Global aphasia without hemiparesis: multiple etiologies. Neurology 1987;37:201-205.

116. Levine $\mathrm{HJ}$. Which atrial fibrillation patients should receive anticoagulation? Cardiovasc Med 1981;6:483-487.

117. Levine RA, Stathogiannis E, Newell JB, Harrigan P, Weyman AE. Reconsideration of echocardiographic standards for mitral valve prolapse: lack of association between leaflet displacement isolated to the apical four chamber view and independent echocardiographic evidence of abnormality. J Am Coll Cardiol 1988;11:1010-1019. 
118. Lloret RL, Cortada X, Bradford J, Metz MN, Kinney EL. Classification of left ventricular thrombi by their history of systemic embolization using pattern recognition of two-dimensional echocardiograms. Am Heart J 1985;110:761-765.

119. Lodder J, Bamford JM, Sandercock PAG, Jones LN, Warlow CP. Are hypertension or cardiac embolism likely causes of lacunar infarction. Stroke 1990;21:375-381.

120. Lodder J, Dennis MS, van Raak L, Jones LN, Warlow CP. Co-operative study on the value of long-term anticoagulation in stroke patients with non-rheumatic atrial fibrillation. $\mathrm{Br}$ Med J 1988;296:1435-1438

121. Lombard JT, Selzer A. Valvular aortic stenosis. Ann Intern Med 1987;106:292-298.

122. Lopez JA, Ross RS, Fishbein MC, Siegel RJ. Nonbacterial thrombotic endocarditis: a rewiew. Am Heart J 1987;113:773-784.

123. Loscalo J. Paradoxical embolism: clinical presentation, diagnostic strategies and therapeutic options. Am Heart J 1986;112:141-145.

124. Lui $C X$. Should patients with lone atrial fibrillation be treated with anticoagulant therapy. J Am Coll Cardiol 1991;18:301-302.

125. Lutas EM, Robuls RB, Devereux RB, Prieto M. Relation between the presence of echocardiographic vegetatious and the complication rate in infective endocarditis. Am Heart J 1986;112:107-113.

126. Lydlen PD, Zivin JA, Clark WA, Madden K, Sasse KC, Mazzarella VA, Terry RD, Press GA. Tissue plasminogen activator- mediated thrombolysis of cerebral emboli and its effect on hemorrhagic infarction in rabbits. Neurology 1989;39:703-708.

127. Lynch JJ, Schuchard GH, Gross CM, Wann LS. Prevalence of right to left atrial shunting in a healthy population: detection by Valsalva manoeuvre contrast echocardiography. Am J Cardiol 1984;53:1478-1480.

128. Maravaste MA, Obeid AI, Potts JL. Approach to the management of atrial myxoma with long-term follow up. Ann Thorac Surg 1984;38:53-56.

129. Markel ML, Waller BF, Armstrong WF. Cardiac myxoma: a rewiew. Medicine 1987;66:114-126.

130. van Merode T, Lodder J, Smeets F, Hoeks APG, Reneman RS. Accurate noninvasive method to diagnose minor atherosclerotic lesions in carotid artery bulb. Stroke 1989;20:1336-1340.

131. Merwijk van G, Lodder J, Bamford J, Kester ADM. How often is non-valvular atrial fibrillation the cause of brain infarction? J Neurol 1990;237:205-207.

132. Meyer J5, Charney JZ, Rivera VM, et al. Cerebral embolisation: Prospective clinical analysis of 42 cases. Stroke $1971 ; 2: 541-554$.

133. Millikan $\mathrm{CH}$, Bauer RB, Goldschmidt J, et al. A classification and outline of cerebrovascular disease: II. Stroke 1975;6:564-616.

134. Mohr JP, Caplan LR, Melski JW et al. The Harvard cooperative stroke registry: A prospective registry. Neurology 1987;28:754-762.

135. Morgan WL, Bland EF. Bacterial endocarditis in the antibiotic era. Circulation 1959;19:753-759.

136. Mori E, Tabuchi M, Yoshida T, Yamadori A Intracarotid urokinase with thromboenbolic occlusion of the middle cerebral artery. Stroke 1988;19:802-812.

137. Morris DC, Hurst JW. Atrial fibrillation. Curr Probl Cardiol 1980;5:1-50.

138. Neilson GH, Galea EG, Hossack KF. Thromboembolic complications of mitral valve disease. Aust NZ J Med 1978;8:372-376.

139. Nishide M, Irino T, Gotoh M, Naka M, Tsuji K. Cardiac abnormalities in ischemic cerebrovascular disease studied by two-dimensional echocardiography. Stroke $1983 ; 14: 541-545$. 
140. Nishimura RA, McGoon MD, ShubC, Miller FA, Ilstrup DM, Tajik AJ. Echocardiographically documented mitral valve prolapse: long-term follow-up of 237 patients. N Engl J Med 1985;313:1305-1309.

141. Nixon JV. Left ventricular mural thrombus. Arch Intern Med 1983;143:1567-1571.

142. Nordrehaug JE, Johanessen KA, von der Lippe G. Usefulness of high-dose anticoagulants in preventing left ventricular thrombus in acute myocardial infarction, Am J Cardiol 1985;55:1491-1493.

143. Norrving B, Nilsson B. Cerebral embolism of cardiac origin: the limited possibilities of secondary prevention. Acta Neurol Scand 1986;73:520 (abstract).

144. Okada Y, Sadoshima S, Nakane H, Utsunomiaya H, Fujishima M. Early computed tomographic findings for thrombolytic therapy in patients with acute brain embolism. Stroke 1992;23:20-23.

145. Ondrias F, Slugen I, Valach A. Malignant tumors and embolizing endocarditis. Neoplasma 1985;2:135-140.

146. Onundarson PT, Thorgeirson G, Jonmundsson E, Sigfusson N, Hardarson T. Cronic atrial fibrillation: epidenniologic features and 14 year follow-up: a case control study. Eur Heart J 1987;8:521-527.

147. Ott BR, Zamini A, Kleefield J, Funkenstein HH. The clinical spectrum of hemorrhagic infarction. Stroke 1986;17:630-637.

148. Owren PA. The results of anticoagulant therapy in Norway. Arch Intern Med 1963;111:240-247.

149. DiPasquale G, Andreoli A, Grazi P, Dominici P, Pinelli G. Cardioembolic stroke from atrial septal aneurysm. Stroke 1988;19:640-643.

150. Pelletier LL, Petersdorf RG. Infective endocarditis: A review of 125 cases. Medicine 1977:56:287-314.

151. Perloff JK, Child JS, Edwards JE. New guidelines for the clinical diagnosis of mitral valve prolapse. Am J Cardiol 1986:57:1124-1129.

152. Pessin MS, Lathi ES, Cohen MB, Kwan ES, Hedges TR, Caplan LR. Clinical features and mechanisms of occipital infarction. Ann Neurol 1987;21:290-299.

153. Petersen P, Godtfredsen J. Embolic complications in paroxysmal atrial fibrillation. Stroke 1986;17:622-626.

154. Petersen P, Godtfersen J, Boysen G. Placebo-controlled, randomized trial of warfarin and aspirin for prevention of thromboembolic complications in chronic atrial fibrillation. Lacet 1989;1:175-178.

155. Petersen P, Godtfredsen J, Boysen G, Andersen ED, Andersen B. Placebo-controlled randomized trial of warfarin and aspirin for prevention of thromboembolic complications of chronic atrial fibrillation. Lancet 1989;1:175-179.

156. Petersen P, Hansen JM. Stroke in thyrotoxicosis with atrial fibrillation. Stroke 1988;19:1518.

157. Petersen P, Madsen EB, Brun B, Pederson F, Boysen G. Silent cerebral infarction in atrial fibrillation. Stroke 1987; 18:1098-1100.

158. Plum F, Posner JB. The diagnosis of stupor and coma. F.A. Davis Co., Philadelphia, 1982, 3rd edition.

159. Pomerance A. Pathological and clinical study of the mitral valve ring. J Clin Pathol 1970;23:254-260.

160. Presti CF, Hart RG. Thyrotoxicosis, atrial fibrillation and embolism, revisited. Am Heart J 1989;117:976-9T7.

161. Pruitt AA, Rubin RH, Karchmer AW, Duncan GW. Neurologic complications of bacterial endocarditis. Medicine 1978;57:329-343.

162. Puletti M, Cusmano E, Testa MG, Borgia C, Fanari F, Curone M. Incidence of systemic thromboembolic lesions in acute myocardial infarction. Clin Cardiol 1986;3:331-333. 
163. Rahimtoola SH. Valvular heart disease: A perspective. J Am Coll Cardiol 1983;1:199-215.

164. Ramirez-Lassepas M, Cipolle RJ, Bjork RJ, Kowitz J, Snyder BD, Weber JC, Stein SD. Can embolic stroke be diagnosed on the basis of neurologic clinical criteria? Arch Neurol 1987:44:87-89.

165. Ridolfi RL, Hutchins GM. Spontaneous calcific emboli from calcific mitral annulus fibrosis.Arch Pathol Lab Med 1976;100:117-120.

166. Roberts WC. Aneurysm (redundancy) of the atrial septum (fossa ovale membrane) and prolapse (redundancy) of the mitral valve. Am J Cardiol 1984;54:1153-1154.

167. Roeltgen DP, Weimer GR, Patterson LF. Delayed neurologic complications of left atrial myxoma. Neurology 1981;31:8-13.

168. Rogers LR, Cho ES, Kempin S, Posner JB. Cerebral infarction from nonbacterialthrombotic endocarditis: clinical and pathological study including the effects of anticoagulation. Am J Med 1987;83:746-756.

169. Ruocco NA, Most AS. Clinical and echocardiographic risk factors for systemic embolisation in patients with atrial fibrillation in the absence of mitral stenosis. J Am Coll Cardiol $1986 ; 7: 165$ (abstract).

170. Sage JL. Prospective study of stroke associated with nonvalvular atrial fibrillation: low frequency of early recurence. Ann Neurol 1986;20:155 (abstract).

171. Sage JI, Van Uitert RL. Risk of recurrent stroke in patients with atrial fibrillation and non-valvular heart disease. Stroke 1983;14:537-540.

172. Salgado AV. Central nervous system complications of infective endocarditis. Current Concepts of Cerebrovascular Disease and Stroke 1991;26:19-22.

173. Salgado AV, Furlan AJ, Keys TF. Mycotic aneurysm, subarachnoid hemorrhage and indications for cerebral angiography in infective endocarditis. Stroke 1987;18:1057-1060.

174. Salgado AV, Furlan AJ, Keys TF, Nichols TR, Beck GJ. Neurological complications of native and prosthetic valve endocarditis: a 12 year experience. Neurology 1989;39:173178.

175. Sandok BA, von Estdorf I, Giuliani ER. CNS embolism due to atrial myxoma. Arch Neurol 1980;37:485-488.

176. Santamaria J, Graus F, Peres J. Cerebral embolism and anticoagulation. Neurology 1983;33:1104.

177. Santamaria J, Graus F, Rubio F, Aribizu T, Peres J. Cerebral infarction in the basal ganglia due to embolism from the heart. Stroke 1983;14:911-914.

178. Sasaki W, Yanagisawa S, Maki K, Onodera A, Awaji T, Kanazawa T. High incidence of silent small cerebral infarction in the patients with atrial fibrillation. Circulation 1987;76(suppl. IV): 104 (abstract).

179. Schachter S, Freeman R. TIA and adriamycin cardiomyopathy. Neurology 1982;32:1380 1381

180. Schnee MA, Bucal AA. Fatal embolism in mitral valve prolapse. Chest 1983;83:285-286.

181. Seneviratne BI, Reimers J. Nonvalvular atrial fibrillation associated with cardioembolic stroke: the role of hypertensive heart disease. Aust NZ J Med 1990;20:127-134.

182. Shenoy MM, Vijaykumar PM, Friedman SA, Greif E. Atrial septal aneurysm associated with systemic embolism and interatrial right to left shunt. Arch Intern Med 1987;147:605606.

183. Sherman DG. Stroke prevention trials in atrial fibrillation. Cerebrovasc Dis $1992 ; 2$ (suppl 1):14-17.

184. Silver MD, Dorsey JS. Aneurysms of the septum primum in adults. Arch Pathol Lab Med 1978;102:62-65.

185. Silvka A, Pulsinelli WA. Hemorrhagic complications of thrombolytic therapy in experimental stroke. Stroke 1987;18:1148-1156. 
186. Stafford WJ, Petch J, Radford DJ. Vegetatious in infective endocarditis: Clinical relevance and diagnosis by cross-sectional echocardiography. Br Heart J 1985;53:310-313.

187. Starkey I, Warlow C. The secondary prevention of stroke in patients with atrial fibrillation. Arch Neurol 1986;43:66-68.

188. Stein PD, Sabbah HN, Pitha JV. Continuing disease process of calcific aortic stenosis. Am J Cardiol 1977;39:159-163.

189. Stroke prevention in atrial fibrillation investigators. Stroke prevention in atrial fibrillation study. Final results. Circulation 1991;84:527-539.

190. Stroke Prevention in Atrial Fibrillation Study Group Investigators. Preliminary report of the Stroke Prevention in Atrial Fibrillation Study. NEJM 1990;322:863-868.

191. Szekly P. Systemic embolism and anticoagulant prophylaxis in rheumatic heart disease. Br Med J 1964;1:209-212.

192. Tegeler CH, Hart RG. Atrial size, atrial fibrillation and stroke. Ann Neurol 1987;21:315316.

193. Tegeler CH, Hart RG, Sherman DG, Quiroga ES, Easton JD. Atrial Fibrillation-Stroke Study. Stroke 1986;17:131 (abstract).

194. Thompson PL, Robinson JS. Stroke after acute myocardial infarction: relation to infarct size. Br Med J 1978;2:457-459.

195. Towbin A. Recurrent Cerebral embolism: A cause of chronic organic brain disease. Arch Neurol Psychiat 1955;73:173-192.

196. Tobin R, Slutski RA, Higgins CB. Serial echocardiograms in patients with congestive cardiomyopathies: lack of evidence for thrombus formation. Clin Cardiol 1984;7:99-101.

197. The t-PA/Acute Stroke Study Group. An open multicenter study of the safety and efficacy of various doses of rt-PA in patients with acute stroke: preliminary results (abstract). Stroke 1988;19:134.

198. Visser CA, Kan G, Meltzer RS, Dunning AJ, Roelandt J. Embolic potential of left ventricular thrombus after myocardial infarction: a two-dimensional echocardiographic study of 119 patients. J Am Coll Cardiol 1985;5:1276-1280.

199. Visser CA, Kan G, Meltzer RS, Lie KI, Durrer D. Long-term follow-up of left ventricular thrombus after acute myocardial infarction. Chest 1984;86:532-536.

200. DeWar HA, Weightman D. A study of embolism in mitral valve disease and atrial fibrillation. Br Heart J 1983;49:133-140.

201. Weinberger J, Rothlauf FB, Matarese EL, Halper $\pi$. Noninvasive evaluation of the extracranial carotid arteries in patients with cerebrovascular events and atrial fibrillation. Arch Intern Med 1988;148:1785-1788.

202. Wells CE. Premonitory Symptoms of cerebral Embolism. Arch Neurol 1961;5:44-50,

203. Weinreich DJ, Burke JF, Pauletto FJ. Left ventricular mural thrombi complicating acute myocardial infarction. Ann Intern Med 1984;100:789-794.

204. Weisberg LA. Nonseptic cardiogenic cerebral embolic stroke: clinical-CI correlations. Neurology 1985;35:896-899.

205. Wiener I. Clinical and echocardiographic correlates of systemic embolisation in nonrheumatic atrial fibrillation. Am J Cardiol 1987;59:177.

206. Wolf PA, Abbott RD, Kannel WB. Atrial fibrillation: a major contributor to stroke in the elderly: The Framingham Study. Arch Int Med 1987;147:1561-1564.

207. Wolf PA, Drawber TR, Thomas HE, Kannel WB. Epidemiologic assessment of chronic atrial fibrillation and risk of stroke: the Framingham Study. Neurology 1978;28:973-977.

208. Wolf PA, Kannel WB, McGee DL, Meeks SL, Bharucha NE, McNamara PM. Duration of atrial fibrillation and imminence of stroke: the Framingham Study. Stroke 1983;14:664667.

209. Wood P. Diseases of the heart and circulation. Philadelphia, JB Lippincott Co, 1956. 
210. Yuen RWM, Gutteridge DH, Thompson PL, Robinson JS. Embolism in thyrotoxic atrial fibrillation. Med J Aust 1979;1:630-631.

211. Zenker G, Bone $G$, Ladurner $G$, Lechner $H$. The myxomatous mitral calve. Eur Neurol $1985 ; 24: 82-84$.

212. Zeumer $\mathrm{H}$. Survey of progress: Vascular recanalizing techniques in interventional neuroradiology. J Neurol 1985;231:287-294.

213. Ziment I. Nervous system complications of bacterial endocarditis. Am J Med 1969;47:593607.

214. Zivin JA, Lyden PD, De Girolami U, Kochbar R, Mazzarella V, Hemenway CC, Johnston $P$. Tissue palsminogen activator reduction of neurologic damage after experimental embolic stroke. Arch Neurol 1988;45:387-391.

215. Del Zoppo GJ, Ferbert A, Otis S, Brückmann H, Hacke W, Zyroff J, Hacker LA, Zeumer $\mathrm{H}$. Local intra-arterial fibrinolytic therapy in acute carotid territory stroke: A pilot study. Stroke 1988;19:307-313.

216. Del Zoppo GJ, Copeland BR, Anderchek K, Hacke W, Koziol JA. Hemorrhagic transformation following tissue plasminogen activator in experimental cerebral infarction. Stroke 1990;21:596-601. 


\section{Cerebral hemorrhagic infarction at autopsy: presumed cardioembolic cause and the relationship to the cause of death}

Adapted from: Cerebral hemorrhagic infarction at autopsy: cardiac embolic cause and the relationship to the cause of death.

J. Lodder, B. Krijne-Kubat, J. Broekman. Stroke 1986;17-4;626-629 
Recent studies suggest that early anticoagulation for secondary stroke prevention can safely be used in presumed cardioembolic strokes. $3,11,21,29,30$ The timing of such treatment, however, remains controversial.9,12,13,15,18,44 Incidental clinical reports on cerebral complications of anticoagulant therapy $4,9,12,14,37$ and autopsy studies support the fear of such complications because a high rate of hemorrhagic infarction was related to embolic stroke.1,16,28 On CT, however, early hemorrhagic infarction is rarely seen $8,25,39,40$ even in presumed embolic stroke (Chapter 3).11,21,30 Furthermore, hemorrhagic infarction is most prevalent in large infarctions with mass effect. 24,31 Presumed embolic strokes result relatively often in large infarctions with a bad outcome. $10,17,27,28,35,36$ Therefore, autopsy findings are probably biased towards establishing a high rate of embolic cause in cases with hemorrhagic infarction. The fact that many more embolic strokes are found in autopsy studies $1,5,16,27$ than in clinical and epidemiological studies $10,20,32,41$ also supports such a bias. Alternatively, the incidence of clinical emboli may be underestimated because of the difference between autopsy and clinical criteria for cardioembolic infarction. Moreover, CT may miss minor hemorrhagic infarction. On the other hand a substantial number of patients with clinically diagnosed presumed cardioembolic stroke have concomitant carotid artery disease as a possible source of their stroke. $6,7,11,19,22$ Clinically the number of presumed cardioembolic strokes may well be overestimated. If the presence of hemorrhages in an infarction depends on its size, hemorrhagic infarction should be seen more often in patients who die from the direct consequence of the large infarction, namely from cerebral herniation, regardless of the cause of the infarction itself. We therefore, studied the incidence of hemorrhagic infarction in patients with and without brain herniation, in a consecutive autopsy series of ischemic stroke.

\section{METHODS}

Clinical data and autopsy findings of patients who died within 15 days following a supra-tentorial, non-lacunar, focal cerebral ischemia between 01-01-1979 and 01-01-1985 were evaluated. On pathological examination the cerebral infarction compatible with the recent stroke was listed as either ischemic necrosis (IN), or as hemorrhagic infarction (HI) when on both macroscopical and microscopical examination a (partial) hemorrhagic infarction was present. ${ }^{43}$ The extent of hemorrhage was judged as "small", if one or more small areas of petechial hemorrhages were present, or as "large" when areas of confluent hemorrhages were observed. Examples of both categories are represented in Figures 1 and 2. The cause of death was judged to be either "cerebral" when death had resulted directly from brain herniation, or "noncerebral" when death had resulted directly from another cause such as: pneumonia, myocardial infarction, pulmonary embolism, etc. 


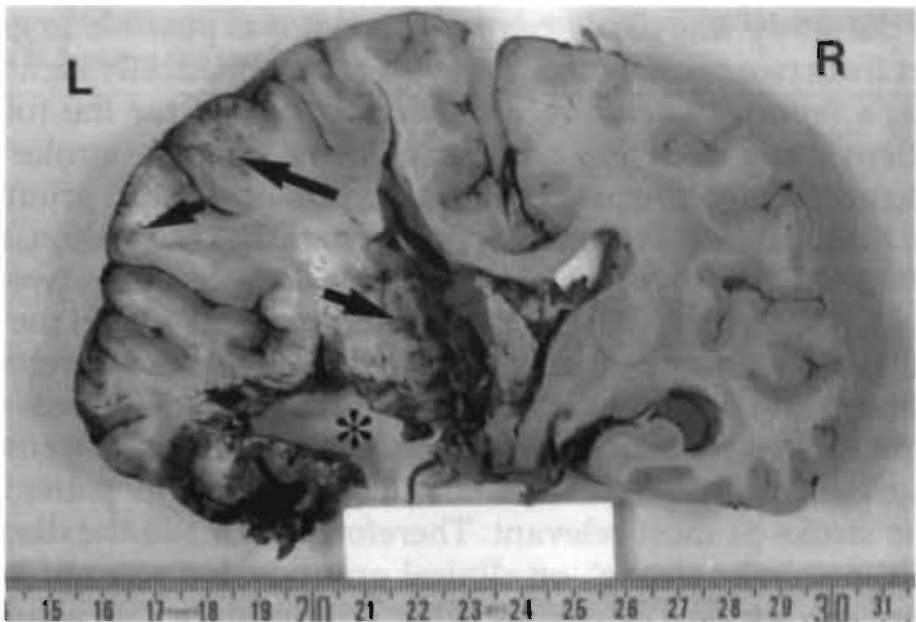

FGURE 1. Small areas of petechial hemorrhages $(\rightarrow)$ within a large infarction in the territory of the left internal carotid artery with destruction of a large part of the temporal pole and a pseudocyst (*) due to thrombosis.

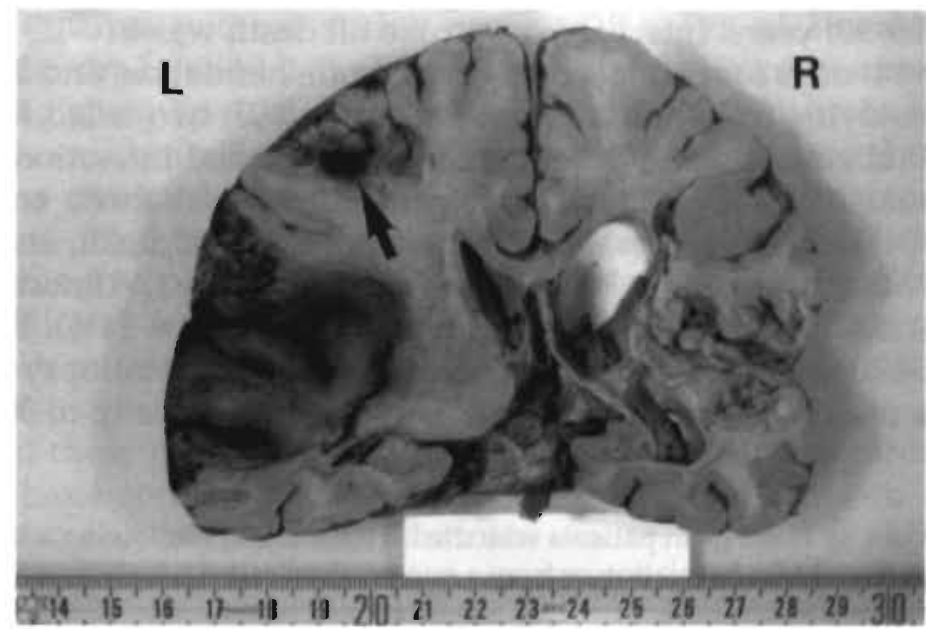

FIGURE 2. Large confluent hemorrhages $(\rightarrow$ ) within an extensive leftsided infarction in the territory of the medial cerebral artery due to cardioembolism. In the contralateral hemisphere an infarction scarr and enlargement of the ventricle can be seen. 
Although the study was partly retrospective, it was possible to gather all the data, apart from two cases, because they were systematically mentioned in the pathologist's report. Patients records were reviewed for the following features: patient's age and sex; number of days between stroke and death; presumed cardioembolic cause of the infarction on clinical grounds such as: rheumatic heart disease, paroxysmal or chronic atrial fibrillation, mitral valve stenosis or prosthesis, myocardial infarction in the preceding two weeks, and myocarditis; whether the cause of death was "cerebral" when the patient had died from brain stem, or uncinate herniation 34 , or "non-cerebral". On the basis of clinical and autopsy data the definite cause of death was established, and if doubt existed the most probable cause was selected. We considered the question of when anticoagulation should be started in patients with cardioembolic stroke as most relevant. Therefore, we made the diagnosis "presumed cardioembolic stroke" on clinical grounds. No attempt was made to separate embolic strokes caused by other criteria since this would not effect the clinical decision about anticoagulation. The statistical comparison of the two groups (with or without presumed cardioembolic stroke) was performed by means of a two-tailed RIDED test and $\mathrm{X}^{2}$ test.

\section{RESULTS}

Data are expressed as median with range. There were 25 males and 23 females aged: $73(39-90)$ years. Interval from stroke till death was $6(0-15)$ days for all cases, 4 (0-14) days for patients dying from brain herniation, and $8(0-15)$ days for patients dying from non-cerebral causes ( $p<0.01$; two-tailed RIDED test). Non-cerebral causes were: pneumonia: 8 , myocardial infarction: 6 , pulmonary embolus: 2, sepsis/shock: 3, hepatic coma: 1, diabetic coma: 1 . The number of cases with cerebral or non-cerebral cause of death, and the corresponding numbers of either $\mathrm{HI}$ or IN are shown in table 1 . Almost all patients with $\mathrm{HI}$ at autopsy died from brain herniation $(15 / 16,=94 \%)$. Fifteen of 2 ? patients (56\%) who died from brain herniation had $\mathrm{HI}$ at autopsy against one of 21 patients $(5 \%)$ who died from a non-cerebral cause $\left(p<0.001 ; X^{2}\right.$-test).

TABLE 1: Autopsy findings in patients who died within 15 days following a supra-tentorial brain infarct, from brain herniation or from a non-cerebral cause.

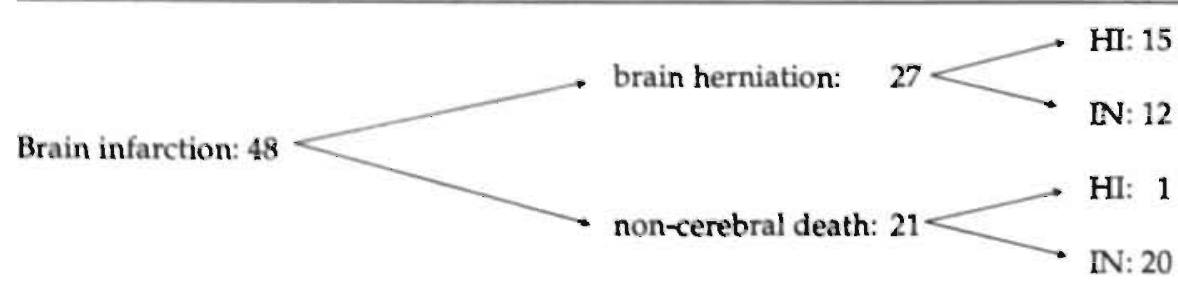

$\mathrm{HI}=$ hemorrhagic infarction; $\mathbb{I N}=$ ischemic necrosis 
TABLE 2: Autopsy-findings in patients with, and without a cardioembolic stroke dying within 15 days following the stroke.

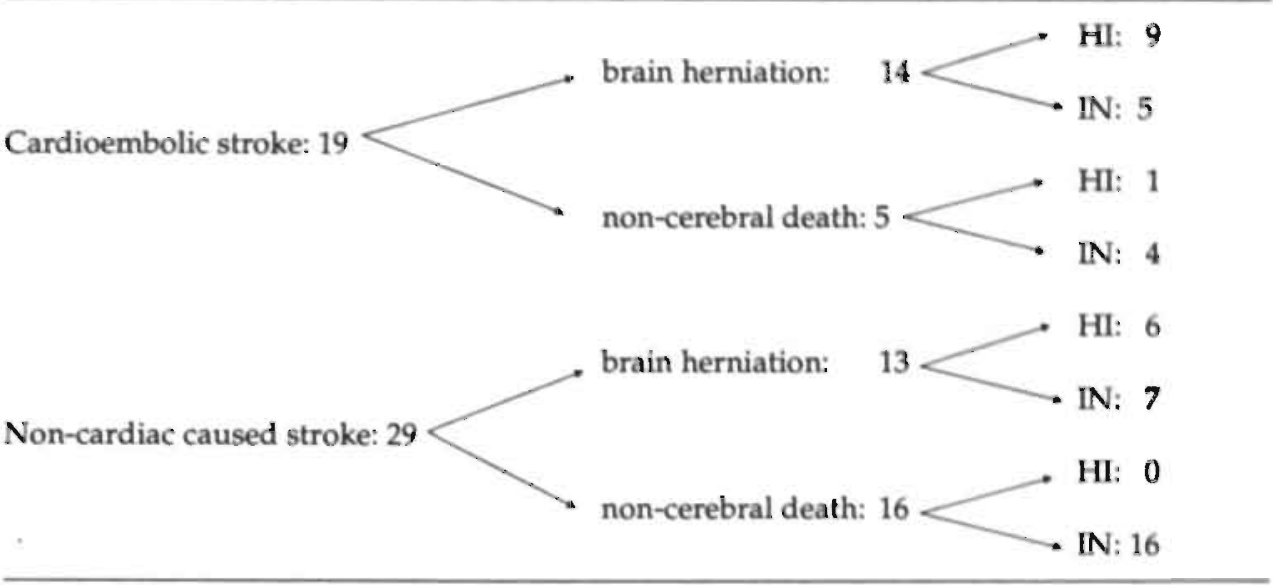

$\mathrm{HI}=$ hemorrhagic infarction; $\mathrm{IN}=$ ischemic necrosis

Table 2 gives the data on the cause of death, and the aspect of the infarction at autopsy; separately for patients with a presumed cardioembolic cause of stroke and patients without such a cause $(63 \%)$. Ten of $19(53 \%)$ with a cardioembolic stroke had $\mathrm{HI}$ at autopsy against only six of 29 cases $(21 \%)$ in the remaining group ( $p<0.05 ; X^{2}$-test). However, 14 of 19 patients $(74 \%)$ with a presumed cardioembolic stroke died from brain herniation against 13 of 29 (45\%) with a non-cardiac cause. Since we expected the difference in this direction, one-tailed testing sufficed to establish the difference to be significant below the five per cent level ( $X^{2}$-test). In patients dyi $\mathrm{ng}$ from brain herniation HI was equally present in the group of cases with a presumed cardiac stroke cause $(9 / 14,=64 \%)$, and those without such a cause of stroke $(6 / 13,=46 \%)$.

However, in these patients six of the nine with a presumed cardioembolic stroke had large confluent hemorrhages, compared to only two of the six patients with a non-cardiac cause of stroke.

\section{DISCUSSION}

The discussion on the timing of anticoagulant treatment in presumed cardioembolic stroke has not been settled $2,21,37$. One of the arguments against early anticoagulation comes from autopsy findings. The close relationship of hemorrhagic infarction with presumed cardioembolic stroke leads to the fear that anticoagulation would induce cerebral bleeding. The concept of hemorrhagic infarction indicating an embolic cause was introduced by Fisher and 
Adams. 16 In an autopsy series they found that 63 hemorrhagic infarctions (95\%) had an embolic cause, and 66 of 132 embolic strokes (54\%) were hemorrhagic infarctions. The authors neither mentioned the interval from stroke till death nor whether patients died from brain herniation. They did not define "embolic stroke", but most probably they referred to cardioembolic strokes. Because Fisher and Adams found no obstruction in the feeding vessel to the infarcted area in ten cases, they suggested that reperfusion of the infarcted area was a pathophysiological mechanism of hemorrhagic infarction. This concept was further validated by autopsy 1,28 and angiography studies. 26,42 At autopsy Adams and Van der Eecken ${ }^{1}$ found hemorrhagic infarction in 26 of 57 cases $(65 \%)$ after a cardioembolic stroke. They also did not mention the interval between stroke and death, nor the direct cause of death. Jörgensen and Torvik ${ }^{28}$ found a cardioembolic cause in 42 of $54(78 \%)$ hemorrhagic infarctions, and hemorrhagic infarctions in 42 of 59 (71\%) cardioembolic strokes. Aggregated data of the three above-mentioned studies indicate that 134 of $239(56 \%)$ embolic infarctions were hemorrhagic, and 105 of 120 (88\%) hemorrhagic infaretions had a cardioembolic cause. If more than half of all the clinically diagnosed presumed cardioembolic strokes consisted of hemorrhagic infarctions, then there is a valid argument against starting anti-coagulation early after such a stroke. However, the following arguments dispute this extrapolation. In the series of Jörgensen and Torvik,27 47 per cent of 79 "recent" large infarctions had a cardioembolic cause as opposed to only 19 per cent of 120 "old" lesions. Obviously, patients with a cardioembolic stroke had a greater chance of dying and consequently coming to autopsy than patients with brain infarctions from other causes. Recent clinical studies indicate likewise. $10,17,35,36$ Since CT studies indicate that hemorrhagic infarction is related to large infarctions 12,31 , hemorrhagic infarctions found at autopsy are likely to have had a cardioembolic origin. The finding of far more cardioembolic strokes in autopsy series than in clinical and epidemiological studies further suggest such a bias. $10,20,32,41$

In the present series $63 \%$ of cases with hemorrhagic infarction had a presumed cardioembolic cause, which is somewhat lower than in the above mentioned studies. Fifty-three per cent of patients with a presumed cardioembolic stroke had a hemorrhagic infarction at autopsy against only 21 per cent without such cause. However, almost all cases with hemorrhagic infarction died from brain herniation. Patients with a presumed cardioembolic origin of stroke died from brain herniation more often than those without. In cases who died from brain herniation, hemorrhagic infarction was equally frequent in the group with a presumed cardioembolic cause of stroke, as it was in the group without such a cause. Therefore, the relative finding of a high rate of hemorrhagic infarction in fatal cardioembolic strokes is related to the higher rate of brain herniation as the cause of death after such a stroke, relative to fatal strokes caused otherwise. However, until now the degree of $\mathrm{HI}$ was not considered in relating $\mathrm{HI}$ to a cardioembolic cause. Hart ${ }^{23}$ suggested that hemorrhagic 
infarctions with extended hemorrhages are most probably due to a cardiogenic embolus. Although our numbers are small, they support Hart's suggestion: of the patients who died from brain herniation six of nine cases with larger hemorrhages had a presumed cardioembolic cause, against only two of six cases without such a cause. Thus, although autopsy studies are biased towards relating $\mathrm{HI}$ to a cardioembolic cause, compared with non-cardiac strokes fatal cardiogenic emboli may result more often in $\mathrm{HI}$ with extensive hemorrhages.

Whether the same is true for non-fatal cardioembolic strokes and, if so, whether this finding would effect the anticoagulant treatment regime remains to be shown. Until then, the view of Toole ${ }^{38}$, that the outcome of autopsy studies should not be used as an argument against early anticoagulant treatment in cardioembolic stroke, still stands. Chapter 7 deals with the question of whether early anticoagulation is indeed safe or not.11,21,29-31 


\section{REFERENCES}

1. Adlams RD, van der Eecken HM. Vascular diseases of the brain. Ann Rev Med 1953;4:213252.

2. Anti-coagulant-related hemorrhage in acute cerebral embolism. Letters to the editor. Martin GI, Biller J, Phillips S, Hefferman LP, Lodder J, Matías-Guíu J, Alvarez J, Cervera C, Codina A. Response: Shields RW, Laureno R, Lachman T, Victor M. Stroke 1985;16:331334.

3. Babikian VL, Kase CS, Pessin MS, Norrving B, Gorelick PB. Intracerebral hemorrhage in stroke patients anticoagulated with heparin. Stroke 1989;20:1500-1503

4. Bass E. Anti-coagulation in cerebral embolism. Can J Neurol Sci 1983;10:32-36.

5. Blackwood W, Hallpike JF, Kocen RS, Mair WGP. Atheromatous disease of the carotid arterial system and embolism from the heart in cerebral infarction: a morbid anatomical study. Brain 1969;92:897-910.

6. Bogousslavsky J, Melle GV, Regli F. The Lausanne Stroke Registry: analysis of 1000 consecutive patients with first stroke. Stroke 1988;19:1083-1092.

7. Bogousslavsky J, Cachin C, Regli F, Despland PA, Van Melle G, Kappenberger L. Cardiac sources of embolism and cerebral infarction - clinical consequences and vascular concomitants: The Lausanne Stroke Registry. Neurology 1991;41:855-859.

8. Caillé JM, Bidabé Am, Billerey J, Piton J. Enhancement of cerebral infarcts with CT. Comput Tomogr 1980;4:73-77.

9. Calandre L, Ortega JF, Berjemo F. Anticoagulation and hemorrhagic infarction in cerebral embolism secondary to rheumatic heart disease. Arch Neurol 1984;41:1152-1154.

10. Caplan LR, Hier DB, D'Cruz I. Cerebral embolism in the Michael Reese Stroke Registry. Stroke 1983; 14:530-536.

11. Cerebral Embolism Study Group. Immediate anticoagulation of embolic stroke: a randomized trial. Stroke 1983;14:668-676.

12. Cerebral Embolism Study Group. Immediate anticoagulation of embolic stroke: brain hemorrhage and management options. Stroke 1984;15:779-789.

13. Cerebral embolism study group. Cardioembolic stroke, early anticoagulation and brain hemorrhage. Arch Int Med 1987;147:636-640.

14. Drake ME, Shin C. Conversion of ischemic to hemorrhagic infarction by anticoagulant administration. Arch Neurol 1983;40:44-46.

15. Easton JD, Sherman DG. Management of cerebral embolism of cardiac origin. Stroke 1980;11:433-441.

16. Fisher CM, Adams RD. Observations on brain embolism with special reference to mechanism of hemorrhagic infarction. J Neuropathol Exp Neurol 1951;10:92-94.

17. Fisher CM. Reducing risks of cerebral embolism. Geriatrics 1979;34:59-66.

18. Fisher CM. Embolism in atrial fibrillation. In: Atrial Fibrillation. Kulbertus HE, Olsson SB, Schlepper M, eds. Hässle, Mölndal, Sweden 1982; pp 192-210.

19. Fogelholm R, Melin J. Echocardiography in ischemic cerebrovascular disease. Br Med J Clin res 1987;295:305-306.

20. Foulkes MA, Wolf PA, Price TR, Mohr JP, Hier BH. The Stroke Data Bank; design, methods, and baseline characteristics. Stroke 1988;19:547-554.

21. Furlan AJ, CavalierSJ, Hobbs RE, Weinstein MA, Modic MT. Hemorrhage and anticoagulation after non-septic embolic brain infarction. Neurology 1982;32:280-282.

22. Hachinski VC, Rem JA, Boughner DR, Barnett HJM. The common coincidence of cardiac embolic and carotid lesions. J Neurol 1985;232:196.

23. Hart RG. Discussion of cardiogenic sources, particularly atrial fibrillation. Cardioembolic Stroke Workshop. IIIrd International brain. Heart Conference. Trier, September 7-9, 1985.

24. Hart RG, Easton. JD. Hemorrhagic infarcts. Stroke 1986;17:586-589. 
25. Houser OW, Campbell JK. Computed tomography in cerebrovascular disease: influences of morphology, tomography, clinical factors and temporal profile. In: Moossy J, Reinmuth OM, eds. Cerebrovascular Diseases. Raven Press, New York, 1981, pp. 181-191.

26. Irino T, Taneda M, Minami T. Angiographic manifestations in post-recanalized cerebral infarction. Neurology 1977;27:471-475.

27. Jörgensen L, Torvik A. Ischemic cerebrovascular diseases in an autopsy series. Part L. J Neurol Sci 1966;3:490-509,

28. Jörgensen L, Torvik A. Ischemic cerebrovascular diseases in an autopsy series. Part II. J Neurol Sci 1969;9:285-320.

29. Koller R. Recurrent embolic cerebral infarction and anticoagulation. Neurology 1982:32:283-285.

30. Lodder J, van der Lugt PJM. Evaluation of the risk of immediate anticoagulant treatment in patients with embolic stroke of cardiac origin. Stroke 1983;14:42-46.

31. Lodder J. CT-detected hemorrhagic infarction; relation with the size of the infarct and the presence of midline shift. Acta Neurol Scan 1984;70:329-335.

32. Mohr JP, Caplan LR, Melski JW, et al. The Harvard Cooperative Stroke Registry: a prospective registry. Neurology 1978;28:754-762.

33. Pessin MS, Hinton RC, Davis KR, et al. Mechanisms of acute carotid stroke. Ann Neurol 1979;6:245-252.

34. Plum F, Posner JB. The diagnosis of stupor and coma. Davis Company, Philadelphia, 1980,3 rd ed., chapter 2.

35. Sage JI, Van Uitert RL: Risk of recurrent stroke in patients with atrial fibrillation and non-valvular heart disease. Stroke 1983;14:537-540.

36. Sherman DG, Goldman L, Whiting RB, Jurgensen K, Kaste M, Easton JD. Thrombo-embolism in patients with atrial fibrillation. Arch Neurol 1984;41:708-710.

37. Shields $\mathrm{R}$, Laureno R, Lachman $\mathrm{T}$, Victor M. Anticoagulant related hemorrhage in acute cerebral embolism. Stroke 1984;15:426-437.

38. Toole JT. Cerebrovascular Disorders. Raven Press, New York, 1984, 3rd ed., chapter 12.

39. Valk J. CT and cerebral infarctions. Rotterdarn: Lennniscaat 136, 1980.

40. Walshe TM, Hier DB, Davis KR. The diagnosis of hypertensive intracerebral hemorrhage: the contribution of computed tomography. Comput Tomog 1977;1:63-39.

41. Wolf PA, Dawber TR, Thomas HE, Kannel WB. Epidemiologic assessment of chronic atrial fibrillation and the risk of stroke: the Framingham Study. Neurology 1978:28:973977.

42. Yamaguchi T, Minematsu $\mathrm{K}$, Choki J, Ikeda $\mathrm{M}$. Clinical and neuroradiological analysis of thrombotic and embolic cerebral infarction. Jpn Circ J 1984;48:50-59.

43. Yates PO. Vascular disease of the central nervous system. In: Greenfield's Neuropathology. Blackwood W, Corselis JAN, eds. Edward Arnold, Lodon, 86-147, 1976.

44. Yatsu FM, Hart RG, Mohr JP, Grotta JC: Anticoagulation of embolic strokes of cardiac origin: An update. Neurology 1988;38:314-316. 



\section{Hemorrhagic infarction on CT in presumed cardioembolic stroke}

Based on: Hemorrhagic infarction on CT in cardioembolic stroke. B. Krijne-Kubat, J. Lodder and P.J.M. van der Lugt.

Clin Neurol Neurosurg 1987;89-2:103-105 
Some neurologists consider CT to be of value in separating cardioembolic causes of ischemic stroke from other causes, based on whether hemorrhagic infarction is present or not.5,7 However, this possible value of CT also depends on the incidence of hemorrhagic infarction in patients with cardioembolic stroke in general. Several studies indicate that the incidence of early hemorrhagic infarction in cardioembolic stroke is less than ten per cent.2$4,8,10,12,14$ Thus in less than ten per cent of patients with a stroke presumably caused by embolism from the heart, CT could be of value in making this diagnosis, solely on the presence of hemorrhagic infarction. However, these studies were small or retrospective, and in some of them CT was performed at different intervals after the stroke. More recent studies with serial CT scanning have shown that eventually up to approximately 40 per cent $7,9-11$ of presumed cardiogenic strokes may become hemorrhagic. A comparison with (non-lacunar) thromboembolic stroke patients has not been done so far. Establishing a cardioembolic cause of stroke at an early stage could be relevant if this were to influence patient management, such as e.g. early anticoagulation. Therefore, we studied early CT findings in a prospective series of 103 consecutive stroke patients with a potential cardiac source of embolism who would possibly benefit from early anticoagulant treatment.

\section{PATIENTS AND METHODS}

Patients with a supratentorial, presumably cardioembolic brain infarction with symptoms lasting longer than 24 hours were included in a prospective study on early anticoagulants (AC). Prior to AC CT was performed on all but one patient. Excluded from AC-treatment were patients with general contraindications to AC, such as a bleeding tendency, hepatic failure, alcoholism or prior spontaneous gastrointestinal or cerebral bleeding. AC was delayed in some patients with the following features, until these disappeared: a) diastolic blood pressure higher than $105-110 \mathrm{~mm} \mathrm{Hg}$; b) impaired consciousness; $c$ ) hemorrhagic infarction (HI) on CT; d) large infarctions with space-occupying effect on $\mathrm{CT}$, such as: flattening of sulci, ventricle compression, or shift of midline structures. Because our aim was to study the frequency of $\mathrm{HI}$ on early $\mathrm{CT}$ in patients considered for early $\mathrm{AC}$, cases with contraindications for such treatment were not included in the present study, unless these contraindications had resolved within 15 days following the onset of the stroke. Cardioembolic stroke was diagnosed if one or more of the following features were present: rheumatic heart disease, persistent or transient atrial fibrillation (AF), recent anterior or apical myocardial infarction, mitral stenosis, valve prosthesis, left ventricular aneurysm, atrial septal defect, intracardiac manipulation. 


\section{RESULTS}

Data are expressed as median with range. There were 58 males and 45 females, aged: 73 (43-87) years. Cardiac source for embolic stroke is shown in Table 1. Twenty-six patients had delayed AC-treatment for the following reasons: impaired consciousness: 6 ; initially elevated blood pressure that was considered to increase the risk of cerebral bleeding: 5 ; patient or doctor delay: 2; transient AF discovered later: 2; $\mathrm{HI}$ on CT: 4; no specific reason: 7. Treatment delay was 5 (1-15) days. CT-findings are shown in Table 2. CT was performed within 24 hours following stroke onset, except for ten cases in whom AC was delayed for 3 (2-10) days.

TABLE 1: Cardioembolic cause of stroke in 103 patients ( $\mathrm{AF}=$ atrial fibrillation).

\begin{tabular}{ll}
\hline Cardiac cause & Patients \\
\hline Persistent or transient AF & 71 \\
Myocardial infarction plus AF & 3 \\
Mitral stenosis with or without AF & 5 \\
Mitral insufficiency plus AF & 9 \\
Valve prosthesis & 2 \\
Recent myocardial infarction & 7 \\
Left ventricle aneurysm & 3 \\
Miscellaneous & 3 \\
\hline
\end{tabular}

TABLE 2: CT-findings prior to early anticoagulation in 103 cardioembolic stroke patients. Early CT: CT performed within $24 \mathrm{~h}$. following stroke onset. Delayed CT: CT delayed for $3(2-10)$ days.

\begin{tabular}{lll}
\hline CT-findings & $\begin{array}{l}\text { Early CT } \\
(\mathrm{N}=93)\end{array}$ & $\begin{array}{l}\text { Delayed CT } \\
(\mathrm{N}=10)\end{array}$ \\
\hline Infarctions & 58 & 8 \\
No lesion & 35 & 2 \\
Cortical infarctions & 45 & 5 \\
Small deep infarctions & 13 & 3 \\
Hemorrhagic infarctions & 4 & 1 \\
\hline
\end{tabular}




\section{DISCUSSION}

It is important to identify cardioembolic cause in stroke patients because such patients should be, either in or out of trials, considered for anticoagulant treatment. The beneficial effects of such treatment remain debatable. ${ }^{16-18} \mathrm{~A}$ stroke is considered to be cardiogenic if the patient has a potential cardioembolic source. However, a substantial number of patients may have significant carotid lesions which may also be a source of embolism.1,5,7 Therefore, in general the diagnosis "cardioembolic stroke" cannot be made accurately. Sorne consider CT to be a valuable tool in identifying patients with a cardioembolic cause of stroke: approximately 75 per cent of patients with $\mathrm{HI}$ on CT had cardiogenic embolism as a probable cause of their stroke. $5,7,13$ However, using this sole finding to diagnose cardioembolic stroke leads to the wrong diagnosis in at least 25 per cent of cases or more, because not everyone found a difference in the number of $\mathrm{HI}^{\prime} \mathrm{s}$ in stroke patients with and without a potential cardioembolic source. ${ }^{2}$ Furthermore, the relevance of a link between $\mathrm{HI}$ on $\mathrm{CT}$ and cardiogenic embolism for the management of patients with cardioembolic stroke also depends on the incidence of $\mathrm{HI}$ in such patients. In some studies repeated CT revealed $\mathrm{HI}$ in as many as 43 per cent. $7,9,11$ However, these series were small and CT was done without aiming at specific management options. We found $\mathrm{HI}$ in only five per cent of our patients in whom early CT was performed to decide on specific treatment. Obviously, if the sole presence of $\mathrm{HI}$ on $\mathrm{CT}$ is considered to indicate cardiogenic embolism as the cause of stroke, then cardiogenic embolism would only be diagnosed in a small group of stroke patients. It is clear that the clinical criteria, however fallible they may be, are considered to be of vital importance in deciding whether or not it was the heart that caused the stroke. ${ }^{7}$ In fact, the diagnosis "cardiogenic embolism" in studies which linked the presence of HI on CT with a cardioembolic cause of stroke were also based on the same imperfect clinical grounds. Thus it may be concluded that the sole finding of HI on CT will never be more accurate than the clinical criteria. Therefore, in our opinion the finding of $\mathrm{HI}$ on $\mathrm{CT}$ does not add any significance in ascertaining a cardioembolic cause of stroke. The value of CT in relation to stroke possibly caused by cardiogenic embolism does not lie in its formerly supposed ability to differentiate between cardioembolic and other causes of ischemic stroke, but in the possibility of minimizing the risk of early anticoagulant treatment in patients with such a stroke (Chapter 7). ${ }^{14}$ The odds of hemorrhagic infarction on CT, major neurological deficit (Rankin 5) and the presence of large infarction, in predicting a potential cardioembolic stroke source, were calculated by logistic regression analysis in Chapter 4. 


\section{REFERENCES}

1. Bogousslavsky J, Cachin C, Regli F, Despland P-A, Van MelleG, Kappenberger L، Cardiac sources of embolism and cerebral infarction - clinical consequences and vascular concomitants: The Lausanne Stroke Registry. Neurology 1991;41:855-859.

2. Britton $M$, Gustafsson $C$. Non-rheumatic atrial fibrillation as a risk factor for stroke. Stroke 1985;16:182-188.

3. Cerebral Embolism Study Group. Immediate anticoagulation of embolic stroke: a randomized trial. Stroke 1983;14:668-676.

4. Cerebral Embolism Study Group. Immediate anticoagulation of embolic stroke: brain hemorrhage and management options. Stroke 1984;15:779-789.

5. Fisher M, Ziro JL, Siva A, DeGirolami U. Hemorrhagic infarction: a clinical and CT-study. Stroke 1984;15:192 (abstract).

6. Furlan AS, Cavalier SJ, Hobbs RE, Weinstein MA, Modic MT. Hemorrhage and anticoagulation after non-septic embolic brain infarction. Neurology 1982;32:280-282.

7. Hakim AM, Ryder-Cooke A, Melanson D. Sequential computerized tomographic appearance of strokes. Stroke 1983;14:893-897.

8. Hart RG, Coull BM, Hart D. Early recurrent embolism associated with nonvalvular atrial fibrillation: a retrospective study. Stroke 1983;14:688-693.

9. Hornig CR, Dorndorf W, Agnoli AL. Hemorrhagic cerebral infarction. A prospective study. Stroke 1986;17:179-185.

10. Horowitz SH, Zito JL, Donnarumma R, Patel M, Alvir J. Computed tomographic-angiographic findings within the first five hours of cerebral infarction. Stroke 1991;22:12451253.

11. Kelley RE, Berger JR, Alter M, Kovacs AG. Cerebral ischemia and atrial fibriliation: prospective study. Neurology 1984;:34:1285-1291.

12. Koller RL. Recurrent embolic cerebral infarction and anticoagulation. Neurology 1982;32:283-285.

13. Laureno R, Shields RW, Narayan T. The diagnosis and management of cerebra! embolism and haemorrhagic infarction with sequential computerized cranial tomography. Brain 1987;110:93-105.

14. Lodder $\mathrm{J}$. A prospective study on the risk of immediate anticoagulation in cardioembolic stroke. In: Stober T, Schimrigk K, Ganten D and Sherman D, eds. Central nervous system control of the heart. Martinus Nijhoff publ. Boston 1986. Chapter 23.

15. Rem JA, Hachinski VC. Boughner DR, Barnett HIM. Value of cardiac monitoring and echocardiography in TIA and stroke patients. Stroke 1985;16:950-956.

16. Sandercock P, Bamford J, Warlow Ch, Peto R, Starkey I. Is a controlled trial of long-term oral anticoagulants in patients with stroke and non-rheumatic atrial fibrillation worthwhile? The Lancet 1986;8484:788-792.

17. Starkey I, Warlow $C$. The secondary prevention of stroke in patients with atrial fibrillation. Arch Neurol 1986;43:66-68.

18. Yatsu FM, Hart RG, Mohr JP, Grotta JC. Anticoagulation of embolic strokes of cardiac origin: an update. Neurology 1988;38:314-316. 



\section{Clinical and CT features predicting cardioembolic versus atherothrombotic non-lacunar brain infarction}

Based on: Clinical and $C T$ features predicting cardioembolic versus atherothrombotic non-lacunar brain infarction.

B. Krijne-Kubat, EPM Heurs-van Raak, AE Boon, AGH Kessels and J. Lodder. Submitted Stroke, 1992 
Recognition of a cardioembolic stroke mechanism soon after stroke may be relevant regarding differences in management options between cardiogenic and atherothrombotic brain infarctions, as well as for early intervention trials. A cardioembolic stroke mechanism is generally inferred from the presence of a distinct cardiac feature known to serve as a potential source of embolism. Such a cardiac source of embolism is not always recognized early, because of its paroxysmal character as in some cardiac rhythm disturbances, or because it requires ancillary cardiac investigation, for example cardiac echo, to be detected. Some clinical and CT-scan features, such as severe neurological deficit, large infarction size on $\mathrm{CT}$, or hemorrhagic infarction on $\mathrm{CT}$, have been suggested to point to a cardioembolic stroke cause.11,14-16,22,25 However, the few studies on the value of the different features in predicting cardioembolic stroke used prospective, well-defined stroke subgroups 23,26 , and therefore the value of these features in differentiating between atherothrombotic and cardioembolic stroke cause remains debatable.

By multivariate logistic regression analysis of data from a prospectively registered series of patients with a first supratentorial brain infarction, we evaluated several early clinical and CT-scan features in predicting a cardioembolic stroke cause.

\section{MATERIALS AND METHODS}

Patients with a first, supratentorial brain infarction were entered into a prospective registry between July 1987 and August 1990. Brain infarction was defined as focal neurological signs with rapid unset, lasting longer than 24 hours or leading to death, and with no apparent cause other than vascular. ${ }^{13}$ When neither CT scan nor autopsy was available, we used the Guy's Hospital Stroke Diagnostic Score to predict the probability that the stroke was due to infarction. Infarction was diagnosed when the score was less than 4 , which means a 90 per cent probability that the stroke was due to infarction. ${ }^{1}$ After clinical examination and CT scan, distinction was made between lacunar infarction and infarction involving the cortex ${ }^{8}$ Infarction involving the cortex was considered as cardioembolic in the presence of a potential cardiac source of embolism, such as: persistent or intermittent atrial fibrillation, rheumatic heart disease, mitral stenosis, mitral or aortic valve prosthesis, left ventricular myocardial infarction within the preceding six weeks, left ventricular aneurysm, endocarditis, cardiac myopathy, ventricle septal defect. In the absence of such cardiac disease a brain infarction was considered as atherothrombotic regardless of the results of carotid ultrasound, unless another obvious cause could be indicated (e.g. arterial dissection, vasculitis, clotting disorders, etc.), in which case it was labelled as miscellaneous. No attempt was made to separate thrombosis in situ and artery-to-artery embolism. Patients with a large, deeply located (striatocapsular) infarction were included in the cortical infarction group because of the similarity of the clinical 
features and underlying pathophysiology.9,27 For the purpose of our study, which was to investigate whether major neurological deficit, the presence of hemorrhagic infarction on CT, the size of the infarction on $\mathrm{CT}$, and the absence of obstructive carotid lesions, predict cardioembolic rather than atherothrombotic stroke cause, patients with miscellaneous stroke causes and those with lacunar infarctions were excluded. We aimed at performing carotid ultrasound investigations in all patients, either by means of multigated pulse Doppler, Duplex or continuous wave Doppler, all of which reliably predict carotid stenosis $>50 \%$. ${ }^{10}$ However, a number of patients did not undergo these tests because they were too ill to cooperate, had major cognitive defects that did not allow reliable examination, or died before the ultrasound could be performed. In some patients the ultrasound examination was not performed, without a specific reason. Based on the initial neurological examination a Rankin score was established in each patient. ${ }^{4}$ Hemorrhagic infarction on CT was defined as small areas of patchy, linear or curvilinear hyperdensities within a larger hypodense area compatible with an arterial territory. ${ }^{18}$ The size of the infarction was classified as "large" when an infarction involved most of the area supplied by one of the three main cerebral arteries, "moderate" when it was restricted to a medium size branch division, and "small" when confined to a smaller branch area. Striatocapsular infarctions were labelled as "moderate". In order to allow for possible differences in stroke risk factors associated diseases such as hypertension, diabetes mellitus, and ischemic heart disease were noted. Hypertension was defined as known hypertension whether or not treated with anti-hypertensive medication, or two or more blood pressure recordings higher than 160/90 on at least two different occasions before, or at least one week after the stroke. Diabetes mellitus was defined as known diabetes treated either with diet and/or medication, or fasting serum glucose higher than $6 \mathrm{mmol} / 1$ measured on at least two separate occasions; ischemic heart disease was defined as a history of angina pectoris, myocardial infarction or coronary bypass operation.

Age, sex, Rankin score, infarction size on $\mathrm{Cr}$, the presence of hemorrhagic infarction on CT, and the presence of a homolateral obstructive carotid lesion, were fed into a logistic regression model for the measurement of independent association of these variables with a cardioembolic cause of stroke. For the analysis, age was considered in three categories of approximately equall size: younger than $70(n=87), 70-80(n=70)$, or over 80 years $(n=61)$. Statistical analysis was performed using BMDP statistical software package. We also compared different features between the cardioernbolic and thromboembolic infarction group, and possible association between different variables, by means of odds ratio (OR) with a $95 \%$ confidence interval (CI). 


\section{RESULTS}

During the study 373 patients were entered. One-hundred-forty-three patients had lacunar, 12 miscellaneous, 137 atherothrombotic, and 81 a cardioembolic stroke cause. Thus, 218 patients (cardioembolic plus atherothrombotic stroke patients) entered the ultimate study. Two-hundred-seven patients had CT, 116 were seen by a cardiologist, 62 had cardiac echo, and 37 al 24-hours ECG. Overall 64\% (139 patients) had non-invasive carotid studies done whereas in five more patients angiographical findings were available (2\%); 22 per cent had continuous wave Doppler, 75 per cent had either multigated pulse Doppler or Duplex study. Mean age in the thromboembolic group was 69.8 (SD 12.7) years, and in the cardioembolic group 73.9 (SD 10.1) years. The male/female ratio was 0.65 in the thromboembolic, and 1.63 in the cardioembolic group (OR: $0.40 ; 95 \%$ CI: $0.22-0.72 ; p=0.01$ ). Potential cardioembolic causes of stroke were: persistent or paroxysmal atrial fibrillation: 68 ( 2 had mitral stenosis, 1 recent myocardial infarction, 1 cardiomyopathy); recent myocardial infarction: 6 ( 1 had cardiomyopathy); valve disease or prosthesis: 3; cardiomyopathy: 2; endocarditis: 1; ventricle septal defect: 1; seven patients had two features. Table 1 compares the numbers of patients with the different features between the two different stroke subgroups. Female gender, a history of ischemic heart disease, severe early deficit indicated by a Rankin score of 5 , and large infarction on CT were significantly more frequent in the cardioembolic stroke group, whereas the frequency of significant ipsilateral internal carotid artery obstruction was significantly lower. Table 2 a shows the logistic regression odds ratios with $95 \% \mathrm{CI}$ as parameter for the association of several diagnostic variables with cardioem-

TABLE 1: Number of different features in 81 patients with cardioembolic, and in 137 with atherothrombotic stroke. Missing numbers are indicated. Percentages between brackets. $\mathrm{COR}=$ crude odds ratio. $\mathrm{Cl}=$ confidence interval. $\mathrm{COR}>1$ : more often in the cardioembolic: group.

\begin{tabular}{|c|c|c|c|c|c|}
\hline & \multicolumn{2}{|c|}{ cardioembolic (81) } & \multicolumn{2}{|c|}{ atherothrombotic (137) } & \multirow[b]{2}{*}{$\operatorname{COR}(95 \% \mathrm{CI})$} \\
\hline & $\mathrm{N}$ & missing & $N$ & missing & \\
\hline female & $49(60)$ & 0 & $52(38)$ & 0 & $2.50(1.42-4.40)$ \\
\hline hypertension & $28(35)$ & 0 & $59(43)$ & 0 & $0.70(0.37-1.33)$ \\
\hline diabetes mellitus & $10(12)$ & 0 & $23(17)$ & 0 & $0.70(0.25-1.94)$ \\
\hline ischemic heart disease & $30(37)$ & 0 & $27(20)$ & 0 & $2.40(1.26-4.57)$ \\
\hline Rankin 5 & $43(53)$ & 0 & $50(37)$ & 0 & $2.02(1.12-3.65)$ \\
\hline large infarction on $C T$ & $22(29)$ & $4^{1)}$ & $20(15)$ & $71)$ & $2.20(1.05-4.54)$ \\
\hline hemorrhagic infarction & $7(9)$ & $4^{1)}$ & $13(10)$ & $7^{1)}$ & $0.90(0-12.7)$ \\
\hline caratid obstruction & $3(8)$ & $43^{2)}$ & $43(32)$ & $31^{2)}$ & $0.11(0.03-0.42)$ \\
\hline
\end{tabular}

1) no CT performed;2) no carotid ultrasound performed 
TABLE 2. Logistic regression odds ratios with $95 \%$ confidence interval as parameters for the association of several diagnostic variables with cardioembolic versus atherothrombotic infarction: results of non-invasive carotid test included $(2 \mathrm{a})$ or excluded (table $2 \mathrm{~b}$ ). OR $>1=$ more strongly associated with cardioembolic stroke cause. $95 \% \mathrm{CI}$ not including $1.00=$ statistically significant difference.

TABLE 2a

\begin{tabular}{lll}
\hline & OR & $95 \% \mathrm{CI}$ \\
\hline age* 70-80 years & 0.89 & $0.39-1.99$ \\
$\quad>$ 80 years & 1.16 & $0.46-2.94$ \\
female gender & 1.96 & $0.96-4.04$ \\
hypertension & 0.96 & $0.47-1.95$ \\
diabetes mellitus & 0.30 & $0.10-0.87$ \\
ischemic heart disease & 2.34 & $1.09-5.01$ \\
Rankin 5 & 1.28 & $0.62-2.66$ \\
large infarction on CT & 2.43 & $0.73-8.11$ \\
hemorrhagic infarction & 0.58 & $0.17-2.02$ \\
carotid obstruction & 0.12 & $0.03-0.46$ \\
\hline
\end{tabular}

TABLE $2 b$

\begin{tabular}{lll}
\hline & OR & $95 \% \mathrm{CI}$ \\
\hline age* 70-80 years & 1.28 & $0.61-2.67$ \\
$\quad>80$ years & 1.78 & $0.79-4.04$ \\
female gender & 2.53 & $1.30-4.92$ \\
hypertension & 0.79 & $0.41-1.53$ \\
diabetes mellitus & 0.39 & $0.15-1.04$ \\
ischemic heart disease & 2.18 & $1.07-4.47$ \\
Rankin 5 & 1.32 & $0.67-2.60$ \\
large infarction on CT & 2.28 & $0.76-6.87$ \\
hennorrhagic infarction & 0.52 & $0.16-1.67$ \\
\hline
\end{tabular}

* as compared with age group $<70$ years

bolic versus atherothrombotic brain infarction. The presence of diabetes mellitus predicted atherothrombotic stroke, whereas a history of ischemic heart disease was more than two times more likely to be associated with cardioembolic stroke. Severe early disability (a Rankin score of 5), large infarction size on CT, or hemorrhagic infarction on CT did not appear to be predictors of cardioembolic stroke cause. The absence of significant ipsilateral carotid disease was highly predictive of a cardioembolic cause. From an analysis leaving the carotid lesion data out (Table 2b), female sex, and ischemic heart disease 
(statistically significant) appeared to independently predict a cardioembolic stroke mechanism.

\section{DISCUSSION}

We found a history of ischemic heart disease to be an independent predictor of a potential cardioembolic stroke cause, whereas diabetes mellitus and especially significant ipsilateral internal carotid artery disease were negative predictors of such stroke cause. Because non-invasive carotid testing was not always available or performed early following the stroke, we performed a separate analysis leaving this item out. From that analysis female sex, and a history of ischemic heart disease were found to be associated with cardioembolic stroke cause. Patients without carotid ultrasound in our study were older and more severely handicapped than those subjected to such tests, and therefore they may have had a higher chance of having carotid stenosis, biasing the number of patients with carotid obstruction towards the lower end in the cardioembolic stroke group. However, the same is true for the atherothrombotic group, although the number of patients without ultrasound was lower in the latter group. In contrast with others $11,14-16,22,25$, we did not find hemorrhagic infarction, large infarction size on CT, or severe initial handicap to be predictors of cardioembolism. Hemorrhagic infarction on repeated CT-scanning might argue in favour of cardioembolism ${ }^{14,22}$, but, when eventually found, would not influence early management. The high frequency of hemorrhagic infarction found in autopsy studies may merely reflect the association between a hemorrhagic component and large infarction size, not thereby reflecting the situation in patients surviving their stroke. ${ }^{20}$ The absence of an association between major deficit, large infarction size or hemorrhagic infarction on $\mathrm{CT}$, and cardioembolic stroke cause in our study which is in contrast to the results of others, may also have been influenced by our exclusion of patients with vertebrobasilar or lacunar infarctions. Lacunar infarctions are not likely to result from cardioembolism, whereas they are generally not only milder but virtually always lack a hemorrhagic component $3,8,19$ Vertebrobasilar stroke is also less likely to result from cardioembolism ${ }^{3}$, whereas hemorrhagic infarction in this area is probably very infrequent. The differences concerning some clinical and CT features between stroke patients with and those without a cardiac source of embolism in the study of Bogousslavsky et $\mathrm{al}^{2}$ are possibly due to the inclusion of vertebrobasilar and lacunar infarction patients. Caplan et al ${ }^{11}$, excluding lacunar infarctions, found early hemorrhagic infarction to be rare. They also found no differences with regard to severe deficit between patients with or without a cardiac source of embolism, and like us, found a history of ischemic heart disease to be associated with cardiogenic embolism. Bogousslavsky ${ }^{7}$ and Ramirez-Lassepas ${ }^{23}$ found no clinical symptoms that reliably differentiated between patients with and those without a potential cardiac source of em- 
bolism in respectively 205 patients with carotid TLA's who underwent angiography, and 193 patients with brain infarction. Using logistic regression analysis D'Olhaberriage et $\mathrm{al}^{12}$ found the duration of prior TLA and stroke onset during activity to be independent predictors of a cardioembolic stroke mechanism. However, such a mechanism was defined as atrial fibrillation in the absence of demonstrable significant carotid disease. As such, the independent variables D'Olhaberriage et al identified may merely have been predicting the absence of carotid lesions in stroke patients with atrial fibrillation. Besides this, the reliability of anamnestic features such as the duration of possible TIA in the past, may be low in patients with severe deficit. Timsit et $\mathrm{al}^{26}$ found in comparing 246 cardioembolic large-vessel atherosclerotic brain infarctions from the Stroke Data Bank, fractional arm weakness to be an independent predictor of atherosclerotic stroke cause, and reduced consciousness an independent predictor of cardioembolic stroke source. However, the study excluded patients with a potential cardioembolic source who had normal CT, and a presumably large group of atherosclerotic infarction patients who did not have a carotid stenosis $80 \%$. Therefore, the results do not apply to unselected brain infarction patients. Moreover, lacunar infarctions were not excluded. Nevertheless, the results of Timsit et al suggest that the presence of a high-grade carotid stenosis strongly predicts atherothrombotic rather than cardioembolic stroke cause. This is in line with our study in which the odds favouring cardiogenic embolism were eight times higher than those favouring atherothrombotic cause in the absence of an ipsilateral carotid stenosis. Kittner et al ${ }^{17}$ found that the presence of cortical signs, and a diminished level of consciousness were predictive of cardioembolic stroke. Their findings may, however, be explained by the fact that their series contained lacunar infarctions in which both a cardioembolic stroke cause and cortical symptoms are infrequent, as they indicated.

When discussing features predicting cardioembolic stroke cause, it should be stressed that even in the presence of a potential cardiac source of embolism differentiation from atherothrombotic cause remains a matter of estimating chances. Certain clinical features and findings from ancillary investigations may lower or increase the chance of either mechanism, but will not allow for full certainty in individual patients. Even pathological studies cannot fully' solve the problem. A part from the fact that such studies are scarce, ${ }^{5}$, the results may not be fully extrapolated to patients who survive their stroke. Pathological differentiation between thrombus and embolus cannot always be made reliably, whereas if embolism is diagnosed, its origin is not always clear. One: could question the need to predict a potential cardiac source of embolism in stroke patients. In many such patients the potential stroke cause may be evident from the start, either because the patient is known to have cardiac disease, or a cardiac source of embolism is found on admission or detected by additional cardiac testing. Some cardiac tests, however, such as 24 hour -ECG 
monitoring can only be performed and interpreted with a certain delay, whereas other tests, such as cardiac echo, cannot always be arranged immediately following hospital admission. If, for specific management options, or for randonnization in early treatment trials, early recognition of a cardioembolic stroke mechanism is mandatory, it could be relevant to identify such a stroke mechanism, or at least increase its likelihood by independent predictors. We found a history of ischemic heart disease and the absence of homolateral carotid obstruction to be such predictors. The absence of carotid obstructive disease does not exclusively favour cardioembolism, but also lacunar infarction, which, however, can be separated reliably by clinical signs. 3,8 However, it seems more rational to prompt ancillary cardiac investigations early in patients who might potentially benefit from specific cardiac and stroke management options, rather than waste time performing carotid ultrasound studies. On the other hand, normal carotid ultrasound should raise the suspicion of a cardioembolic cause of stroke if the patient does not present with a lacunar syndrome. 


\section{REFERENCES}

1. Allen CMC: Clinical diagnosis of the acute stroke syndrome. QJ Med 1983;208:515-523.

2. Bamford J, Sandercock P, Dennis M, Burn J, Warlow C: Classicifation and natural history of clinically identifiable subtypes of cerebral infarction. Lancet 1991;337:1521-1526.

3. Bamford J, Sandercock P, Jones L, Warlow C: The natural history of lacunar infarction: The Oxfordshire Community Stroke Project. Stroke 1987;18:545-551.

4. Bamford J.M. Sandercock PAG, Warlow CP, Slattery J: Interobserver agreement for the assessment of handicap in stroke patients. Stroke 1989;20:828.

5. Blackwood W, Hallpike JF, Kocen RS; Mair WGP: Atheromatous clisease of the carotid system and embolism from the heart in cerebral infarction: morbid anatomical study. Brain 1969;92:897-910.

6. Bogousslavsky J, Cachin C, Regli F, Despland PA, van Melle G, Kappenberger L: Cardiac sources of embolism and cerebral infarction - clinical consequences and vascular concomitants: The Lausanne Stroke registry. Neurology' 1991,41:855-859.

7. Bogousslavsky J, Hachinsky VC, Boughner DR, Fox A.l, Viñuela F, Barnett HJM: Clinical predictors of cardiac and arterial lesions in carotid transient ischemic attacks. Arch Neurol 1986;43:229-233.

8. Boiten J, Lodder J: Lacunar infarcts. Pathogenesis and validity of the clinical syndromes. Stroke 1991;22:1374-1378.

9. Boiten J, Lodder J: Large subcortical infarcts are not lacunar. Acta Neurol Scand 1992, in press.

10. Caplan LR: Carotid artery disease. N Engl J Med 1986;315:886-888.

11. Caplan LR, Hier DB, D'Cruz I: Cerebral embolism in the Michael Reese Stroke Registry. Stroke 1983;14:530-536.

12. D’Olhaberriage L, Hernández-Vidal A, Molina L, Soler-Singla L, Marrugat J, Pons S, Moral A, Pou-Serradell A: A prospective study of atrial fibrillation and stroke. Stroke 1984;20:1648-1652.

13. Hatano S: Experience from a multicenter stroke register: a preliminary' report. Bull World Health Organ 1976;54:54:1-553.

14. Hornig CR, Dorndorf W, Agnoli AL: Hemorrhagic cerebral infarction - a prospective study. Strake 1986;17:179-185.

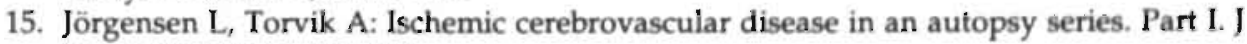
Neurol Sci 1966;3:490-509.

16. Jörgensen $\mathrm{L}$, Torvik A: Ischemic cerebrovascular disease in an autopsy series. Part II. J Neurol Sci 1969;9:285-320.

17. Kitmer SJ, Sharkness CM, Sloain MA, Price Tr, Dambrosia JM, Tuhrim S, Wolf PA, Mohr JP, Hier DB, Caplan LR: Infarcts with a carciliac source of embolism in the NINDS Stroke Datal Bank: neurologic examination. Neurology' 1992;42:299-302.

18. Krijne B, Lodder J: Computertomogra phische Merkmale von Morphologisch gesicherten Hämorrhagischen Hirninfarkten. Der Nervenarzt 1992, in press.

19. Lodder J, Bamford JM, Sandercock PAG, Jones LN', Warlow CP: Are hyperiension or cardiac embolism likely causes of lacunar infarction? Stroke 1990;21:375-381.

20. Lodder I, Krijne-Kubat B, Broekman J: Cerebral hemorrhagic infarction at: autopsy: cardiac embolic course and the cause of death. Stroke 1986;17:626-629.

21. Morris JA, Gardner MJ: Calculating confidence intervals for relative risks (odds ratios) and standardized ratios and rates. Br Med J 1988,296:1313-1316.

22. Ott BR, Zamani A, Kleefield J, Funkenstein HH: The clinical spectrum of hemorrhagic infarction. Stroke 1986;17:630-637.

23. Ramirez-Lassepas M, Cipolle RJ, Bjork RJ, Kowitz J, Snyder BD, Weber JC, Stein SD: Can embolic stroke be diagnosed on the basis of neurologic clinical criteria? Arch Neurol 1987;44:87-89: 
24. Sandercock P: The odds ratio: a useful tool in neurosciences. J Neurol Neurosurg Psych 1989:52:817-820.

25. Sherman DG, Goldman L, Whiting RB, Jurgensen K, Kaste M, Easton JD: Thromboembolism in patients with atrial fibrillation. Arch Neurol 1984;41:708-710.

26. Timsit SG, Sacco RL, Mohr JP, Foulkes MA, Tatemichi TK, Wolf PA, Price TR, Hier DB: Early clinical differentiation of cerebral infarction from severe atherosclerotic stenosis and cardioembolism. Stroke 1992;23:486-491.

27. Weiller C, Ringelstein EB, Reiche W, Thron A, Buell U: The large striatocapsular infarct; a clinical and pathophysiological entity. Arch Neurol 1990;47:1085-1091. 


\section{CT features of autopsy confirmed hemorrhagic infarction}

Adapted from." Computertomographische Merkmale von morphoiogisch gesicherten hämorrhagischen Hirninfarkten.

B. Krijne-Kubat, J. Lodder. Der Nervenartz 1992, in press. 
Early' anticoagulation is often considered in patients with cardioembolic brain infarction in order to prevent recurrences. ${ }^{5} \mathrm{~A}$ certain number of these patients develop hemorrhagic transformation of the infarction on CT.4,7,9,11 Such hemorrhagic transformation is considered dangerous should anticoagulants be started. ${ }^{6}$ Sometimes CT does not allow for a reliable distinction between hemorrhagic infarction and a small, primary intracerebral hematoma. Differentiation between these two is important because anticoagulation can be delayed until the hemorrhagic component of the infarction has disappeared, but it is strongly and completely contra-indicated in cases with primary intracerebral bleeding. Therefore, it would be desirable to be able to differentiate between hemorrhagic infarction and primary cerebral bleeding, using CT-features. Hemorrhagic infarction during life is mainly a radiological diagnosis based on CT features that, however, have hardly been validated. We therefore studied whether currently used CT features of hemorrhagic infarction could be ascertained by autopsy findings.

\section{MATERIAL AND METHODS}

In six hospitals we looked at pathology reports, patient files, and radiology reports over a period of approximately seven years. We collected 19 cases who had suffered a cerebral infarction, had undergone CT showing presumed hemorrhagic infarction, had died within two weeks after stroke onset, had been autopsied and were found to have hemorrhagic infarction on both macroscopical and microscopical pathological examination. We noted: age, sex, the degree of initial neurological deficit as either minor, moderate, or severe; use of anticoagulants; the presence of a potential cause of cardioembolism (as defined in Chapter 7); and whether death was caused by coning. The number of days between stroke onset, performance of $\mathrm{CT}$, and death were also noted. From CT the vascular territory involved was noted as well as the location of the hemorrhagic components, being either mainly cortical or mainly subcortical. The number of hemorrhages in each case was counted. The appearance of the hemorrhages on CT were classified as "dense": small, rounded, uniformally hyperdense areas; "slitlike": rather long and narrow, straightly arranged hyperdensity; "guirlande": same as the previous one but curvilinear; "mottled": small, hyperdense areas of irregular shape and size. The volume of hyperdensities and the total infarction volume were estimated by multiplying width and length at straight angles, multiplied by the number of consecutive CT-slices and slice thickness. Thus, the percentage of hyperdensity volume compared to the whole infarction volume was estimated. For comparison we also looked at cases that had died following a small intracerebral hematoma. However, we did not find any such cases presumably because small hematomas rarely result in death. 


\section{RESULTS}

There were fourteen males and five females aged 70 (49-85) year (median with range). Seventeen had major, and two had moderate deficit at stroke onset. Median (with range) number of days between stroke onset and CT was: 2 (0-8), between stroke onset and death: 5 (1-14), and between CT and death: 1 (1-11). One patient had been anticoagulated. Eight cases had a potential cardiac source of embolism. The infarction was in the medial cerebral artery territory in all but one case, in which it was in the anterior cerebral artery territory. Sixteen patients died from coning. All cases had macroscopical and microscopical pathological investigations showing hemorrhagic infarction. The hemorrhages on CT were located mostly in the cortical area in twelve (fig. 1,2 ), mostly subcortically in three (fig. 3,4,5), whereas four had cortical as well as subcortical hemorrhages. Four cases had one single hemorrhage, whereas in fifteen cases hemorrhages were multiple with a median number of 4 (range: 2-10). Small, dense hemorrhages on CT were observed in six cases, slitlike ones in two, guirlande-like ones in four, whereas in two cases hemorrhages had a mottled aspect (fig. 6). In five cases the hemorrhages showed a combination of these different aspects. Two of the dense, single hemorrhagic infarctions had been radiologically diagnosed as primary hematomas. The median estimated percentage of hyperdensity volume on CT compared to the whole infarction volume was four per cent, range: $0,5-23$ per cent.

\section{DISCUSSION}

Radiological diagnosis of hemorrhagic infarction is clinically important for two reasons: firstly, hemorrhagic infarction is often considered as a sign of cardiogenic embolism, although the differentiation between cardiogenic and artery-to-artery embolism cannot be made with CT alone (Chapters 2,3), 6 Secondly, depending on timing and frequency of CT-scanning, hemorrhagic infarction is detected in stroke patients with a potential cause of embolism in up to 43 per cent. ${ }^{7}$ Patients with a cardioembolic cause of stroke are often considered eligible for anticoagulant treatment 5,12 but the development of hemorrhagic infarction is considered dangerous should such treatment be started. 6 The risk of early bleeding can be minimized by excluding patients with certain CT and clinical features (Chapter 7$){ }^{8}$ However, sometimes CT does not allow for distinction between al small primary intracerebral hemorrhage and hemorrhagic infarction, especially if the hemorrhages are located in the brain cortex as e.g. in amyloid angiopathy. ${ }^{2}$ The presence of a potential cardioembolic source does not exclude primary hemorrhage, because approximately ten per cent of patients who suffer a primary intracerebral hematoma may have non-rheumatic atrial fibrillation. ${ }^{10}$ Patients with hemorrhagic infarction could receive anticoagulant treatment as soon as the hemorrhagic component has disappeared, whereas the treatment is strongly contraindicated in patients with a primary intracerebral hematoma. In this study we 

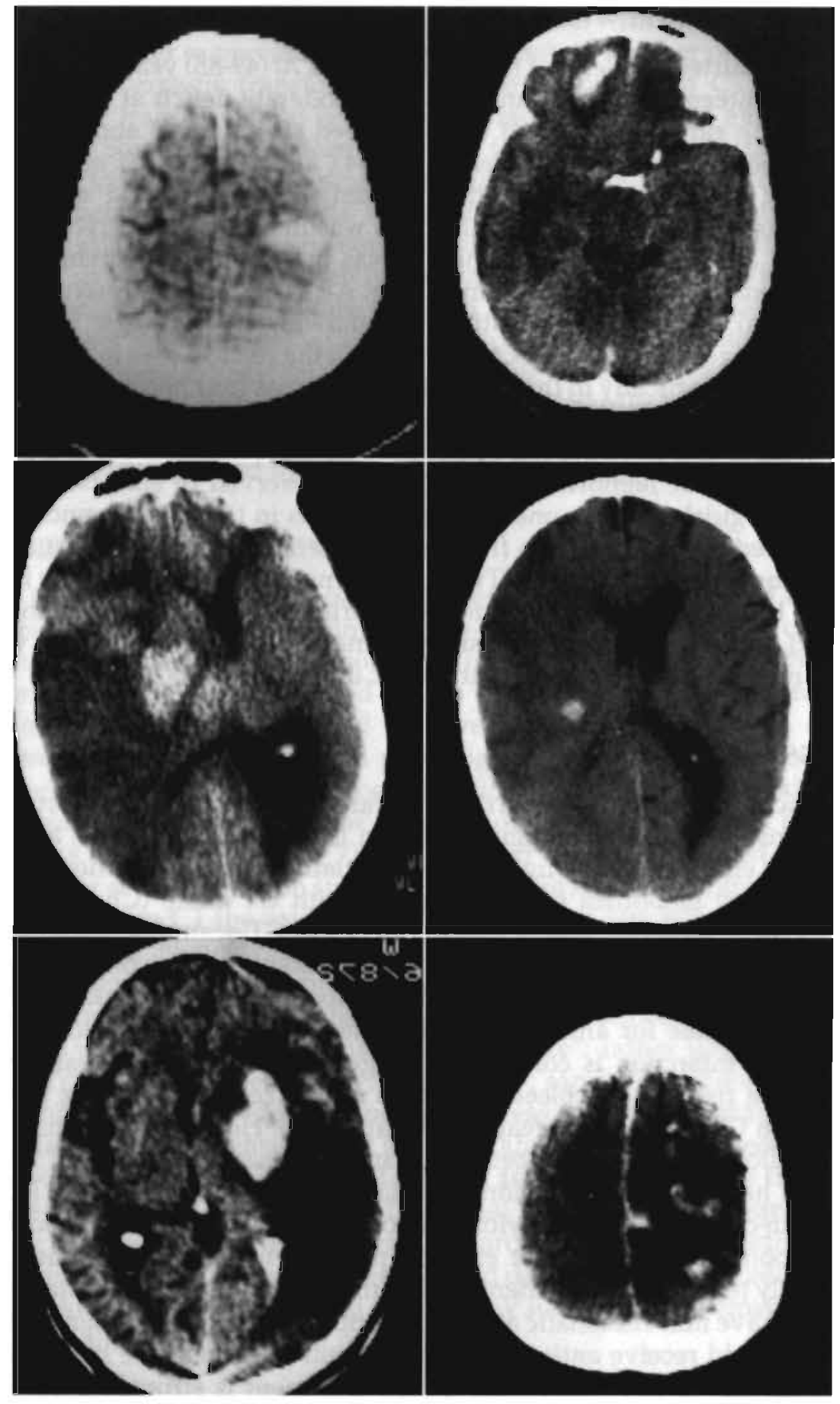
FIGURE 1. Parietal, small, dense, mainly cortical hyperdensity in hemorrhagic infarction.

FIGURE 3. Larger, deep, hyperdensity within a hypodense area compatible with infarction in the middle and anterior cerebral artery territory.

FIGURE 5. Larger, deep hyperdensity in medial cerebral artery territory infarction. Note the presence of blood in the posterior horn of the ventricle.
FIGURE 2. Frontal, cortical/sub-cortical hyperdensity representing hemorrhagic infarction.

FIGURE 4. Smail, dense, deep hyperdensity. Signs of edema indicate large infarction in the right hemisphere.

FIGURE 6. Multiple, "mottled" hyperdensities in medial cerebral artery territory infarction.

aimed, in the first place, to characterize some CT features of hemorrhagic infarction in comparison with small primary intracerebral hematoma, using autopsy findings as the golden standard. However, cases who had died from small hemorrhages could not be found. Therefore, we had to suffice with hemorrhagic infarction cases. Our data show that the currently assumed CT features of hemorrhagic infarction, which are mainly cortically located curvilinear, slitlike, and small mottled hyperdensities, indeed represent secondary hemorrhages within infarcted areas. In our cases these hyperdensities comprised only a small percentage of the total estimated infarction volume. In a few cases larger, dense hyperdensities on CT could be mistakingly taken for small hemorrhages especially when blood collections are found within the ventricle system. If hyperdensities lie within a hypodense areal compatible with a vascular territory of a major cerebral artery or one of its branches, they are more likely to represent hemorrhagic infarction. If on early CT the infarction boundaries are ill-defined and cannot be differentiated from edema surrounding a possible small bleeding, $\mathrm{CT}$ could be repeated after approximately two weeks, when infarction boundaries appear more distinct. If doubt remains, CT after one or two months will either show a vascular territory hypodensity in most cases of infarction, or a more ill-defined, slitlike hypodense scar as a sign of sustained primary intracerebral hematoma. ${ }^{3}$

As our data indicate, deep location of a hyperdensity does not rule out hemorrhagic infarction. Deeply located hemorrhage in cases with hemorrhagic infarction is probably confined to large, mainly cardioembolic brain infarctions. 6

The number of patients in whom the differentiation between hemorrhagic infarction and primary intracerebral hematoma is a problem, is probably low. However, the risk of hemorrhagic complications should by all means be kept as low as possible in all the cardioembolic stroke patients that are considered for anticoagulant treatment, whether in or out of clinical trials. Correct radiological diagnosis is crucial in this respect. 


\section{REFERENCES}

1. Cerebral Embolism Study Group. Immediate anticoagulation of embolic stroke: brain hemorrhage and management options. Stroke 1984;15:779-789.

2. Cosgrove GR, Leblanc R, Meagher-Villemure K, Ethier R. Cerebral amyloid angiopathy. Neurology 1985;35:625-631.

3. Franke CL, Van Swieten JC, Van Gijn J. Residual lesions on computed tomography after intracerebral hemorrhage. Stroke 1991;22:1530-1533

4. Hakim AM, Ryder-Cooke A, Melanson D. Sequential computerized tomographic appearance of strokes. Stroke 1983;14:893-897.

5. Hart RG. Prevention and treatment of cardioembolic stroke. In: The heart and stroke, chapter 7, p. 117. Edited by A.J. Furlan. New York, Spinger Verlag 1987.

6. Hart RG, Easton JD. Hemorrhagic infarcts. Stroke 1986;17:586-589.

7. Hornig CR, Dorndorf W, Agnoli AL. Hemorrhagic cerebral infarction. A prospective study. Stroke 1986;17:179-185.

8. Lodder J, Van der Lugt PJM. Evaluation of the risk of immediate anticoagulant treatment in patients with embolic stroke of cardiac origin. Stroke 1983;14:42-46.

9. Lodder J. CT-detected hemorrhagic infarction; relation with the size of the infarct and the presence of midline shift. Acta Neurol Scand 1984;70:329-335.

10. Merwijk van G, Lodder J, Bamford J, Kester ADM. How often is non-valvular atrial fibrillation the cause of brain infarction? J. Neurol 1990;237:205-207.

11. Ott BR, Zamani A, Kleefield J, Funkenstein $\mathrm{HH}$. The clinical spectrum of hemorrhagic infarction. Stroke 1986;17:630-637.

12. Stroke Prevention in Atrial Fibrillation Study. Final Results. Circulation 1991;84:527-539. 


\section{Timing of autopsy-confirmed hemorrhagic infarction with reference to presumed cardioembolic stroke}

Adapted from: Timing of autopsy-confirmed hemorrhagic infarction with reference to carioembolic stroke.

J. Lodder, B. Krijne-Kubat and P.J.M. van der Lugt.

Siroke 1988;19:1482-1484 
Studies on the value of anticoagulant treatment of patients with cardioembolic stroke have revived interest in the occurrence and mechanism of hemorrhagic infarction ( $\mathrm{HI}), 1,8,9,17$ The relationship between the occurrence of $\mathrm{HI}$ and the size of the infarction, as well as the implications for predicting cardioembolic etiology of stroke are discussed more extensively in Chapter 2 and 3. Anticoagulation during hemorrhagic transformation of an infarction may worsen the eventual clinical outcome. 8 The incidence of $\mathrm{HI}$ on computed tomography (CT) performed shortly after a cardioembolic stroke is approximately $5 \%$ (Chapter 3 ). This percentage increases to $25 \% 6,10,11$ or even $43 \% 9$, when serial CT scanning is performed. With regard to early anticoagulation, it is important to consider the timing of hemorrhagic transformation in the early phase following the onset of stroke. There is only one study addressing this issue by means of early CT-scanning at different intervals after stroke to detect $\mathrm{HI}^{3}$ Therefore, we studied the timing of hemorrhagic transformation in autopsied patients who had undergone CT during life.

\section{PATIENTS AND METHODS}

We studied the neuropathological reports of patients dying within 15 days after a CT-confirmed supra-tentorial brain infarction. On patholugical examination $\mathrm{HI}$ was diagnosed in the presence of a (partial) hemorrhagic infarction on macroscopical inspection, confirmed by a microscopical examination. Cases with HI were included only when large, confluent hemorrhages that would not have gone undetected by $C T$ were present. Infarction size was classified as "large" when an infarction involved most of the area supplied by one of the three main cerebral arteries, as "moderate" when it was restricted to a medium-sized branch division, and as "small" when it was confined to a smaller branch area. The cause of death was considered cerebral following brain herniation and as noncerebral following other causes. Patient records were reviewed for age, sex, and number of days between stroke, CT, and death. A cardicembolic cause of stroke was diagnosed in the presence of rheumatic heart disease, paroxysmal or persistent atrial fibrillation, myocardial infarction in the preceding two weeks, or mitral valve stenosis or prosthesis. Initial neurologic deficit was categorized according to Pessin et al 18 , with a slight modification ${ }^{15}$, as mild, moderate, or severe. (T was studied with special reference to the presence of HI. Because the number of cases fulfilling all our criteria (i.e., dying within 15 days after a supratentorial brain infarction, CT as well as eventual autopsy performed, significant $\mathrm{HI}$ on pathological examination) was very small in Maastricht University Hospital alone, we collected data from five other major Dutch hospitals as well. 


\section{RESULTS}

Data are expressed as median (range). Thirty-four cases (13 men, 21 women; age 70 (75-86) years) with confluent hemorrhages in an infarcted area were identified. The interval from stroke until death was 5 (1-15) days, from stroke until CT 2 (0-8) days, and from CT until death 2 (1-11) days.

Two patients, without a cardioembolic cause, were receiving anticoagulant treatment at the time of the stroke. In one patient, warfarin treatment with a thrombo-test percentage within the therapeutic range was antagonized at stroke onset; CT on day 3 was without HI. The other patient had been receiving heparin treatment because of suspected pulmonary embolus, without the activated partial thromboplastin time being therapeutically prolonged at the time of stroke, when the treatment was antagonized; CT on day 2 showed HI. Warfarin treatment with a thrombotest percentage within the therapeutic range in two patients with cardioembolic stroke was immediately discontinued on admission. Because $C T$ on days 4 and 6 respectively, in these two patients showed no HI, we considered the ultimate occurrence of $\mathrm{HI}$ not to be caused by the previous anticoagulation. All the other patients had no anticoagulation treatment.

Initial neurological deficit was severe in all but one patient, who had a moderate deficit. Considering both clinical and autopsy data, 25 patients died of brain herniation while eight of the other nine died of cardiac causes (3), pneumonia (2), pulmonary embolism (1), septic shock (1), or mesenteric artery embolism (1); in one case the exact cause of death could not be identified. Thirty-three cases had large infarctions, one had a moderate-sized infarction at autopsy. All infarctions were located in the middle cerebral artery territory. In eight cases the anterior and/or posterior cerebral artery territory was involved as well, while five had bilateral middle cerebral artery infarctions.

Twenty-one cases had a potential cardioembolic source for their stroke; seven of the 21 had HI on CT. Figure 1 shows the number of CT scans with HI in relation to the interval from stroke onset to $C T$ for all 34 cases. In the 21 cases with cardioembolism, Figure 2 shows the interval during which $\mathrm{HI}$ developed (from stroke or negative CT until positive CT or autopsy).

\section{DISCUSSION}

Particularly large cerebral infarctions are considered prone to hemorrhagic transformation (Chapter 4) $8,13,17,21$ Although the question which subgroup of cardioembolic stroke patients would benefit from anticoagulant treatment is not answered $5,7,14,16,19,20,22$, such treatment is often considered in an attempt to lower the recurrence rate, especially in the early phase following stroke onset. 2,4 Hemorrhagic transformation during anticoagulant treatment: may worsen the eventual clinical outcome. ${ }^{8}$ Therefore, it is important to know whether CT can detect $\mathrm{HI}$ reliably, and how hemorrhagic transformation. 


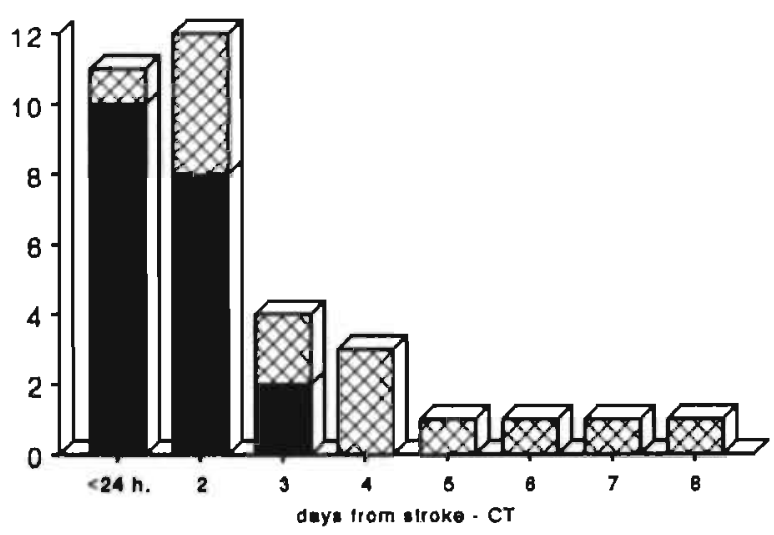

FIGURE 1. Hemorrhagic infarction (black bars) on computed tomograms $(\mathrm{C} T$ ) related to interval from stroke to $\mathrm{CT}$ in 34 stroke patients with hemorrhagic infarction at autopsy within 15 days after the onset of stroke. Shaded bars, no evidence of hemorrhagic infarction on CT.

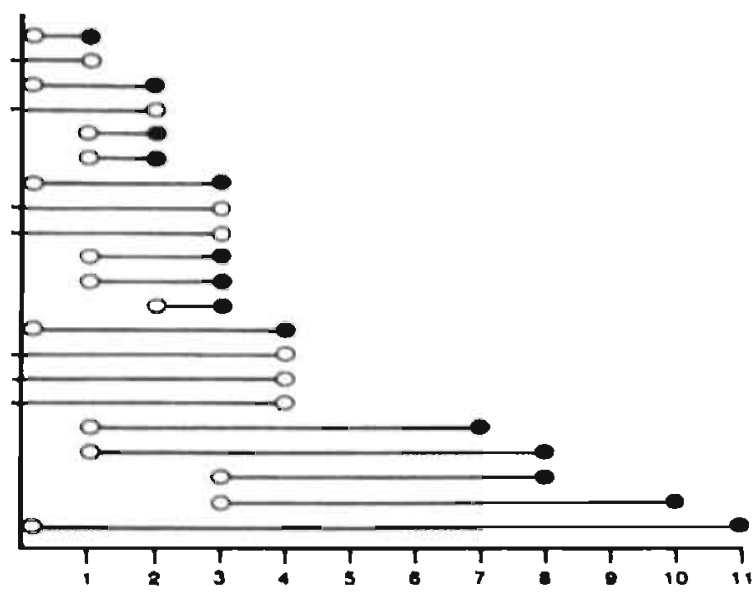

FIGURE 2. Interval during which hemorrhagic transformation developed in 21 patients with cardioembolic stroke. Beginning of interval is marked by stroke onset (day 0) or negative computed tomogram (CT scan) (O) and end by positive $\mathrm{CT}$ scan $(\mathrm{O})$ or autopsy (O). 
develops over time. Ideally, given the dynamic nature of $\mathrm{HI}$, to answer the first question postmortem CT should be compared with autopsy findings, but this option hardly seems feasible. Therefore, although there are no studies available comparing CT and autopsy findings of $\mathrm{HI}$, it was not our primary aim to relate CT and autopsy data in this study. This question was addressed in Chapter 5. As to the second question, the only available study with serial early CT's found $\mathrm{HI}$ in 18 of 27 (67\%, 95\% confidence interval (CI) $36-97 \%)$ CT scans performed within 48 hours after stroke onset in 27 non-anticoagulated cardioembolic stroke patients with eventual HI on CT, whereas 20 of 27 scans (74\%, 95\% CI $41-100 \%)$ showed $\mathrm{HI}$ within four days. ${ }^{3}$ Chapter 5 showed that, based on the same morphological criteria as in this study, autopsy proven hemorrhagic infarction was visualized on all CT's. All cases in this study had eventually autopsy-proven $\mathrm{HI}$ to such a degree that its presence would have been unlikely to have gone undetected by $\mathrm{CT}$; this allowed us to conclude that in the instance of a negative CT scan there was indeed no significant $\mathrm{HI}$ at that time, thus enabling us to consider both $\mathrm{CT}$ and autopsy findings in relation to the timing of HI. We found six of 21 cases $(29 \%, 95 \% \mathrm{CI} 1-51 \%)$ within 48 hours, and 16 of 21 cases $(76 \%, 95 \% \mathrm{CI} 39-100 \%)$ with $\mathrm{HI}$ within four days after stroke. Both studies agree that if $\mathrm{HI}$ develops, it does so in approximately $75 \%$ of patients within the first four days after the onset of a cardioembolic stroke, irrespective of whether the patient survives the stroke or dies. When both studies are analyzed together, hemorrhagic transformation within four days occurred in 36 of 48 patients (75\%, 95\% CI 50-100\%); the lower limit of the $95 \%$ $\mathrm{Cl}$ indicates that at four days at least half of the patients have developed $\mathrm{HI}$. When anticoagulant treatment is being considered in patients with a presumed cardioembolic stroke, it may be judicious to postpone such treatment for at least four days, after which CT has effectively excluded HI in most patients. This may be particularly important in patients with large infarctions, who appear to be especially at risk. 8,10 However, cautious clinical monitoring of anticoagulated stroke patients remains necessary after this time limit as well, because in some patients hemorrhagic transformation is delayed substantially longer. 12 Nevertheless, the question remains whether patients anticoagulated even during the period in which hemorrhagic transformation often occurs, continue to have a high risk of cerebral bleeding complications. Chapter 7 addresses this question in more detail. 


\section{REFERENCES}

1. Albers GW, Sherman DG, Gress DR, Paulseth JE, Petersen P. Stroke prevention in nonvalvular atrial fibrillation: a review of prospective randomized trials. Ann Neurol 1991;30:511-518.

2. Cerebral Embolism Study Group. Immediate anticoagulation of embolic stroke: brain hemorrhage and management options. Stroke 1984;15:779-789.

3. Cerebral Embolism Study Group. Timing of hemorrhagic transformation of cardioembolic stroke. In: Stober T, Schimrigh K, Ganten D, et al. (eds.) Central Nervous System Control of the Heart. Martinus Nijhoff Publ. Boston. Chapter 20, 1986, pp 229-232.

4. Cerebral Embolism Task Force. Cardiogenic brain embolism; The second report. Arch Neurol 1989;46:727-743.

5. Gustafsson C, Britton M. Pathogenetic mechanism of stroke in non-valvular atrial fibrillation: follow-up of stroke patients with and without atrial fibrillation. J Int Med 1991;230:11-16.

6. Hakim AM, Ryder-Cooke A, Melanson D. Sequential computerized tomographic appearance of stroke. Stroke 1983;14:893-897.

7. Hart RG. Prevention and treatment of cardioembolic stroke. In: Furlan AJ (Ed.): The heart and stroke. New York, Springer Verlag, 1987, chapter 7, pp. 117-138.

8. Hart RG, Easton JD. Hemorrhagic infarcts. Stroke 1986;17:586-589.

9. Hornig CR, Dorndorf W, Agnoli AL. Hemorrhagic cerebral infarction. A prospective study. Stroke 1986;17:179-185.

10. Horowitz Sh, Zito JL, Donnaruma R, Patel M, Alvir J. Computed tomographic findings within the first five hours of cerebral infarction. Stroke 1991;22:1245-1253.

11. Kelley RE, Berger JR, Alter M, Kovacs AG. Cerebral ischemia and atrial fibrillation: prospective study. Neurology 1984;34:1285-1291.

12. Laureno R, Shields RW, Narayan T: The diagnosis and management of cerebral embolism and haemorrhagic infarction with sequential computerized cranial tomography. Brain 1987;110:93-105.

13. Lodder J. CT-detected hemorrhagic infarction; relation with the size of the infarct and the presence of midline shift. Acta Neurol Scan 1984;70:329-335.

14. Lodder J, Dennis MS, van Raak L, Jones LN, Warlow CP. Co-operative study on the value of long-term anticoagulation in stroke patients with non-rheumatic atrial fibrillation. BMJ 1988;296:1435-1438.

15. Lodder J, van der Lugt PJM. Evaluation of the risk of immediate anticoagulant treatment in patients with embolic stroke of cardiac origin. Stroke 1983;14:42-46.

16. Lui CY. Should patients with lone atrial fibrillation be treated with anticoagulant therapy. J Am Coll Cardiol 1991;18:301-302.

17. Ott BR, Zamani A, Kleefield J, Funkenstein $\mathrm{HH}$. The clinical spectrum of hemorrhagic infarction. Stroke 1986;17:630-637.

18. Pessin MS, Hinton RC, Davis KR, et al. Mechanisms of acute carotid stroke. Ann Neurol $1979 ; 6: 245-252$

19. Sherman DG, Hart RG, Easton JD. The secondary prevention of stroke in patients with atrial fibrillation. Arch Neurol 1986;43:68-70.

20. Starkey I, Warlow C. The secondary prevention of stroke in patients with atrial fibrillation. Arch Neurol 1986;43:66-68.

21. Wipf JE, Lipsjy BA. Atrial Fibrillation. Thromboembolic risk and indicators for anticoagulation. Arch Int Med 1990;150:1598-1603.

22. Yatsu FM, Hart RG, Mohr JP, Grotta JC: Anticoagulation of embolic strokes of cardiac origin: An update. Neurology 1988;38:314-316. 


\section{Low risk of early anticoagulation in stroke patients with non-rheumatic atrial fibrillation}

Adapted from: Low risk of early anticoagulation in stroke patients with non-rheumatic atrial fibrillation.

B. Krijne-Kubat, J. Lodder. Submitted The Clinical Investigator 1992. 
The risk of early stroke recurrences in patients with non-rheumatic atrial fibrillation (NRAF) is probably substantial when compared with stroke recurrences in patients with sinus rhythm. 4,7,11 Whether the benefits of long-term anticoagulation $(\mathrm{AC})$ outweigh the risks in these patients is currently being investigated in the European Atrial Fibrillation Trial, the EAFT. ${ }^{25}$ However, this trial will probably not clarify the question of the timing of early AC, or settle the question of $\mathrm{AC}$ for stroke patients with an overall handicap greater than Rankin score 3.21,24 Some clinicians may feel reluctant to start early AC in stroke patients with a presumed cardioembolic infarction whether in or out of trials, because some authors have suggested that this treatment, although possibly preventing early stroke recurrences, could lead to hemorrhagic transformation of the infarction with consequent neurological deterioration $8,12,19,23$ Others, however, collecting data from different studies, found such fears to be unjustified.1,2 Because of this ongoing uncertainty about the magnitude of the risk of early AC in stroke patients with NRAF, we evaluated the risk of this therapy in a prospectively registered series of consecutive stroke patients with NRAF, admitted during a period of two years.

\section{PATIENTS AND METHODS}

We registered prospectively all consecutive NRAF patients with a supratentorial brain infarction. Brain infarction was defined as an acute or fast progressing focal neurological deficit with symptoms lasting longer than 24 hours, and no other apparent cause than ischemia. All patients were examined by a neurologist and a cardiologist. Patients with cardiac complaints or abnormalities on routine cardiological examination had transthoracic 2-dimensional echocardiograms or 24-hours Holter monitoring as indicated. Cerebral CT scan was performed prior to anticoagulation. Neurological deficit was categorized as "mild", "moderate" or "severe", according to Pessin et al 20 , except that mere aphasia was regarded as "moderate" deficit. Infarction size was classified as "large" when an infarction involved most of the area supplied by one of the three major cerebral arteries, as "moderate" when it was restricted to the territory of a medium sized branch division, and "small" when it was confined to a smaller branch area. Hemorrhagic infarction was diagnosed when small areas of patchy, linear or curvilinear hypodensities were found within a larger hypodense area compatible with an arterial territory. Cerebral hemorrhage was diagnosed in the presence of a sharply demarcated, strongly hyperdense area with or without surrounding hypodensity not compatible with an arterial territory. ${ }^{14}$ Patients with decreased consciousness, a diastolic blood pressure higher than $105-1.10 \mathrm{~mm} \mathrm{Hg}$, and those with $\mathrm{HI}$, or with an infarction showing space-accupying effect on CT (such as shift of the midline structures, compression of ventricles, or flattened sulci) did not receive anticoagulation, unless these features disappeared. Furthermore, 
patients with a bleeding tendency, hepatic failure, alcoholism or prior spontaneous gastrointestinal or cerebral bleeding did not receive anticoagulation. Early AC was started with a bolus of 5,000 international units of heparin, followed by a continuous intravenous infusion of 20,000 to 25,000 inte:national units per day. We aimed to prolong the control activated prothrombin time 2.5 to 3 times. Heparin was discontinued when oral AC reached therapeutic levels of 5-10\% thrombotest, corresponding with 4.8-2.8 international normalized ratio. If a patient was on oral $\mathrm{AC}$ at the time of stroke, oral $\mathrm{AC}$ was continued provided there were no contraindications. All patients were attended daily and monitored carefully. CT scanning was always repeated when neurological deterioration occurred. Some patients had a repeated CT for reasons not related to this study. The early risk of AC was studied for three weeks following the stroke onset.

\section{RESULTS}

A total of 188 patients with NRAF and stroke were registered during the study period. Ninety-eight of the 188 patients were anticoagulated and entered the study. There were 48 males and 50 females, aged 70 (53-87) years median (range). Sixty-three patients received $\mathrm{AC}$ within 24 hours after stroke onset. In 35 patients AC was delayed for 2 (2-18) days median (range), because of: delayed discovery of NRAF by 24 -hours Holter monitoring in 8; signs of space occupying effect on early CT in 9; $\mathrm{HI}$ on initial CT in 4; delayed hospital admission in 4; initial elevated diastolic blood pressure in 5; inadequate oral $A C$ in 2; and no specific reason in three patients. Neurological deficit on admission was severe in 27 , moderate in 35 and minor in 36 patients. CT revealed 21 large, 29 medium-sized, and 18 small infarctions, whereas no specific abnormalities were found in 30 . Anticoagulation was discontinued in four patients after $1,3,4$, and 10 days respectively for the following reasons: $\mathrm{HI}$ on the follow-up CT: 2 ; non-cerebral hemorrhage: 1 ; no specific reason: 1 . CT showed HI in seven of the 38 patients who had repeated CT. The table shows the numbers with non-fatal or fatal deterioration, and the reasons for this. None of the 98 anticoagulated patients developed clinically apparent cerebral hematoma within the three weeks following stroke. Only one of the five survivors with $\mathrm{HI}$ on follow-up $\mathrm{CT}$ deteriorated, this patient received $\mathrm{AC}$ within 24 hours after stroke onset. An autopsy was performed in all seven patients who died during the follow-up period. Three patients died because of hemorrhagic complications, of which two were cerebral. One patient with $\mathrm{HI}$ at autopsy had been given AC for pulmonary embolism within 24 hours after stroke onset. AC would have been delayed in this patient because of lowered consciousness if the pulmonary embolism had not occurred. Beside these three, none of the seven autopsied cases showed hemorrhagic complications. 
TABLE. Three-week outcome in 98 non-rheumatic atrial fibrillation stroke patients selected for early anticoagulation

$A C+N R A F$

\section{Survivors}

cerebral hematoma

hemorrhagic transformation on $\mathrm{CT}$

minor extracranial hemorrhage

recurrent ischemic stroke

Deaths

hemorrhagic transformation

gastrointestinal hemorrhage

recurrent ischemic stroke

peripheral embolism

brain herniation

cardiac/pulmonary complications

\section{1}

5

1

1

NRAF $=$ Non-rheumatic atrial fibrillation

\section{DISCUSSION}

In the absence of the definite evaluation of early AC in NRAF patients with stroke we applied the current view that $A C$ would probably do more good than harm. This view was favoured by the Cerebral Embolism Study Group who presented data indicating a high early recurrent stroke rate in these patients. 4,7 Recently, Gustafsson and Britton presented evidence of a high early stroke recurrence rate in patients with NRAF as compared to those in sinus rhythm. ${ }^{11}$ The question of whether NRAF stroke patients benefit from long-term $\mathrm{AC}$ is currently being subjected to a large randomized trial, the EAFT ${ }^{25}$ It is, however, unlikely that a sufficient number of patients will be randomized early enough following stroke to resolve the problem of the timing of $\mathrm{AC}$, should this treatment be beneficial. Furthermore, the EAFT excludes patients whose handicap scores more than Rankin 3 . Therefore, the trial will not settle the question as to when to start $A C$ in patients with an overall handicap greater than Rankin 3, some of whom might be considered for AC treatment despite a more severe handicap.

In our study we investigated the risk of early AC in NRAF associated stroke patients, including some with major neurological deficit. We did not intend to evaluate the efficacy of this treatment and we did not anticoagulate our patients to improve their short-term outcome. We excluded those patients whom we considered to be at a high risk of cerebral bleeding. These were 
mainly older patients with decreased consciousness, very severe deficit, and a bad short-term outcome. Nevertheless, even after excluding these patients, the remaining group was also at substantial risk of developing cerebral hemorrhagic complications, considering that all of them had a potential cardiac source of embolism. Approximately one quarter had major deficit with a large infarction on CT, and $63 \%$ were fully anticoagulated within 24 hours following stroke onset.

These features have been discussed in the literature to carry an increased risk of hemorrhagic transformation of the ischemic infarction. $4,6,8,10,13,16,23$ No clinically apparent intracerebral hematoma occurred in our patients, whereas only one out of the five survivors with hemorrhagic transformation on repeated CT deteriorated. However, one patient died from gastrointestinal hemorrhage, and two patients died in association with henorrhagic transformation either due to or merely during $A C$ treatment. Thus in total four patients (4\%) experienced clinically significant bleeding events during $\mathrm{AC}$ therapy. Whether all these bleeding complications were indeed caused by $\mathrm{AC}$ is debatable. Spontaneous hemorrhagic transformation eventually occurs in 40 to $60 \%$ of cardioembolic brain infarctions 12,19 , whereas about $75 \%$ of these occur within the first ten days. 5,9 The number of clinically significant hemorrhagic events in our AC-treated group was slightly higher than the two per cent found by Rothrock et al 22 in 49 patients anticoagulated within 96 hours following a cardioembolic stroke, and even lower than the $11 \%$ in 43 patients with spontaneous hemorrhagic transformation that sustained worsening of symptoms in the study of Hornig et al. ${ }^{12}$ We repeated $C T$ in all cases with neurological deterioration, and in a limited number of other patients for reasons not related to this study. Therefore, we are not fully informed about the total number of patients with hemorrhagic transformation without clinical symptoms. However, should spontaneous hemorrhagic transformation have been as high as the $40-60 \%$ found by others 12,19 , the number of patients with neurological deterioration associated with hemorrhagic complications is low in our series. It could be argued that a large proportion of our AC-treated group might have been lacunar strokes, with a low expectat ion of bleeding. However, cardiogenic embolism is an unlikely cause of lacunar stroke 3,17 , whereas 21 of our patients had large, and 29 had moderate size infarctions, which by definition were tentorial infarctions involving the cortex. Therefore, although some of the CT negative strokes might have been lacunar, this would be unlikely to be the only explanation for the low number of cerebral bleeding complications.

Hemorrhagic transformation could may been mainly confined to those patients whom we excluded from anticoagulation. Some of the reported bleeding complications in the literature may have occurred in such patients.8,23 However, it does not seem clinically expedient to prevent possible early stroke recurrences in patients with an expected bad short-term outcome, or in those who are fully care-dependent should they survive. 
Why only a small minority of all supposed hemorrhagic transformed infarctions resulted in extensive bleeding with $A C$ treatment remains unclear. Excessive $\mathrm{AC}$, large infarction size, decreased consciousness, and advanced age may play a role in hemorrhagic transformation, but if present, they are no reliable predictors of bleeding risk. $2,7,12,16,19$ Although hemorrhagic transformation may develop late ${ }^{3}$, in the majority of patients it occurs 2-10 days following stroke ${ }^{5,9}$, an interval similar to that of the development of AC-related hemorrhage. 2,22 Therefore, some bleeding complications may indeed be related to the $\mathrm{AC}$-induced conversion of an ischemic infarction into a hemorrhagic one. ${ }^{2}$ However, the frequency of hemorrhagic transformation leading to clinical deterioration is likely to be low. Reviewing the literature Babikian et $\mathrm{al}^{2}$ found a total of only 26 such published cases, whereas the Cerebral Embolism Study Group ${ }^{4}$ reviewing CT files from ten hospitals collected only 30 cardioembolic stroke cases with anticoagulant associated hemorrhagic transformation, many of whom did not deteriorate clinically. Summarizing data from recent randomized trials on stroke prevention in NRAF, Albers et al noted that there was no evidence that ischemic strokes occurring under anticoagulation were "more severe or more likely to be hemorrhagic". 1

Our data do also not lend support to the view that early AC purports a substantial risk when administered early following a brain infarction, not even when the stroke is likely to have resulted from cardiogenic embolism in NRAF and produced major deficit, providing the patient's consciousness is not lowered, or the infarction is without space-occupying signs on CT. In the absence of proven benefit of early AC, but considering an expected substantial risk of early recurrences depending on cardioembolic stroke subtype, our findings may be of value in deciding on the timing of $\mathrm{AC}$. The more so, because a recent North-American study showed that over 60 percent of clinicians interviewed about their anticoagulation policy applied $A C$ in elderly stroke patients with atrial fibrillation. 15 Considering the temporal profile of spontaneous hemorrhagic transformation, most clinicians may favour waiting at least a few days with $A C$ in patients with a presumed cardioembolic stroke. 5,18 In younger patients, especially those with rheumatic valve disease, $\mathrm{AC}$ should rather be started as early as possible.

Our results also show that including an early AC strategy in treatment trials on early stroke outcome does not subject patients to unproportional risks of cerebral bleeding complications. 


\section{REFERENCES}

1. Albers GW, Sherman DG, Gress DR, Paulseth JE, Petersen P.Stroke prevention in nonvalvular atrial fibrillation: a review of prospective randomized trials. Ann Neurol 1991;30:511-518

2. Babikian VL, Kase CS, Pessin MS, Norrvig B, Gorelick PB. Intracerebral hemorrhage in stroke patients anticoagulated with heparin. Stroke 1989;20:1500-1503;

3. Boiten J, Lodder J. Lacunar infarcts. Pathogenesis and validity of the clinical syndromes. Stroke 1991;22:1374-1378.

4. Cerebral Embolism Study Group. Immediate anticoagulation of embolic stroke: brain hemorrhage and management options. Stroke 1984;15:779-789.

5. Cerebral Embolism Study Grouip. Timing of hemorrhagic transformation of cardioembolic stroke. In: Stober T, Schimrigk K, Ganten D, et al. (eds.) Central Nervous System Control of the Heart. Martinus Nijhoff Publ, Boston, 1986, chapter 20.

6. Cerebral Embolism Study Group. Cardioembolic stroke, early anticoagulation, and brain hemorrhage. Arch Intern Med 1987;147:636-640

7. Cerebral Embolism Task Force. Cardiogenic brain embolism. Arch Neurol 1989;46:727743.

8. Drake ME, Shin C. Conversion of ischemic to hemorrhagic infarction by anticoagulant administration. Arch Neurol 1983;40:44-46.

9. Fisher $\mathrm{CM}$. Management of occlusive cerebrovascular disease. In: Ropper AH, Kennedy SK, Zervas NT (eds) Neurological and neurosurgical Intensive care. University Park Press, Baltimore, 1983, pp 189-205

10. Fisher CM, Adams RD. Observations on brain embolism with special reference to mechanism of hemorrhagic infarction. J Neuropathol Exp Neurol 1951;10:92-94.

11. Gustafsson C, Britton M. Pathogenetic mechanism of stroke in non-valvular atrial fibrillation: follow-up of stroke patients with and without atrial fibrillation. I Int Med 1991;230:11-16.

12. Hornig CR, Dorndorf W, Agnoli AL. Hemorrhagic cerebral infarction. A prospective study. Stroke 1986;17:179-185.

13. Jörgensen L, Torvik A. Ischemic cerebrovascular diseases in an autopsy series. Part II. J Neurol Sci 1969;9:285-320

14. Krijne-Kubat B, Lodder J. Computertomographische Merkmale von morphologisch gesicherten hämorrhagischen Hirninfarkten. Derr Nervenarzt 1992 (in press).

15. Kutner M, Nixon G. Physicians' attitudes towards oral anticoagulants and antiplatelet agents for stroke prevention in elderly patients with atrial fibrillation. Arch Lint Med $1991 ; 15: 1950-1953$.

16. Lodder J. CT-detected hemorrhagic infarction; relation with the size of the infarct and the size of the presence of midline shift. Acta Neurol Scand 1984;70:329-335.

17. Lodder J, Bamford JM, Sandercock PAG, Jones LN, Warlow CP. Are hypertension or cardiac embolism likely causes of lacunar infarction? Stroke 1990;21:375-381.

18. Lodder J, Krijne-Kubat B, Van der Lugt PJM. Timing of autopsy confirmed hemorrhagic infarction with reference to cardioembolic stroke. Stroke 1988;19:1482-1484.

19. Okada Y, Yamaguchi T, Minematsu K, Miyashita T, Sawada T, Sadoshima S, Fujishima M, Omae T. Hemorrhagic transformation in cerebral embolism. Stroke 1989;20:598-603.

20. Pessin MS, Hinton RC, Davis KR, Duncan GW, Robertson GH, Ackerman RH, Mohr JP. Mechanisms of acute carotid stroke. Ann Neurol 1979;6:245-252

21. Rankin J. Cerebral vascular accidents in people over the age of 60. II. Prognosis Scott Med J 1957;2:200-215.

22. Rothrock JF, Dittrich HC, McAllen S, Taft BJ, Lyden PD. Acute anticoagulation following cardioembolic stroke. Stroke 1989;20:730-734. 
23. Shields RW, Laureno R, Lachmon T, Victor M. Anticoagulant related hemorrhage in acute cerebral embolus. Stroke 1984;15:426-437.

24. The Dutch TIA Study Group. The Dutch TIA Trial: prospective effects of low dose aspirin and atenolol in patients with transient ischemic attacks or nondisabling stroke. Stroke 1988;19:512-517.

25. Walker MD. Atrial fibrillation and antithrombotic prophylaxis: a prospective metaanalysis. Lancet 1989;I:325-326. 


\section{Summary and conclusions}

Up till now, hemorrhagic infarction has been considered to be of significance for both the diagnosis and the treatment in patients whose brain infarction is likely to have resulted from a cardiogenic embolus. The long held conviction that hemorrhagic infarction indicates cardiogenic embolism stems from the observations of pathological studies. However, Chapter 2 shows that even in patients who died following a brain infarction, hemorrhagic infarction is related to the size of the infarction rather than the underlying cause. Probably more patients die following a cardioembolic stroke than following strokes from other causes and therefore pathological studies are likely to be biased towards finding hemorrhagic infarction to be associated with a presumed cardiac cause of stroke. Also in patients surviving their stroke, some of whom may be considered for possible prevention of stroke recurrences by anticoagulation, the presence of hemorrhagic infarction on CT-scan is of no value in diagnosing a cardioembolic stroke because its prevalence in the early phase following stroke is low. This is even true in patients with a potential cardioembolic stroke source (Chapter 3 ). Chapter 4 shows by means of stepwise logistic regression analysis that early hemorrhagic infarction does not predict cardioembolic origin of stroke. However, the validity of the CT-scan in diagnosing a hemorrhagic infarction can be questioned. Besides the fact that small hemorrhages may go undetected by CT, no study has so far validated CT features of hemorrhagic infarction with pathological findings. Chapter 5 describes such a study and shows that the current CT criteria for hemorrhagic infarction are largely correct. However, CT cannot always differentiate between dense hemorrhagic infarctions and primary intracerebral hematoma. The significance of hemorrhagic infarction in relation to the treatment of cardioembolic stroke or, rather the prevention of a recurrence, lies in the risk for further hernorrhagic transformation or cerebral bleeding with consequent clinical deterioration should anticoagulants be started. In considering anticoagulant treatment, there are two major questions: does anticoagulation reduce the risk of recurrent stroke, and if, when should it be started. There is no simple yes or no to the first question. If the answer was to be measured by the standards of the outcome of clinical trials, a question mark remains for almost all cardiac abnormalities that potentially give rise to embolism with the possible exception of recent myocardial infarction. Nevertheless many 
clinicians are more or less convinced of the benefit of anticoagulant treatment. In some categories of cardiac disease, such as rheumatic heart disease, the consensus on the use of anticoagulation is so strong that the withholding of this treatment is generally regarded as malpractice. The most prevalent potential cause of cardioembolism, non-rheumatic atrial fibrillation, bears a more than five-fold increased risk of stroke. The value of anticoagulants in primary stroke prevention has been firmly established by some recent trials. Whether anticoagulation reduces the risk of recurrent stroke in NRAF patients is currently being tested in the European Atrial Fibrillation Trial. However, this trial, if the outcome should favour anticoagulation, will probably not solve the question of when to start this treatment. Depending on the type of the cardicembolism source, early stroke recurrences are particularly feared. Therefore, the question is how to balance the risk of early anticoagulation against this supposed, but largely unknown, effect on early recurrent stroke risk reduction. Nevertheless, many physicians favour anticoagulants in NRAF stroke patients. Some strongly advise against early anticoagulation because of the above-mentioned uncertainties. They fear hemorrhagic conversion of ischemic infarctions in particular of those with cardioembolic etiology. However, in both our series, one with a consecutive number of 188 cardioembolic stroke patients, and the other with 270 patients with a first, supratentorial brain infarction prospectively registered, the incidence of early hemorrhagic infarction is low. Chapter 6 and some other studies indicate that approximately 75 per cent of all infarctions eventually do become hemorrhagic and this within approximately four days following the stroke, although some may become hemorrhagic much later. The risk of clinically significant hemorrhagic complications in some patients may be higher than in others. Therefore patients with raised intracranial pressure, or with general contraindications to anticoagulation and those with hemorrhagic infarction already on the initial CT should not be given early anticoagulation, regardless of the underlying cardioembolic source, because the treatment might do more harm than good. Providing these "high risk" patients are excluded from anticoagulation, this therapy would be unlikely to result in cerebral bleeding, even if hemorrhagic transformation does eventually develop, if it does so during anticoagulation therapy started as early as within 24 hours following stroke onset and even in patients with large infarctions.

\section{In conclusion}

- The findings that an infarction is hemorrhagic or large, or causing major deficit cannot be used to predict a cardioembolic stroke cause; absence of carotid obstructive disease increases the possibility of such a cause of stroke in patients with a cortical infarction syndrome.

- Pathological studies are biased towards finding hemorrhagic infarction related to cardioembolism. 
- In most patients that eventually develop hemorrhagic infarction, about 75 per cent do so within one to four days following stroke.

- CT features used to diagnose hemorrhagic infarction match pathological findings.

- Early anticoagulation can safely be adopted as a potential treatment regime without a substantial risk of cerebral hemorrhagic complications, both in clinical practice and in trials on secondary cardioembolic stroke prevention, as well as in trials on early stroke outcome, providing the patients who are ro receive this treatment are selected according to certain obvious features. 



\section{Samenvatting en conclusies}

Tot op heden wordt aangenomen dat het optreden van een hemorrhagisch herseninfarct van belang is voor zowel de diagnostiek als de behandeling van patiënten met vermoedelijk cardicembolische herseninfarcten. De sinds lang bestaande overtuiging dat een hemorrhagisch herseninfarct op een cardioembolische oorzaak wijst, stamt van pathologisch-anatomische studies. In hoofdstuk 2 echter wordt aangetoond dat, zelfs bij patiënten die overlijden ten gevolge van een herseninfarct, hemorrhagische infarcering niet gerelateerd is aan de oorzaak doch aan de grootte van het infarct. Waarschijnlijk overlijden er meer patiënten na een cardioembolisch infarct dan na een infarct van andere origine, en de pathologisch-anatomische studies zijn daarom "biased" ten aanzien van de associatie hemorrhagische infarcten en een cardiale oorzaak. Echter ook bij patiënten die het infarct overleven, en waarvan sommigen mogelijk in aanmerking komen voor antistollingstherapie ter preventie van een recidief, is het optreden van een hemorrhagisch infarct op de CT-scan niet relevant voor het vaststellen van een mogelijke cardioembolische oorzaak. Met name het aantal hemorrhagische infarcten dat in de vroege fase na het infarct optreedt is laag, zelfs bij patiënten met een mogelijke cardiale emboliebron (Hoofdstuk 3). Hoofdstuk 4 toont door middel van "stepwise logistic regression analysis" aan dat vroege hemorrhagische infarcering geen aanwijzing is voor een cardiale embolie als oorzaak voor het herseninfarct. De betrou wbaarheid van de CT-scan bij de diagnose van hemorrhagische herseninfarcten kan echter in twijfel worden getrokken. Afgezien van het feit dat kleine bloedinkjes op de CT-scan gemist kunnen worden, zijn de CT-criteria voor hemorrhagische herseninfarcten nog niet eerder in een studie aan de hand van morphologische bevindingen gevalideerd. Hoofdstuk 5 beschrijft een dergelijke studie en laat zien dat de huidige CT-criteria voor hemorrhagische herseninfarcten in de meerderheid der gevallen zonder meer van toepassing zijn. Computertomografie kan echter niet altijd differentiëren tussen hemorrhagische infarcten met een hoge dichtheid en primaire cerebrale bloedingen. Het diagnostiseren van een hemorrhagische infarcering is van belang indien, ter voorkoming van een recidief bij een cardioembolisch infarct, antistolling gegeven wordt. Men is beducht voor het optreden van een hemorrhagische transformatie van het ischemisch infarct of een hersenbloeding, met de daaruit voortvloeiende klinische verslechtering. Wat betreft de antistollingstherapie zijn er twee belangrijke vragen: verlaagt antistolling inderdaad het risico op infarctrecidieven, en zo ja, wanneer mag deze therapie gestart 
worden. De eerste vraag is niet eenvoudig te beantwoorden. Gezien de resultaten van verschillende klinische studies blijft de vraag open voor vrijwel alle cardiale emboliebronnen, mogelijk met uitzondering van het recente myocardinfarct. Desondanks zijn veel clinici min of meer overtuigd van de waarde van deze preventieve behandeling. Bij sommige hartaandoeningen, zoals bijv. rheumatisch hartlijden, is de consensus over het gebruik van anticoagulantia zo duidelijk dat het niet toepassen van deze therapie beschouwd wordt als een medische fout. Het niet-rheumatisch atriumfibrilleren (NRAF) dat mogelijk de grootste veroorzaker van embolieën vanuit het hart is, geeft een vijfvoudig verhoogde kans op een herseninfarct. De waarde van antistolling voor de primaire preventie van herseninfarcten bij NRAF werd duidelijk aangetoond in een aantal recent gepubliceerde studies. De vraag of antistolling tevens het risico op infarctrecidieven vermindert, wordt momenteel onderzocht in de "European Atrial Fibrillation Trial". Echter, deze studie zal geen antwoord geven op de vraag welk het meest geschikte tijdstip is waarop deze therapie, indien effectief, gestart dient te worden. Omdat de meeste recidieven in de vroege infarctfase optreden, is het belangrijk een goed evenwicht te vinden tussen het risico van vroege antistolling en een maximaal preventief effect. Ondanks deze onzekerheden kiezen veel clinici voor antistolling bij patiënten met een herseninfarct en NRAF. Sommigen adviseren deze patiënten echter helemaal niet vroeg te ontstollen. $Z \mathrm{ij}$ vrezen een hemorrhagische transformatie van, met name de mogelijk cardioembolische, herseninfarcten. In de twee in dit proefschrift beschreven series, één met 188 opeenvolgende patiënten met waarschijnlijk cardioembolische infarcten, en de ander met 270 prospectief verzamelde patiënten met een eerste, supratentorieel gelegen herseninfarct, is echter de incidentie van vroeg optredende hemorrhagische infarcering laag. In hoofdstuk 6 en in een aantal andere studies wordt aangetoond dat ongeveer $75 \%$ van alle herseninfarcten op den duur hemorrhagisch wordt. Meestal gebeurt dit binnen de eerste vier dagen na het ontstaan van het infarct, alhoewel hemorrhagische transformatie ook nog veel later kan optreden. Het risico van klinisch relevante hemorrhagische complicaties kan bij sommige patiënten hoger liggen dan bij andere. Daarom zouden patiënten met een verhoogde intracraniële druk, met algemene contraindicaties tegen antistolling, of met een hemorrhagisch infarct op de CTscan, niet ontstold dienen te worden, ongeacht het al dan niet aanwezig zijn van een cardiale emboliebron, omdat de behandeling bij deze patiënten meer kwaad dan goed zou doen. Indien patiënten met dit hoge risico uitgesloten worden van vroege antistolling is het niet te verwachten dat deze behandeling zal leiden tot het optreden van een hersenbloeding, zelfs niet als hemorrhagische transformatie optreedt tijdens de binnen 24 uur na de ictus ingestelde ontstolling, en evenmin bij patiënten met een groot herseninfarct. 


\section{Conlusies}

- De diagnose hemorrhagisch en/of groot herseninfarct, of een herseninfarct met ernstige uitvalsverschijnselen kan niet gebruikt worden om een cardioembolische oorzaak van een herseninfarct vast te stellen. Het ontbreken van een obstructief carotislijden bij patiënten met een corticaal infarct vergroot de kans op het bestaan van een cardioembolische oorzaak.

- Pathologisch-anatomische studies zijn "biased" ten aanzien van het diagnostiseren van cerebrale hemorrhagische infarcering bij een cardiale emboliebron.

- Vijf-en-zeventig procent van de hemorrhagische transformaties van ischemische herseninfarcten treden op tussen de eerste en vierde dag na het ontstaan van het herseninfarct.

- CT-criteria voor hemorrhagische herseninfarcten blijken, uit de vergelijking met morphologische bevindingen, betrouwbaar te zijn.

- Antistolling kan veilig toegepast worden als mogelijke preventie van infarctrecidieven en binnen studies betreffende secundaire infarctpreventie of vroege infarctprognose, indien op grond van duidelijke criteria patiënten voor deze behandeling geselecteerd worden. 



\section{Tot slot}

Gaarne wil ik mijn dank uitspreken aan mijn promotoren, Prof.dr. J. Troost en Prof.dr. J.W. Arends, voor hun interesse en hun kritische opmerkingen. Zij hebben mij zeer geholpen en gestimuleerd bij de bewerking van dit proefschrift.

Dr. J. Lodder, in het bijzonder jou, Jan, ben ik zeer veel dank verschuldigd, voor je vriendschap, je niet aflatende steun en enthousiasme die mij al die jaren hebben begeleid. Zonder jou zou dit boekje niet tot stand zijn gekomen. İhnen, Frau Professor Dr. L. Gerhard möchte ich von ganzem Herzen danken für Ihre uneingeschränkte Hilfe und Ermutigung, die ich noch immer bei Ihnen erfahre. Ihre besondere Art, Probleme anzugehen und Fragen zu stellen hat für mich eine "neue Welt" geöffnet.

Verder wil ik Drs. Lisette Heuts-van Raak en Drs. Arthuur Boon bedanken voor hun hulp bij het verzamelen van de gegevens voor dit proefschrift, evenals Drs.Ir. A.G.H. Kessels, die de statistische bewerkingen heeft gedaan. Prof.dr. J.L. Slooff, neuropatholoog (Radboudziekenhuis te Nijmegen), Dr. F.W.M. Arts, neuroloog (Westeinde ziekenhuis te 's-Gravenhage), Dr. C.L. Franke, neuroloog (De Wever-ziekenhuis te Heerlen), Prof.dr. S. Stefanko, neuropatholoog en Dr. P.J. Koudstaal neuroloog (Dijkzigt ziekenhuis te Rotterdam), en Drs. B.J. Meems, neuroloog (Sint Maartens Gasthuis te Venlo) ben ik dankbaar voor hun persoonlijke hulp en de toestemming gegevens van hun patiënten voor de studies te gebruiken.

Mevrouw Thera van Lieshout heeft mij zeer geholpen bij het uittypen van de tekst en alle administratieve horden, waarvoor mijn hartelijke dank.

Tot slot dank ik mijn ouders en Ruud, die mij met liefde, raad en veel begrip aldoor ter zijde stonden. 


\section{Curriculum vitae}

The author was born on $10^{\text {th }}$ January, 1957, in Prague, Czechoslovakia. In 1971 she came to the Netherlands. She completed secondary school (VWO) in Nijmegen in 1976 and started her medical training in 1976 at the University of Nijmegen. During her medical study she worked at the Department of Anatomy (prof. Dr. H.J. Lammers) and was involved in research at the Department of Pathology (prof. Dr. G.P. Vooys). After completing her medical studies in August 1983, she started training in neurology at the University of Maastricht (prof. Dr. P.J.M. van der Lugt) and spent one year at the Department of Internal Medicine (prof. Dr. J.A. Flendrig) in 1985 - 1986. In 1986 she stopped her training due to her husband's employment in Duisburg, Federal Republic of Germany and the birth of her son, Ruud. In 1987 she started training in neuropathology at the University of Essen, FRG (prof. Dr. L. Gerhard), where she now works as a resident. In 1990 her second son Karel was bork. 
DATAWYSB I Universitaire Pers Masstricht

ISBN 9052780536

NUGI 742 